Florida International University

FIU Digital Commons

FIU Electronic Theses and Dissertations

University Graduate School

$1-27-2020$

\title{
The Impact of Stress on Episodic Memory in the Workplace
}

Jennifer Houston

jhous003@fiu.edu

Follow this and additional works at: https://digitalcommons.fiu.edu/etd

Part of the Cognition and Perception Commons, and the Industrial and Organizational Psychology Commons

\section{Recommended Citation}

Houston, Jennifer, "The Impact of Stress on Episodic Memory in the Workplace" (2020). FIU Electronic Theses and Dissertations. 4447.

https://digitalcommons.fiu.edu/etd/4447

This work is brought to you for free and open access by the University Graduate School at FIU Digital Commons. It has been accepted for inclusion in FIU Electronic Theses and Dissertations by an authorized administrator of FIU Digital Commons. For more information, please contact dcc@fiu.edu. 


\title{
FLORIDA INTERNATIONAL UNIVERSITY \\ Miami, Florida
}

THE IMPACT OF STRESS ON EPISODIC MEMORY IN THE WORKPLACE

\author{
A dissertation submitted in partial fulfillment of the \\ requirements for the degree of \\ DOCTOR OF PHILOSOPHY \\ in \\ PSYCHOLOGY
}

by

Jennifer L. Houston

2020 
To: Dean Michael R. Heithaus

College of Arts, Sciences, and Education

This dissertation, written by Jennifer L. Houston, and entitled The Impact of Stress on Episodic Memory in the Workplace, having been approved in respect to style and intellectual content, is referred to you for judgment.

We have read this dissertation and recommend that it be approved.

Sean J. Allen Hermanson

$\overline{\text { Asia A. Eaton }}$

Chockalingam Viswesvaran

Leslie D. Frazier

Bennett L. Schwartz, Major Professor

Date of Defense: January 27, 2020

The dissertation of Jennifer L. Houston is approved.

Dean Michael R. Heithaus

College of Arts, Sciences, and Education

Andreś G. Gil

Vice President for Research and Economic Development and Dean of the University Graduate School

Florida International University, 2020 


\section{DEDICATION}

This dissertation is dedicated to each and every one of my students - past, present, and future. You have given me the will to keep going even in moments when nothing else has. You've given my story a purpose and let me learn from your stories as well. And you've allowed me the opportunity to look at my past not as something that defines me as a failure but as something that gives me character... even if it's a little too much character sometimes.

I found the strength to finish this journey in being given the promise that doing so will allow me to spend the rest of my life making a difference in the journeys of those to come.

To my students, and anyone else who needs to hear it: your shortcomings do not determine who you get to be, and where you came from does not dictate the places you will go. Things like anxiety and depression are just as real as any other illness, and there will be days when getting out of bed seems like an insurmountable obstacle. Don't punish yourself for being human. Instead, make the most of the days that you do see sunshine. Spend time reaching out to other people who understand you instead of devaluing you, because they do exist. There is a path for you, even if it's not the beaten one. Walk it at

your own pace and give yourself permission to seek as much help as you need in reaching the end.

I believe in you. Thank you for helping me believe in me. 


\section{ACKNOWLEDGMENTS}

Thank you to the following individuals:

My three-generation heritage of FIU Panthers: Rhonda Malone Houston, FIU Class of 2013 (Education). My mom and my best friend... I'm everything I am because you loved me. Gary Malone, FIU Class of 1992 \& 1998 (Business \& Master of Accounting). My uncle and role model... Your belief in me has meant more than you could ever know. Richard Doc Malone (1934-2014), FIU Class of 1978 (Education). My grandfather and my biggest fan... I know you're somewhere looking down on me with pride. I hope to continue the legacy of the Doc name that will always and forever remind me of you.

To my major professor, Dr. Bennett L. Schwartz: O Captain! my Captain! our fearful trip is done, The ship has weather'd every rack, and the prize we sought is won! Thank you, and Dr. Leslie D. Frazier, for believing in me through thick and thin. You both are the best academic parents and guardian angels I could have ever asked for. Thank you also to my committee: Dr. Asia Eaton, Dr. Sean Allen Hermanson, \& Dr. Vish and to Amanda Niguidala from the DRC and Jessica Herrera from the Department of Psychology.

To my love, Jean Paul Pascual, Esq: thank you for giving me the $25^{\text {th }}$ hour, without which I would have never found the light at the end of the tunnel. I love you, and I love my life because you're in it. P.S. I'm the real doctor, now!

To my longtime mentor, Dr. Victoria Pace: For twelve years you have been my mentor (and my friend), no matter the distance. I am eternally grateful for having you in my life and will always look up to you for the amazing educator and woman you are. 


\begin{abstract}
OF THE DISSERTATION
THE IMPACT OF STRESS ON EPISODIC MEMORY IN THE WORKPLACE by
\end{abstract}

Jennifer L. Houston

Florida International University, 2020

Miami, Florida

Professor Bennett L. Schwartz, Major Professor

The purpose of this dissertation was threefold: to identify the relationship between experience of stress and episodic memory encoding and retrieval, to examine the interpersonal factors of personality and psychopathology that impact how individuals cope with or mitigate workplace stress, and to pinpoint how interpersonal differences and memory processes impact the workplace outcomes of job satisfaction and motivation. The results suggest that the relationship between work stressors and memory processes does exist, that personality and psychopathology play a significant role in the relationship between stress and memory, and that the experience of negative memories moderates the relationship between work stress and motivation. The findings suggest that memories of workplace stress as well as an employee's engagement in mental time travel are each important and should be included in both cognitive psychology research related to episodic memory and $\mathrm{I} / \mathrm{O}$ research related to interpersonal differences, the experience of work stress, and job-related outcomes. 


\section{TABLE OF CONTENTS}

$\begin{array}{ll}\text { CHAPTER } & \text { PAGE }\end{array}$

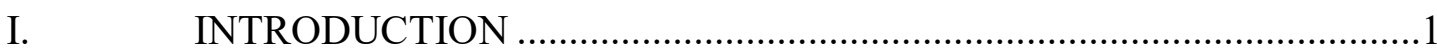

II. LITERATURE REVIEW .........................................................4

Memory, Identity, \& Cognition: Theories and Models of Work Stress ......4

Developing Interdisciplinary Support: Memories of Workplace Events...11

Emotion-Focused Models of Cognition and Work Stress ........................14

Beyond the Current Models: Personality, Memory \& Work Stress ..........20

Understanding the Impact of Psychopathology on Episodic Memory \&

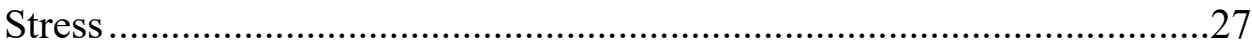

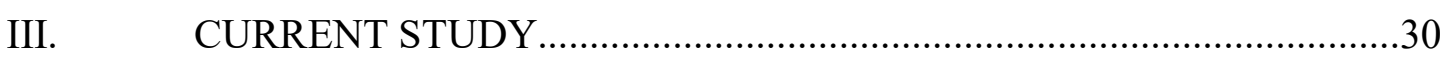

Study 1: The Impact of Work Stress on Episodic Memory ......................31

Study 2: The Relationship Between Work Stress \& Mental Time Travel.37

Developing an Integrated Model ...........................................................41

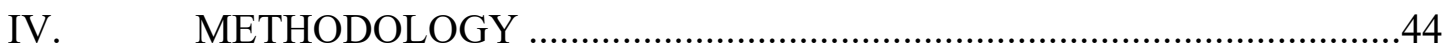

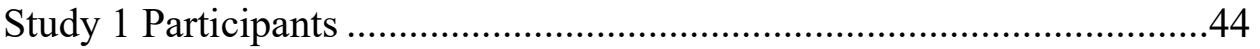

Study 1 Procedures ......................................................................44

Study 2 Participants .....................................................................45

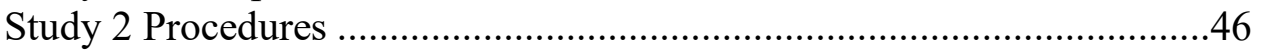

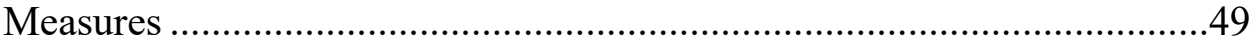

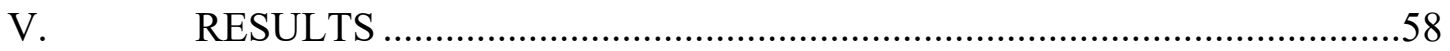

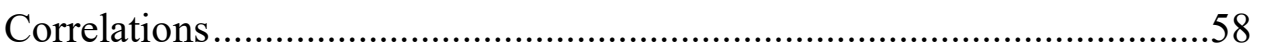

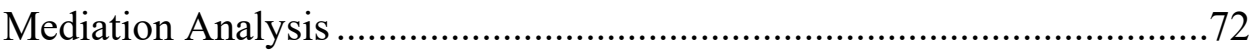

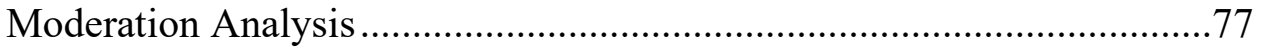

Exploratory Data Analysis (Study 2) ................................................ 79

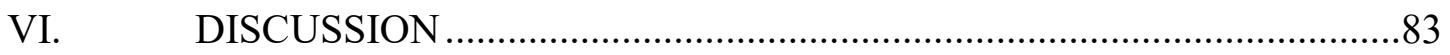

Work Stress and the Experience of Voluntary vs. Involuntary Memory...83

Work Stress and Mental Time Travel .......................................................86

Interpersonal Differences, Memory Processes, and Work Stress ..............88

The Implications and Impacts on Job Outcomes ...................................98

The Highlights of Other Exploratory Findings ......................................99

Limitations of the Current Study ..........................................................102

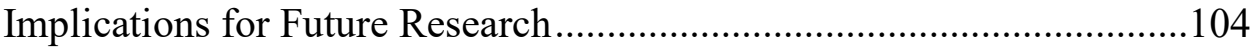

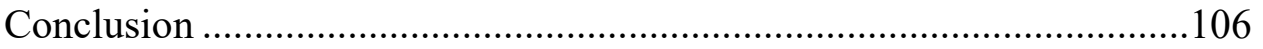




\section{TABLE OF CONTENTS, CONTINUED}

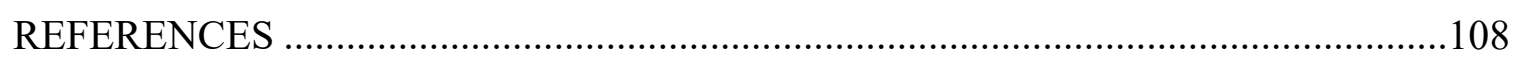

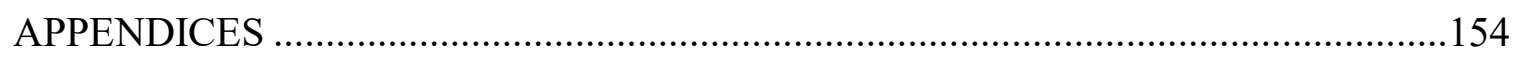

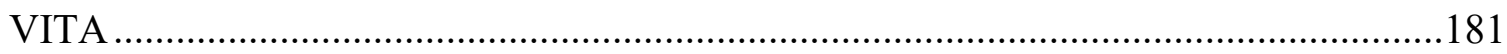




\section{LIST OF TABLES}

\section{TABLE}

1: Summary of Support for All Hypotheses ……………….....................................123

2: Means, Standard Deviations, and Correlations (Study 1)..........................................128

3: Correlations - Individual Variables \& Episodic Memory Sub-Measures ....................130

4: Means, Standard Deviations, and Correlations (Study 2)..........................................131

5: Correlations - Memory Phenomenology \& Individual Variables .................................133

6: Mediation of Negative Affect on Stress-Memory Relationship ..................................135

7: Mediation of Positive Affect on Stress-Memory Relationship.....................................136

8: Mediation of JAWS on Stress-Memory Relationship ...............................................137

9: Mediation of Emotional Intelligence on the Stress-Memory Relationship ..................138

10: The Moderating Role of Memory on the Work Stress-Motivation Relationship ......139

11: Means \& Frequencies, Averages Across Groups ……….........................................140

12: Means \& Frequencies, Actual Past Events .............................................................141

13: Means \& Frequencies, Imagined Past Events..............................................................142

14: Means \& Frequencies, Imaginary Future Events......................................................143

15: Correlations - Actual Past Events Qualitative Data ....................................................144

16: Correlations - Imagined Past Events Qualitative Data..............................................145

17: Correlations - Imaginary Future Events Qualitative Data..........................................146 


\section{LIST OF FIGURES}

\section{FIGURE}

1: Proposed Model of Work Stress, Episodic Memory, and Interpersonal Differences..147

2: Proposed Model of Work Stress, Episodic Memory, and Job Outcomes 148

3: Integrated Model of Memory, Stress, Individual Differences, and Job Outcomes .....149

4: Voluntary Memory Recall as a Moderator of Work Stress \& Motivation at 1SD, M, and -1SD

5: Involuntary Memory Recall as a Moderator of Work Stress \& Motivation at 1SD, $\mathrm{M}$, and $-1 \mathrm{SD}$.

6: Recurrent Involuntary Memory Recall as a Moderator of Work Stress \& Motivation at $1 \mathrm{SD}, \mathrm{M}$, and $-1 \mathrm{SD}$

7: Frequencies of Exploratory Analyses Variables (Study 2) 153 
The Impact of Stress on Episodic Memory in the Workplace

\section{INTRODUCTION}

According to the American Institute of Stress (2018), work stress is the leading source of stress in adults. The Handbook of I/O Psychology defines work stress as the process of how an employee responds to and manages the demand of meeting multiple goals over a specific timeframe (Griffin \& Clarke, 2010), with 80\% of U.S. employees reporting experiences of stress as a result of workplace demands or expectations. The proportion of the working population that experiences stress increases from year to year (AIS, 2018), resulting in an increasing number of employees who are requesting aid from their employers in coping with workplace stressors. The outcomes of unmitigated workplace stress can lead to several detrimental and costly outcomes for both employees and their organizations. Individuals experiencing high levels of workplace stress have been found to require an increase in healthcare services, requiring nearly double the amount of insurance coverage than less stressed employees (Elkin \& Rosch, 1990). Furthermore, research on absenteeism suggests that approximately half of all employee absences are a symptom of experiencing job-related stress (Sonnetag \& Frese, 2003).

An individual experiences stress when the cognitive appraisal of an event (or the interaction between a worker and the workplace) is taxing their cognitive resources and/or presents a danger to their physical or psychological wellbeing (Bergdahl, Larsson, Nilsson, Ahlstrom, \& Nyberg, 2005; Lazarus \& Folkman, 1984). When the perceived demand of a stressor exceeds an individuals' available cognitive resources to attend to or cope with the stress, an individual experiences the physiological or psychological 
response of strain (inadequate power to respond to work demands) (Hart \& Cooper, 2001; Hurrell, Nelson, \& Simmons, 1998). Compromised immune systems, health problems, increase in anxiety and depression, diminished overall wellbeing, lower organizational commitment, burnout, and higher turnover intent are just some of the wide variety of strains that can affect the lives of employees. (Halbesleben \& Buckley, 2004; Jex, 1998; Kahn \& Byosiere, 1992; LePine, Podsakoff, \& LePine, 2005; Maslach, 1982; Sonnetag \& Freese, 2003). Strains can impact individuals both within the workplace and within one's home life because of spillover, or the transfer of negative feelings and experiences related to workplace stress into domains of one's life unrelated to work.

Although there is significant research exploring variables related to work stress, there are two significant issues related to work stress that psychologists have not yet addressed. The first issue relates directly to the field of I/O psychology. Despite the ongoing effort to elucidate the causes of and responses to the experience of work stress, the field of organizational psychology has largely operated in seclusion from other subfields within psychology that are more clinical and less applied to the workplace. Although there are a variety of $\mathrm{I} / \mathrm{O}$ researchers that discuss that cognition and the management of cognitive resources is important to understand the stressor-strain relationship within the context of one's organization, there have been few (if any) attempts to integrate theories and researchers directly from the field of cognitive psychology. As a result, there may be unexplored explanations for, or ways of mitigating, experiences of work stress that could benefit both the employee and the employer.

A second issue relates to the field of cognitive psychology, in which there is a similar, but opposite, phenomenon of keeping research in the laboratory and out of 
applied populations in which there are risks concerning an experimenter's control over confounding variables. Though there are areas of cognitive psychology that cite the importance of the impact of stress on autobiographical, episodic memory, there has yet to be research conducted focusing on studying the day-to-day implications of stress on memory in the workplace. Many of an individual's life experiences that relate to or result from stress are occurrences that cannot be simulated in a laboratory setting, which necessitates a need for collaboration with other areas with an expertise in conducting and interpreting applied research.

Though the fields of I/O and cognitive psychology seldom overlap, they should overlap with respect to studying work stress and the impact stress (and strain) may have on episodic memory. In the words of Ralph Waldo Emerson, "we become what we think about all day long". An average employee spends anywhere between 30 and $50 \%$ of their waking hours engaged in work-related activities (Bureau of Labor Statistics, 2017). The portion of one's life spent working, coupled with Emerson's philosophy, suggests that an individual's identity is composed, at least in part, by how they are as an employee. Klein and Nichols (2012) suggest that the sense of personal identity is built upon our memories of prior experiences, highlighting episodic (or autobiographical) memory as an important process in connecting what we do to our ideas of who (or what) we are. Furthermore, the importance of work and amount of time spent in work-related activities implicates that many of our most important memories are narratives of events that have happened in the workplace.

The aim of the dissertation is a) to identify the relationship between the experiences of stress and episodic memory (encoding and retrieval), b) to examine how 
the manner in which an individual copes with stress impacts both memory processing and work related outcomes (such as stress-related strains and job attitudes), c) to determine the interpersonal factors that impact how individuals cope with stress (and may exacerbate or mitigate the impact of stress), and d) to conduct some degree of exploratory research to pinpoint the intersections in which cognitive psychology and I/O psychology overlap with regard to each of the aforementioned variables.

\section{LITERATURE REVIEW}

The research under the overarching umbrella of each field, I/O and cognitive psychology, generally covers drastically different topics in each of the subject areas. There are, however, models and theories in both fields that link both areas (whether directly or indirectly) regarding the topics of cognition/memory and workplace stress. The following are some of the most potentially useful theories and models to establish a foundation for achieving the purpose of this dissertation.

\section{Memory, Identity, \& Cognition: Theories and Models of Work Stress}

Bluck's (2003) autobiographical memory model. Several theories have been

posited to describe autobiographical memory and its function in the human memory system, from models focused on the self-narrative to explanations involving classifications by chronological life periods (Berntsen \& Rubin, 2005; Berntsen, Rubin, \& Salgado, 2015; Watson, Berntsen, Kuyken, \& Watkins, 2013). Bluck’s (2003) model focuses on memory functions summarizes autobiographical memory via three functional categories: self (self-concept and self-continuity), social (communication and social belonging), and directive (instrumental, guiding behaviors). The functional model of 
memory differs from the more structural understanding of autobiographical memory developed by researchers such as Conway and Pleydell-Pearce (2000; See also: Conway, 2005), who emphasize the importance of and difference between specific events, general events, and lifetime periods. Each of Bluck's (2003) categorizations touch on interdisciplinary concepts and create an ease in overlapping concepts concerning selfidentity and the importance of the work environment.

Bluck's first functional category, the self, relates to self-relevant autobiographical memories that closely represent an individual's personal identity and self-esteem (Bluck, 2003; Rasmussen \& Berntsen, 2009). Memories tied to self-identity tend to be positive and susceptible to a pleasantness bias to construct a productive and confident selfnarrative. The second function, social memory, deals with the relationship between one's self and others in one's immediate environment. These memories are also often positive in nature, and are tied to persuading others, easing communication, facilitating social bonding, eliciting sympathy, and building intimacy (Bluck, 2003; Rasmussen \& Berntsen, 2009). The shared nature of social memory necessitates less private rehearsal, and both the self and social functions of autobiographical memory are thought to be most frequently and easily accessed through voluntary retrieval and strategic recall. Though self and social memories are generally positive in the construction of one's identity, it is important to note that these memories may also be negative depending on situational and intrapersonal differences. Experiences such as negative self-imagery (e.g., shyness or clumsiness on a first date as a part of remembered narratives) and difficulty creating and maintaining social relationships may be interwoven with positive memories in defining an individual's self-conception. 
Bluck's (2003) final functional category, directive, involves one's ability to engage in present and future thinking behavior, assists in problem solving and planning, and ties into one's ability to inspire, inform, and self-motivate (also see Rasmussen \& Berntsen, 2009). Though much of the existing research on the directive function underplays the importance and prevalence of directive memories in day-to-day life, Rasmussen and Berntsen (2009) found that though the directive function may not be easily accessed through strategic recall, directive memories are just as pivotal to one's life story as the self-function. Additionally, memories in the directive function tend to be mostly negative (in terms of emotions, such as remembering feelings of failure or fear) and involuntary in nature. An employee in an organization might utilize a similar memory strategy in remembering negative work experiences that should not be repeated to appease one's supervisors and/or advance one's career.

Sonnetag \& Frese's (2003) work resources theory. Sonnetag and Frese (2003) suggest three main types of resources at work - individual resources, social support, and control at work - that each draw a parallel to one of Bluck's (2003) functional categories of memory. Individual resources are self-related similarly to Bluck's first functional category and include coping styles (problem solving vs emotional coping), an internal locus of control, high self-esteem, high self-efficacy, and hardiness (Jex \& Elacqua, 1999; Kahn \& Byosiere, 1992; Kobasa, Maddi, \& Kahn, 1982; Rotter, 1966; Sonnetag, 2002; Sonnetag \& Frese, 2003). Social support, as with Bluck's second category, refers to communal resources such as emotional contagion (mood transmission between employees) and shared skillsets related to stressful tasks (Frese \& Zapf, 1994; Sonnetag, 2000). Control at work relates to the higher-order goals, such as personal control, 
problem solving, and planning (Frese, 1989), resembling Bluck's third (directive) category.

Within the scope of I/O psychology, resources can moderate the relationship between the perception of a stressor and the experience of a strain. Though the theories on work resources have not been studied in direct relation to autobiographical memory processes, it can be posited that the resources an employee utilizes to manage stressors may affect their cognitive ability to process memories of workplace events.

Berntsen's (2002) discussion of tunnel memories. There are several theories in cognitive psychology related to the experience of heightened stress and the distinct effect it has on the encoding process of episodic memory. Situations appraised as stressful or traumatic incite a feeling of urgency and are characterized by the experience of tunnel vision: the restrictive, narrowing of attention to the critical, central details of an event (Safer, Christianson, Autry, \& Osterlund, 1998). Loftus, Loftus, and Messo's (1987) research on weapon focus exemplifies how an individual's attention narrows in highstress situations; participants in studies in which a weapon was present in the witness of a crime had poorer overall memory recall of the event than those who did not experience the presence of a weapon (Loftus et al., 1987).

Berntsen (2002) proposed that tunnel vision results in tunnel memories, or memories whose peripheral details (of autobiographical events) are dampened by the acuteness in severity of the emotional state evoked. The heightened stress and/or states of fear provoked by such events, therefore, create an emphasis on the central details and 'gist' of the event that are deemed most relevant to one's self-narrative. Disproportionate amounts of central details remembered above and beyond peripheral details are unique to 
experiences of heightened stress or arousal. In neutral or positive events, peripheral details are encoded (and thus retrievable) in addition to the central gist of an event (Berntsen, 2002; Christianson \& Loftus, 1991). The bulk of autobiographical memory research suggests that, on average, individuals have more positive memories than negative memories throughout a lifespan. Trauma memories of negative events, however, because of their distinctiveness and level of impact on an individual, may be more persistent and accessible than neutral or positive memories (Berntsen \& Rubin, 2005; Thomsen \& Berntsen, 2009).

\section{Berntsen et al.'s theories on the phenomena of involuntary memory. In} general, autobiographical memory retrieval is thought of as a voluntary process wherein an individual can intentionally purposefully cue the retrieval of specific memories. Involuntary autobiographical memory, however, is characterized by spontaneous recall of memories with no conscious attempt at memory retrieval (Berntsen, 1996). Compared to voluntarily recalled memories, involuntary memories are "more specific, have more mood impact, and generate stronger emotional and physical reactions" (Watson et al., 2013, p. 8). Berntsen et al. (2015) suggest that most of involuntary memory retrieval is of positive, common memories that come to fruition when an individual has daydreams or performs a task that requires little concentration or attention. However, involuntary recall of episodic memories depends, in part, on factors at the time of encoding, such as a strong emotional reaction to the initial event and existing schema related to the to-belearned material (Hall \& Berntsen, 2008; Niziurski \& Berntsen, 2019). The experience of positive versus negative involuntary memory recall is linked to the relevance of the memory to one's general disposition and likelihood of adopting a self-narrative focus 
(Rubin, Berntsen, Deffler, \& Brodar, 2019). In a workplace setting, involuntary memory retrieval might occur during mundane tasks that are routinized and require minimal effort for someone, such as an employee, to complete.

Theories of recurrent involuntary memories. Though involuntary memories can be single instances of remembering autobiographical events, involuntary memories can also become recurrent and persistent, with the same memory image reappearing more than once over a longer period of time (Berntsen \& Hall, 2004; Berntsen \& Rubin, 2002 \& 2008). Healthy individuals are thought to have a positivity bias that both prevents them from imagining unfavorable past events from recurring and allows them to project this positivity onto what they believe will happen in future events. A positivity bias when perceiving external events may also limit negative environmental cues that would evoke memories of prior stressful experiences (Walker, Skowronksy, \& Thompson, 2003).

Horowitz and Reidbord (1992) argue that the experience of negative recurrent involuntary memories relates to the magnitude of stressful events that an individual experiences. Furthermore, the persistence of these memories directly correlates with the intensity of the traumatic event (Ehlers, Hackmann, \& Michael, 2004; Horowitz \& Reidbord, 1992). The intensity of the event correlates to the vividness and emotionevoking qualities that an involuntary memory may have, and heightened intensity (trauma) can lead to more frequent rehearsals that result in a longer lasting impact than more neutral events. Secondly, an individual may try to consciously suppress thoughts about a stressful event, which may lead to heightened rehearsal and accessibility of those memories. When comparing healthy individuals versus individuals experiencing symptoms of post-traumatic stress, healthy individuals can recall positive events more 
readily from their past and experience recurrent involuntary memories of stressful events less frequently than individuals with post-traumatic stress (Walker et al., 2003).

\section{Berntsen et al.'s theory linking recurrent involuntary memory to post-}

traumatic stress. Post-traumatic stress is characterized by the re-experiencing of symptoms resulting from acute stressors (traumas). Traumatic events may violate a person's expectations related to self-knowledge and one's understanding of the world (Janoff-Bulman, 1988), and may be difficult to process and integrate with previously encoded memories (Berntsen, Willert, \& Rubin, 2003). The memories that result from these events may result in outcomes that are harmful to an individual's physical and mental health, including recurrent intrusive memories or thoughts, avoidance symptoms, and arousal symptoms such as sleep and concentration difficulties (Thomsen \& Berntsen, 2009). Additionally, trauma survivors may have trouble retrieving specific memories of events, potentially recalling over-general memories that are often experienced from an outside perspective as opposed to a first-person view (Berntsen, Willert, \& Rubin, 2003; Finnbogadottir, 2011; Tulving, 2002). These over-generalizations of traumatic events, because of distinctiveness and emotional impact, may remain highly accessible as fragmented memories that serve as cognitive reference points in the organization of selfknowledge (Berntsen \& Rubin, 2007; Hall, Brodar, LaBar, Berntsen, \& Rubin. 2018). Fragmented encoding of memories can lead to dissociation, or disintegration of traumatic or stressful memories, which impacts an individual's ability to create a coherent, nondisjoined narrative of the original event (Nijenhuis \& van der Hart,1999).

With regard to negative and unpredictable events, the severity of the event and the centrality of the event to one's life story (or identity) can influence how an individual 
attributes meaning to both ordinary events associated with the stressor and an individual's generation of expectations for events that may happen in the future (Berntsen \& Rubin, 2005). Post-traumatic stress can result in the suppression of thoughts, changes in the appraisal of the emotional valence or intensity of an event, increased depression and anxiety, rumination, unnecessary worrying, and compulsive attempts to avoid similar events in the future (Berntsen \& Rubin, 2005; Berntsen et al., 2015; Palacio-Gonzalez, Watson, \& Berntsen, 2018). Furthermore, these ruminative behaviors may cause an individual to have more intense reactions toward nontraumatic events, to predict an unrealistically high risk of experiencing future traumas and create a linkage between the original stressor to otherwise unrelated material or events (Thomsen \& Berntsen, 2009).

\section{Developing Interdisciplinary Support: Memories of Workplace Events}

Though each of these models and theories were proposed within the boundaries of their respective fields, there are critical parallels that can be drawn from each to support the interdisciplinary study of work stress and memory.

When looking at Bluck's (2003) functional categories of autobiographical memory and Sonnetag and Frese's (2003) work resources theory, each type of function and resource is integral in describing how the cognitive processing of memory relates to the workplace. The 'self' category and importance of individual resources manifests in the way that employees maintain an identity within their respective careers, tied into the self-esteem and self-efficacy that they feel in their ability to be a productive member of the workforce (Judge \& Bono, 2001). Employees accomplish their work within a culture, or social atmosphere, and are expected to operate within the bounds of certain organizational and sociocultural norms (Hofstede, 1979). Becoming part of a work 
culture involves utilizing resources tied to social/interpersonal support, and a successful employee would be able to understand the relationship between themselves and the community that they work in. Furthermore, the 'directive' category of memory relates closely to how individuals' function within the workplace, tying into job specification, task management, crisis planning, leadership, and a variety of other work-related duties and outcomes. As directive memories are the most privately rehearsed of the three memory functions (Bluck, 2003), the directive function may contribute to an inner dialogue relating to self-improvement and meeting organizational goals and standards.

Regarding the existing research on tunnel memories, there are many ways in which the impact of stressful situations in the workplace may be relevant. Abusive supervision, sexual harassment, sexism, ageism, racism, and many other aspects of an employee's workplace can evoke heightened states of stress or fear that could result in tunnel memories specific to one's occupation. An acute stressor could create a tunnel memory for a specific workplace situation (such as an interaction with an aggressive coworker) that not only carries over into other situations within that organization (interactions with all coworkers in the present job) but may persist throughout an employee's overall career (future coworkers in other organizations). As experiences of stress in the workplace can impact the encoding of memory, so it is reasonable to believe that work-related episodic memories are susceptible to becoming involuntarily recalled as well. A tunnel memory of an aggressive interaction with an abusive supervisor, for instance, could be triggered by several cues in the environment, such as listening to the supervisor interact with fellow employees or receiving criticism from other individuals in the workplace. Employees may create a general gist of supervisor interactions as negative 
and aversive stimuli while failing to recall neutral or positive stimuli present in these interactions.

Involuntary memories of stressful or traumatic workplace situations may become recurrent and serve as constant reminders and reinforcement of the subsequent negative interpersonal schemas an employee may develop. Employees experiencing recurrent negative involuntary autobiographical memories related to stressful workplace events may face a variety of unfavorable work-related outcomes. The experience of acute stress in an important event, such as a performance appraisal, may result in frequent rehearsals of negative thoughts related to one's performance in the workplace. The consequence of an employee's conscious attempts to repress these thoughts may lead an employee to block out important information related to this appraisal, such as positive feedback or advice on how an employee can progress in their job. Furthermore, the post-traumatic stress trauma could result in rumination, avoidance of the workplace or supervisor involved in the appraisal, and psychosomatic symptoms. Post-traumatic stress may lead an employee to overgeneralize feelings towards other workplace events that occur after the initial incident, creating spillover and anxiety in other workplace interactions and/or social situations (see Thomsen \& Berntsen, 2009).

The summation of the research on memory and work stress provides evidence for the idea that a) the juxtaposition of memory processes and the experience of workplace stress is a viable topic of future research; b) the encoding of episodic memory is an important process to examine in an employee population, as it relates to an employee's identity within the workplace, how an employee interacts socially in the workplace, and how an employee organizes and prioritizes tasks; c) the experience of workplace stress 
impacts the process of work-related memory encoding and retrieval; and d) the result of this impact can result in tunnel memories, involuntary memory retrieval, and recurrent involuntary retrieval of stressful events.

\section{Emotion-Focused Models of Cognition and Work Stress}

Contemporary research in organizational psychology emphasizes the impact of emotions on the stressor-strain relationship, with findings suggesting that the relationship between stressors and strains is stronger when looking at affective (emotional) reactions over physical reactions to stress (Chen \& Spector, 1991). Folkman and Lazarus (1988) showed that emotions are present in both problem-focused and emotion-focused coping, further emphasizing the role that emotions play in stress appraisal and strain experience. Spector's (1988) model of job stress depicts emotional appraisal as a moderator of the relationship between perceived stressors and experienced strains, with positive emotional states decreasing the experience of strain, and negative emotional states increasing the experience of strains. Grandey, Cordeiro, \& Crouter (2005) look at stress by way of job autonomy (employee control), suggesting that emotional regulation is central in the perception of stress, the experience of strain, and energy depletion via emotional exhaustion (Grandey et al., 2005; Gross, 1998; Maslach \& Jackson, 1981). Appraisals of stress, moods, and emotion-focused coping strategies are all factors that relate to an employee's usage of cognitive resources and ability to access and utilize these resources when encoding and recalling workplace memories.

Cote's (2005) cognitive-behavioral \& perception-appraisal theories. In addition to stressor-strain research, several theories also highlight the influence that emotions have on the cognitive-behavioral, perception-appraisal process of job stress. 
Cote (2005) asserts that emotions influence perception such that subjective responses to stressors can result in emotion amplification (initiating or enhancing public displays of emotion) or emotional suppression (reducing or eliminating public displays of emotion; Cote, 2005). Moreover, in the primary appraisal process, an individual assesses the stake invested in the situation which influences the interpretation of the event as harmful, threatening, or challenging (Perrewe \& Zellars, 1999). The process of appraisal and emotional response is ongoing and cyclical, and emotions arise from a combination of event appraisals and the individual's motives and beliefs relevant to how they perceive harm of threat in their environment (Lazarus \& Folkman, 1984).

An employee's appraisal of and response to stressful work events, therefore, depends on their ability to engage in emotional regulation. Employees who can perceive workplace events through the lens of positive emotionality may be able to suppress responses to stress as opposed to amplifying or exacerbating stressful situations.

Fontaine et al.'s studies on emotion and memory encoding. Research on tunnel memories implicates two variables that contribute to their encoding: emotional arousal and emotional valence. According to studies by Fontaine, Scherer, Roesch, \& Ellsworth (2007), valence and arousal can account for up to $46.7 \%$ of the observed variance between two distinct emotions. Emotional arousal can be measured in terms of how calming versus agitating an event (or experience) is to an individual. Emotional arousal has been implicated in prior research (Berntsen, 2001; Safer et al., 1998) as the main variable that causes the creation of tunnel memories, positing that states of fear (high arousal) require quicker reactions than states of calmness (low arousal). Although both positive and negative arousal stimulates a cognitive-behavioral response in memory 
retrieval, negatively appraised situations initiate the release of stress hormones, which quicken and enhance the consolidation of memory (Ford, Addis, \& Giovanello, 2012; Holland \& Kensinger, 2010; Steinmetz, Addis, \& Kensinger, 2010). The process of rapid memory consolidation creates an extraordinarily durable memory of the central details of extremely stressful (arousing) events, leading to the highly vivid recall and reliving of personal traumas (Berntsen, $2001 \& 2002$ ).

Emotional valence is measured on the level of highly positive (pleasant) to highly negative (unpleasant) and refers to one's own subconscious interpretation (or discrete emotion) of an event (Levine \& Pizarro, 2006). Although some research on the emotional dimensions of memory implicates arousal as the most important dimension of emotion, positive and negative valence have shown a significant impact on the mnemonic effects of memory encoding in emotional situations (Ford et al., 2012). Valence takes into account the individual differences in the perception of stress or trauma, and thus the impact an event may have on the process of memory encoding; positively-valenced experiences trigger cognitive processing that attends to the peripheral details of an experience, whereas negative valence enhances encoding of central event details (Clore, Wyer, Dienes, Gasper, Gohm, \& Isbell, 2001; Clore \& Storbeck, 2006; Fiedler, 2001; Kensinger \& Schacter, 2006).

Emotional arousal and emotional valence both play an important role in an employee's memory processes, from encoding to retrieval of workplace events. The experience of highly arousing events while on the job could lead to increased encoding of tunnel memories that are subject to being frequently relived. The negative versus positive 
context of an event also contributes to an employee potentially encoding tunnel memories of unpleasant episodic memories related to their jobs.

Schulkind and Woldorf (2005) and mood congruence. Research suggests that the emotional state, or mood, of an individual plays a significant role in the emotional organization and retrieval facilitation of autobiographical memories (Conway \& Bekerian, 1988). Schulkind and Woldorf (2005) reviewed the work on mood-congruence in memory or the tendency of an individual to recall memories that are consistent with the valence of their current mood. Individuals with positive moods, therefore, will perpetuate the feeling of positivity through the retrieval of positively-encoded memories, whereas individuals with negative moods display a tendency towards the retrieval of adverse or stressful memories that may perpetuate their dysphoria and reinforce negative cognitions (Schulkind \& Woldorf, 2005). The theory of mood congruence implies that the emotional state of an employee will yield the recall of congruent memories, and that employees with more negative moods may have more frequent or severe memory recall of stressful events.

Theories of emotion-driven episodic future thinking. Just as stress and trauma impact the encoding of past events, experiences of trauma may also influence episodic future thinking, or "the projection of the self into the future to pre-experience an event" (Atance \& O'Neill, 2001, p. 533; Berntsen \& Bohn, 2010; Berntsen \& Jacobsen, 2008). Episodic future thoughts can be voluntary as well as involuntary and tend to relate directly to the context of what an individual is currently involved in (e.g., imagining being pulled over while driving on the highway; see Berntsen et al., 2015). Involuntary future thoughts involve more specific episodic memories than voluntary future thoughts 
and are impacted more significantly by mood congruence and the emotional state of the individual experiencing the thought. In addition, episodic future thinking taps into an individual's schema regarding episode construction, which may be more susceptible to both the positivity bias and preexisting negative mindsets about the future experience. Episodic future thinking is thought to be supported by the same neurocognitive processes as autobiographical memory and involves mental time travel (the ability of individual to imagine themselves at a specific point in time) that is driven by both the sense and emotion-based knowledge of one's self (Berntsen \& Bohn, 2010).

Episodic future thinking may be especially important as it relates to how an employee might envision their future within their current organization. The ability of an employee to foresee a future for themselves within an organization may drastically impact an individual's sense of self, ability to set goals, and motivation towards achievement. Sudenddorf and Corballis, (2007) emphasize the importance of goal achievement in the experience of mental time travel, suggesting that goal setting and attainment involves revisiting past scenarios and constructing future scenarios that provide an individual the blueprints for personal success. An employee with impaired (or negative) future thinking could experience a decrease in the directive memory activities (see Bluck, 2003), resulting in an employee that has difficulties with their self-image within an organization. Behaviors such as setting and achieving work goals, finding motivation to complete tasks, and imagining a future within one's company may significantly impact an employee's productivity and satisfaction levels.

Each of these models shows how cognitive and I/O psychology can be interwoven and utilized to pinpoint the role of emotion in the experience of stress. Cote's (2005) and 
Fontaine et al.'s (2007) theories on perception imply the involvement of emotion at the onset of one's experience of a stressor, suggesting that an employee's emotions play a pivotal role in the subjective appraisal of workplace situations. Coupled with the assessment of an employee's feeling of personal investment in a situation, employees could engage in emotion amplification or suppression dependent on how much they perceive the outcome will directly affect them. Events that threaten job security, for example, would provoke a more heightened state of negative emotional arousal than an event appraised as less harmful to an employee's wellbeing within their environment. Depending on the employee's emotional valence, an acutely stressful event (e.g., an angry customer persistently threatens to get the employee fired) could impact the employee's memory encoding process. Emotion, therefore, is an important variable in the creation of tunnel memories and the ways in which these negative episodic memories are retrieved by an employee. Emotions are also an important factor related to how significant interpersonal differences may be when looking at an employee's perception of and reaction to workplace stressors.

These emotion-focused models emphasize the importance of a) how an individual's perception of stress can be positively and negatively affected by their emotions; b) how emotional appraisal of events are inherently cognitive processes integral to understanding interpersonal differences in experiences of workplace stress; c) how emotions contribute to episodic memory encoding and retrieval; and d) how emotions can influence an employee's ability to foresee a fruitful future within their organization. The influence of emotions, an affect-based variable within the context of the research cited, also implicates how other interpersonal differences (such as 
personality and psychopathology) may be of similar importance in understanding the relationship between work stress and episodic memory processes.

\section{Beyond the Current Models: Personality, Memory, \& Work Stress}

Stress research, both in the fields of I/O and cognitive psychology, emphasizes the important role of personality on perceiving and coping with stress. Temperament, personality, and affect influence emotional reactivity and positive versus negative cognitive appraisals of stressful situations (Larson \& Ketelaar, 1991). Historically, positive personality traits play a direct role in the sensitivity to and appraisal of attending to positive events, and negative personality traits are associated with sensitivity to attending to negative events (Larson \& Ketelaar, 1991; McCrae \& Costa, 1991). Behavioral activation (attending to signals of reward) and behavioral inhibition (attending to signals of punishment) also differ on the basis of an individual's positive or negative traits (Tellegan, 1985). Additionally, differences in individual perceptions of the world as a threat (e.g., an individual high in negative affect or neuroticism) influence the coping mechanisms an individual utilizes in different kinds of events. Thus, personality has been found to influence positive and negative emotional experiences, sensitivity and appraisal to the valence of events, and behavioral activation and inhibition (Larson \& Ketelaar, 1991) - all important factors in memory encoding and retrieval processes.

Personality traits, especially those that tie emotional regulation and mood predisposition, are important in managing the resources necessary to utilize problemsolving and positive coping techniques when dealing with workplace stressors (Cohen \& Edwards, 1989; Frese, 1989; Jex \& Elacqua, 1999; Sonnetag, 2002; Sonnetag \& Frese, 2003). Furthermore, emotion-focused personality traits may play a role in how an 
employee processes a stressful situation and subsequently engages in memory recall. An employee with negative personality traits may be unable to utilize techniques in coping with highly arousing and/or negatively valenced workplace events, and in turn be subject to more frequent occurrences of unwanted, involuntary recall of stressful memories.

Positive affect. Positive affect is a resilient (long-term), positive personality trait that can be maintained during high periods of stress and generated and sustained in even the most dire and stressful of situations (Moskowitz, Schmueli-Bumberg, Acree, \& Folkman, 2012). In the context of dealing with stressful situations, positive affect is associated with replenishing vital personal and self-regulatory resources depleted by stress, preventing major stress spillover, positive coping mechanisms, interpersonal trust, self-control, greater eliciting of social support, emotional intelligence, life satisfaction, positive perceptions, communication, self-confidence, and positive problem solving (Chen \& Spector, 1991; Elliot, Sherwin, Harkins, \& Marmarosh, 1995; Harvey, Stoner, Hochwarter, \& Kacmar, 2007; Hoobler \& Hu, 2013; Kong, Zhao, \& You, 2012; Moskowitz et al., 2012). Frederickson (1998) posited a 'broaden-and-build' model that suggests that positive emotions, such as those associated with positive affect, broaden an individual's attentional focus and behaviors, which strengthens (builds) social, intellectual/cognitive, and physical resources, leading to more self-control.

Lazarus, Kanner, and Folkman (1980) hypothesized that positive affect may provide a psychological break or respite under conditions in which negativity is predominant (Lazarus et al., 1980; Moskowitz et al., 2012). Additionally, the predisposition to experiencing positive emotional states has a general enhancing effect on both the encoding and retrieval process in memory. Positive affect promotes relational 
cognitive processing (Ford et al., 2012), and facilitates the activation of both exterior and central details regardless of emotional content (Clore et al., 2001; Clore \& Storbeck, 2006; Fiedler, 2001); Positive mood also facilitates the access to one's general knowledge, and increases the interconnectivity of conceptual nodes and one's associative network (Bower, Black, \& Turner, 1979 ; Jhean-Larose, Leveau, \& Denhiere, 2014). The affect infusion model (AIM; Forgas, 1995) suggests that positive affect impacts memory encoding through the ability to distinguish the valence of situations and judge the appropriate processes' necessary to facilitate thorough memory encoding, potentially increasing the memory of peripheral event details and preventing the creation of tunnel memories.

Individuals high in positive affect also seek out more social support, which can buffer adverse consequences of workplace stressors (Schat \& Kelloway, 2003). Harvey, Stoner, Hochwarter, and Kacmar (2007) suggest that individuals high in positive affect are more likely than individuals low in positive affect to perceive a communicator (such as a supervisor or coworker) in a favorable light, and that they are more optimistic and likely to cope well with stressful interpersonal workplace situations than employees low in positive affect. Harvey et al., (2007) argue that individuals who try to positively influence how others view them, and who are also upbeat in nature, can shield themselves from job-induced tension and emotional fatigue typically associated with acute workplace stressors. The overarching link between positive affect and productive coping techniques suggests that individuals who are high in positive affect will both experience workplace stressors less severely and engage in coping techniques that improve overall episodic memory functions. 
Negative affect. Whereas positive affect may signal that a person is satisfied or emotionally content, high negative affect is typified by feelings of anger, contempt, disgust, fear, and nervousness (Hoobler \& Hu, 2013; Watson, Clark, \& Tellegan, 1988). Negative affect is associated with a broad range of subjective complaints and reported physical and psychological symptoms, such as overall frustration, life and job dissatisfaction, health problems, somatic complaints, low self-esteem and heightened levels of stress (Brief, Burke, George, Robinson, and Webster, 1991; Chen \& Spector, 1991; Penney \& Spector, 2005). Chen and Spector (1991) assert that individuals high in negative affect experience negative emotions, undesirable physical symptoms, and overall feelings of dissatisfaction that persist regardless of directly experiencing an objective stressor. Negative affect also has an enhancing effect on memory, albeit substantially different than that of positive emotional states by promoting the specificity involved in encoding the central details (gist) of an event. Mood-congruent recall, in addition to the accuracy of event-specific memory, is also bolstered by underlying negative emotional states (Ford et al., 2012).

Several researchers have asserted that negative affectivity is a broader measure than being just another facet of more frequently studied negative personality traits such as neuroticism, depression, or anxiety. Tepper (2006) looked specifically at negative affect in relation to the experience of highly stressful events (abusive supervision). His findings suggested that employees high in negative affect not only experience heightened states of abuse because of their mood predisposition, but that these employees may also be more likely to incite abuse than individuals low in negative affect. That is, supervisors may target subordinates high in negative affect over subordinates low in negative affect when 
perpetrating abuse. The reciprocal relationship between negative affect and abusive supervision suggests that individuals high in negative affect may tend to be the abusers as well as the abused.

Tepper's findings parallel research conducted by Brief, Burke, George, Robinson, and Webster (1988) who found that emotionally negative states are pervasive and create a disposition to experience aversive situations and negative interpersonal encounters. Not only may individuals high in negative affect be inherent targets for scrutiny, but a perpetrator in a stressful workplace situation may believe that the employee "has it coming" as a result of the perpetrators trait negative affect or the victim's negative selfprojections in social situations (Hoobler \& Hu, 2013; Tepper, 2006). If a reciprocal relationship between negative affect and the experience of heightened levels of stress, a cyclical connection may exist between the tendency to encode negative autobiographical memories of workplace events and the propensity to recall these memories ruminatively in congruence with one's negative mood. Employee's high in negative affect may also have more frequent involuntary and recurrent involuntary memories of stressful events due to insufficient coping and emotional regulation techniques.

Emotional intelligence and emotional states. Above and beyond the traits of positive and negative affect, emotion is a prominent component of an individual's personality. Goleman's (1995) seminal work marks the emergence of emotional intelligence as a measure of personality in psychological research, defining emotional intelligence as the ability to be aware of your own feelings, to identify emotional aspects of a situation, to control one's own emotions effectively, and to understand the emotions of others. Emotional intelligence can be broken down into four components: self- 
awareness (self-assessment and self-confidence), self-management (self-control, adaptability, achievement orientation, and optimism), social awareness (empathy and service orientation), and relationship management (helping others, conflict resolution, inspirational leadership, and influence) (Goleman, 1995). Though there are multiple models and interpretations of emotional intelligence, research on emotion and personality has implicated a connection between emotional intelligence and the ability to maintain positive personal relationships (Van Rooy, Viswesvaran, \& Pluta, 2005) and elements of cognitive ability (Brackett \& Mayer, 2003; Janovics \& Christiansen, 2001).

Van Katwyk, Fox, Spector, \& Kelloway (2000) elaborate on the relationship between emotion and personality within the scope of the workplace in the construction of the job-related affective well-being scale (JAWS) - a measure of emotional states that includes emotional reactions to stressors in the workplace (see also: Pekrun \& Frese, 1992). Job-affective well-being differs from general positive and negative affect (a context-free measure of affect) by including context-specific affective responses to experiences an employee has in the workplace (Van Katwyk et al., 2000). Emotional states, within the context of the JAWS model, include dimensions of emotion like the measures of emotional valence and arousal used by memory researchers when categorizing emotional responses to memory recall. Misery-pleasure and arousalsleepiness are used to create a structure for understanding an employee's range of emotional responses to workplace experiences (e.g., anger, boredom, excitement, contentment, and distress) (Russel, 1980; Van Katwyk et al., 2000).

Regarding episodic memory and workplace stress, emotional states and levels of emotional intelligence may have an impact on the encoding and retrieval process similar 
to general affect; positive emotional states and high levels of emotional intelligence can buffer the effect of workplace stress, contribute to positive emotion-focused coping, and prevent the acuteness of negative workplace situations that might result in the encoding of tunnel memories.

Core self-evaluations. Judge, Locke, and Durham (1997) define core selfevaluations as an overarching personality construct that is thought to be the lens through which people see themselves and their environment. Additionally, one's core selfevaluation reflect an individual's emotional stability and capacity to emotionally adjust in social situations (Judge \& Bono, 2001; Judge et al., 1997). Each of the four facets of the measure of core self-evaluations addresses a different aspect of an individual's perception of and response to environmental interactions: self-esteem refers to an individual's general feeling of self-worth or value; general self-efficacy reflects how confident an individual feels in specific situations; neuroticism relates to an individual's negative predisposition, emotional fluctuation, and levels of anxiety, anger, depression, hostility, self-consciousness, and vulnerability; and locus of control is determined by how an individual attributes successes and failures as internal (e.g.,, I am smart) versus external (e.g., I was lucky) (Judge \& Bono, 2001; Judge \& Bono, 2003; Judge et al., 1997; Sonnetag \& Frese, 2003).

Within the context of the workplace, an employee's core self-evaluation would affect their overall feeling of worth as a member of a company or organization and how confident they feel in handling both tasks and social situations at work. Additionally, facets of core self-evaluations may determine how an employee interacts with customers, coworkers, and superiors (e.g., calmly versus with hostility), and whether an employee 
attributes successes or failures within their job (e.g., caused by their own inputs versus resulting from others in the workplace). Positive versus negative core self-evaluations may also impact how an employee encodes and retrieves memories of workplace experiences. High self-esteem and self-efficacy may help an employee engage in emotion-focused coping techniques when faced with workplace stressors, allowing for more accurate encoding of memories and less susceptibility to tunnel memories and potential involuntary recall of negative events than employees who do not engage in emotion-focused coping. Prior research also suggests that internal locus of control is a key individual difference associated with a more proactive approach in dealing with work environments and improved overall wellbeing - factors that may positively impact the appraisal process in processing memory (Cohen \& Edwards, 1989; Kahn \& Byosiere, 1992). Furthermore, an employee who is high in neuroticism may have a predisposition to attend to what is negative or stressful in the workplace and subsequently encode and retrieve more traumatic memories than those who are lower in neuroticism (Griffin \& Clarke, 2010).

\section{Understanding the Impact of Psychopathology on Episodic Memory \& Stress}

Akin to neuroticism, trait social anxiety and depression are both typified by ruminative behaviors that are triggered by and susceptible to fluctuations in mood and emotional states (O’Toole, Watson, Rosenberg, \& Berntsen, 2015; Watson, Berntsen, Kuyken, \& Watsen, 2012). These traits are associated with memory biases and a decrease in memory performance, both at encoding and at retrieval (Williams, J. M. G., Barnhofer, T. Crane, C. Hermans, D., Raes, F., Watkins, E., et al.., 2007). Furthermore, individuals who are anxious and/or depressed are more likely than non-anxious or depressed 
individuals to experience stress at a heightened level, engage less in emotion-focused coping techniques, and be predisposed to have negative perceptions when engaging with others in social situations (Heinrichs \& Hofmann, 2001; O'Toole et al., 2015).

Trait social anxiety. Social anxiety is characterized by persistent fear and worry pertaining to social situations that can result in negatively skewed appraisals of social situations (Stopa \& Clark, 2000). The perpetual experience of social anxiety is rooted in cognitive schemas that influence an individual's information processing - the intake, organization, and recall of information is connected to specific social events (Cody \& Teachman, 2010). Individuals with social anxiety view these situations through a negatively distorted lens, reinforcing negative and anxious thoughts and behaviors (Heinrichs \& Hofmann, 2001). Not only do individuals with social anxiety view situations negatively, but these individuals also have tendencies towards negative selfopinions and memory biases when receiving feedback from internal and external stimuli. Research on social anxiety and memory recall suggests that individuals higher in trait social anxiety experience more negative memory recall than those who report no or little experience with anxiety (O'Toole et al., 2015).

Combined with a predisposition to ruminate about events after they occur, negative opinions and memory biases may lead to negative perceptions of workplace interactions that are exaggerated by what may be imprecise recollections of actual events. Though there may be evidence to the contrary, a person suffering from social anxiety will bolster negative events by self-catastrophizing, "interpreting a [specific negative event] as having global and negative implications for one's view of the self and/or one's future" (Stopa \& Clark, 2000, p. 276). Feeling as if everyday workplace tasks and social 
interactions with coworkers may ultimately result in a catastrophe directly induces anxiety and perceived danger in the workplace while decreasing perceived self-efficacy in coping and productivity in these scenarios (Stopa \& Clark, 2000). Negative memory biases may result in a tendency to engage in anticipatory processing: focusing on what 'might happen' in future social events and oftentimes ignoring what may actually be happening (Kocovski, Endler, Rector, \& Flett, 2005).

Depression. According to the National Institute of Mental Health (2019), depression is a serious mood disorder impacting how individuals feel, think, and engage in daily activities (such as working). It includes symptoms such as persistent anxiety, feelings of hopelessness, pessimism, irritability, feelings of worthlessness, decreased energy, decreased motor function, restlessness, difficulty concentrating, memory problems, decision making problems, difficulty sleeping, and other general (negative) physical symptoms (NIH, 2019). Within the scope of the workplace, depression is a strain that results from the experience of workplace stressors - situations that are appraised as either potentially threatening to aspects of one's overarching career, personal growth, or potential future gains (Jex, 1998; Lazarus \& Folkman, 1984; LePine et al., 2005). Though some individuals can appraise stressors as positive challenges that have the potential to promote personal gain, individuals who suffer from depression are more likely than healthy individuals to perceive workplace stressors as threatening or hindering. Hindrance stressors trigger negative emotions and passive emotional coping techniques such as withdrawal and rumination (LePine et al., 2005).

Regarding the encoding and retrieval of memories, individuals who suffer from depression experience both voluntary and involuntary memories differently than their 
non-depressed counterparts. Williams et al. (2007) hypothesized a CaR-Fa-X (Capture and Rumination, Functional Avoidance and Executive Function) model as the reasoning behind the cognitive-functional differences between depressed and never depressed individuals. Depressed individuals have less specific voluntary recall as a result of avoidance of negative emotional content, tied to the tendency to ruminate over negative situations and have issues with integration of stressful memories into their schemacentered knowledge (Watson et al., 2012). Abstract (or non-direct) environmental cues may serve as triggers for the process of rumination, which reinforces abstract schema and self-knowledge and further inhibits the encoding of specific event details. Depression may also cause an individual to have experiential avoidance, reliving episodic memories from an outsider's perspective as opposed to reliving the memory in first-person (Finbogadottir, 2011). In terms of involuntary recall, however, depressed individuals report more specific recall of information that is related to both stronger emotions (mood impact) and heightened physical reactions to the memory of one's experience (Watson et al., 2012).

Overall, the association of social anxiety and depression with both poorer memory performance and increased susceptibility to stress implicates the importance of including both traits when looking at the impact of work stress on episodic memory.

\section{CURRENT STUDY}

Although I/O and cognitive psychology both emphasize the importance of understanding the experience of stress, employee memory processes in relation to workplace stressors have yet to be examined. There is a significant body of existing 
research on the variables of memory, stress, and interpersonal difference that interweave concepts from I/O and cognitive psychology and justify interdisciplinary research. The current study is split into two parts to fully assess the desired variables in the appropriate temporal context.

\section{Study 1: The Impact of Work Stress on Episodic Memory}

Study 1 focuses on the impact of stress on episodic memory via assessing how stress impacts the frequency of episodic memory reports. I suggest that episodic memories of workplace experiences are encoded and retrieved using the same processes involved with general episodic memory, and as such the experience of workplace stress should impact how positive versus negative episodic (tunnel) memories are recalled. I also posit that work stress will impact the frequency of negative involuntary memories and recurrent negative involuntary memories, such that heightened levels of work stress will result in more frequent reports of involuntary and recurrent involuntary negative episodic memories related to the workplace.

Hypothesis 1a-b: Workplace stress will a) positively correlate with measures of negative episodic memory recall, and b) negatively correlate with positive measures of episodic memory recall

Hypothesis 2a-b: Workplace stress will a) positively correlate with the number of involuntary episodic memories of stressful work events and b) positively correlate with the number of recurrent involuntary episodic memories of stressful work events 
My study will assess the role of personality in perceiving and coping with stress. Positive and negative affect are personality traits that directly parallel the emotional valence and arousal that impact an individual's experience of stress. Positive affect is associated with resource replenishment with dealing with stress and utilizing positive coping mechanisms (Chen \& Spector, 1991; Ford et al., 2012). Additionally, positive affect has also been connected to enhanced memory encoding and retrieval, and better accessing of one's general autobiographical knowledge (Bower et al., 1979; Jhean-Larose et al., 2014, Moskowitz et al., 2012). Negative affect is associated with heightened experiences of stress, an inability to cope, negative emotions, and impacted memory recall (Chen \& Spector, 1991; Ford et al., 2012; Tepper, 2006). The influence of mood congruence (remembering events consistent with one's current mood) on both the experience of stress and the memory encoding process suggests that positive affect may serve as a buffer against the experience of stress and encoding of negative workplace memories, and that negative affect may amplify the experience of stress and negatively impact the memory encoding process.

Hypothesis 3a-b: a) Positive affect will negatively correlate with workplace stress, and b) Negative affect will positively correlate with workplace stress. Hypothesis 4a-f: Positive affect will a) negatively correlate with voluntary episodic memory recall of stressful work events, b) negatively correlate with involuntary episodic memory recall of stressful work events, and c) negatively correlate with recurrent involuntary episodic memory recall of stressful work events; Negative affect will d) positively correlate with voluntary episodic memory recall of stressful work events, e) positively correlate with 
involuntary episodic memory recall of stressful work events, and f) positively correlate with recurrent involuntary episodic memory recall of stressful work events

Several researchers have emphasized the importance of emotion in both coping with stress (e.g., utilizing positive coping techniques to lessen the impact of stress) and in episodic memory processes (such as the accuracy of memory encoding and retrieval). To investigate the impact of emotion on the experience of workplace stressors, three additional emotion-related personality traits from the modern I/O literature will be included in the current study: job-affective wellbeing (one's emotional state at work; Van Katwyk, Fox, Spector, \& Kelloway, 1999), emotional intelligence (the ability to identify, control, and understand emotions; Goleman, 1995), and core self-evaluations (a composite measure of self-esteem, generalized self-efficacy, locus of control, and neuroticism/emotional stability; Judge \& Bono, 2001; Sonnetag \& Frese, 2003).

Hypothesis 5a-c: Job affective wellbeing (emotional state) will a) negatively correlate with workplace stress, b) emotional intelligence will negative correlate with workplace stress, and c) core self-evaluations will negatively correlate with workplace stress

Hypothesis 6a-c: Job affective wellbeing (emotional state) will a) negatively correlate with voluntary episodic memory recall of stressful work events, b) negatively correlate with involuntary episodic memory recall of stressful work events, and c) negatively correlate with recurrent involuntary episodic memory recall of stressful work events 
Hypothesis 7a-c: Emotional intelligence will a) negatively correlate with voluntary episodic memory recall of stressful work events, b) negatively correlate with involuntary episodic memory recall of stressful work events, and c) negatively correlate with recurrent involuntary episodic memory recall of stressful work events

Hypothesis 8a-c: Core self-evaluations will a) negatively correlate with voluntary episodic memory recall of stressful work events, b) negatively correlate with involuntary episodic memory recall of stressful work events, and c) negatively correlate with recurrent involuntary episodic memory recall of stressful work events

Two psychopathology traits, social anxiety and depression, will be included in my study to determine the relationship between mental health and wellbeing and the memory-stress experience. I think that individuals who suffer from social anxiety and depression will 1) have a predisposition toward perceiving experiences as negative or stressful, 2) more frequently encode and recall negative episodic memories than nonanxious, non-depressed employees, and 3) experience acute workplace stressors with more severity than non-anxious, non-depressed employees.

Hypothesis 9a-b: a) Social anxiety will positively correlate with workplace stress, and b) Depression will positively correlate with workplace stress.

Hypothesis 10a-c: Social anxiety will a) positively correlate with voluntary episodic memory recall of stressful work events, b) positively correlate with involuntary episodic memory recall of stressful work events, and c) positively 
correlate with recurrent involuntary episodic memory recall of stressful work events

Hypothesis 11a-c: Depression will a) positively correlate with voluntary episodic memory recall of stressful work events, b) positively correlate with involuntary episodic memory recall of stressful work events, and c) positively correlate with recurrent involuntary episodic memory recall of stressful work events

Two of the most well-studied stress outcomes in I/O literature are job satisfaction and motivation. Job satisfaction can be defined as a job attitude related to the favorability of one's job, and is formed through evaluations, emotional responses, and prior behavior or experiences with one's organization (Locke, 1976). High levels of job satisfaction are associated with higher organizational commitment and positive mood, whereas low levels of job satisfaction are associated with anxiety, stress, frustration, tension, and counterproductive work behaviors (such as absenteeism, turnover, and ineffective job performance) (Judge, Thoreson, Bono, \& Patton, 2001). Job satisfaction has also been found to correlate strongly with attitudinal variables such as job and career involvement, work ethic, and self-esteem.

Job satisfaction is related to cognitive-behavioral processes such as beliefs an individual has towards his or her job (such as believing one's job to be challenging, boring, stimulating, or inspiring) (Spector, 1997). Emotional states also relate to an individual's perception of job satisfaction, often resulting in satisfaction from the feeling that one's job has allowed them to fulfill personal goals and values (Locke, 1969). An individual's disposition (affectivity) and personality also influences an employee's level 
of job satisfaction, with positive affect and positive core self-evaluations correlating with higher job satisfaction and negative affect and negative core self-evaluations correlating with lower job satisfaction (Judge et al., 1997; Watson \& Slack, 1993; Watson \& Tellegen, 1985). In addition, satisfaction is reflected by an employee's behavior within an organization, with more satisfied employees exhibiting more positive workplace behaviors such as organizational citizenship.

Motivation is defined as "the psychological processes that determine (or energize) the direction, intensity, and persistence of action within the continuing stream of experiences, characterizing a person in relation to his or her work" (Kanfer, 1990, p. 662). Levels of motivation impact job performance, job satisfaction, absenteeism, turnover, and growth-needs strength (the extent to which an employee sees their job fulfilling needs such as self-actualization and personal achievement; see Champoux, 1991; Hackman \& Oldham, 1976; Maslow, 1943).

Cognitive-behavioral factors, personality factors (such as self-esteem and selfefficacy) and stress management all impact the relationship between environmental events and levels of workplace motivation (Bandura, Barbaranelli, Vittorio Caprara, \& Pastorelli, 2001). Self-regulation of attentional resources and how an individual interprets the motivation behind the tasks that they perform (autonomy vs. feeling controlled) are two ways in which cognitive evaluation relates to employee motivation (Deci \& Ryan, 1985; Kanfer \& Ackerman, 1989; Ryan \& Deci, 2000). Self-efficacy and self-esteem link personality to belief in one's capability to attain goals, strive for desired outcomes, learn from social situations, and evaluate goal progress (Bandura, 1997; Schunk \& Usher, 2012). LePine, Podsakoff, and LePine (2005) suggest that positive emotions and active 
coping strategies when dealing with stress are important for an employee to feel motivated, as these factors lead an employee to believe that the effort they exert will result in expected outcomes or rewards. Furthermore, Hart and Cooper (2001) suggest that adverse work experiences, such as experiences of workplace stress or trauma, can lead to a lack of motivation within one's organization.

Hypothesis 12a-c: Job satisfaction will a) negatively correlate with voluntary episodic memory recall of stressful work events, b) negatively correlate with involuntary episodic memory recall of stressful work events, and c) negatively correlate with recurrent involuntary episodic memory recall of stressful work events

Hypothesis 13a-c Motivation will a) negatively correlate with voluntary episodic memory recall of stressful work events, b) negatively correlate with involuntary episodic memory recall of stressful work events, and c) negatively correlate with recurrent involuntary episodic memory recall of stressful work events

\section{Study 2: The Relationship Between Work Stress \& Mental Time Travel}

Study 2 focuses on the relationship between work stressors and episodic future thinking via one critical aspect of episodic memory: the phenomenon of mental time travel (Berntsen \& Bohn, 2010). Mental time travel involves the processes of mentally reliving an experience and imagining one's self experiencing an event in the future, with the ability to discern events that have truly happened in one's past from imaginary future events. To date, there is no research looking at mental time travel through the lens of one's workplace. The nature of my study allows participants to project their current 
feelings and emotions about their job into the future by measuring short-term and longterm episodic future thoughts. I believe that work stress will impact the frequency of negative episodic memories and negative episodic future thoughts similarly to Study 1 , such that heightened levels of work stress will result in more frequent reports of negative episodic memories and negative episodic future thoughts related to the workplace. I will also examine the impact of work stress on the memories' vividness, emotionality, intensity, importance to the participant, frequency of occurrence, and ease of remembering. Study 2's additional hypotheses are as follows:

Hypothesis 14a-c: Workplace stress will a) negatively correlate with the recall of positive episodic memories that have actually occurred, b) negatively correlate with the recall of positive episodic memories that are imagined, and c) negatively correlate with positive episodic future thoughts

Hypothesis 15a-f: Workplace stress will a) positively correlate with vividness, b) negatively correlate with positive emotionality, c) positively correlate with event importance, d) positively correlate with intensity, e) positively correlate with frequency, and f) positively correlate with ease of recall

In Study 2 I will reexamine each of the hypotheses pertaining to memory using the three episodic future thinking variables in place of voluntary and involuntary memory recall.

Hypothesis 16a-c: Positive affect will a) positively correlate with the recall of positive episodic memories that have actually occurred, b) positively correlate 
with the recall of positive episodic memories that are imagined, and c) positively correlate with positive episodic future thoughts

Hypothesis 17a-c: Negative affect will a) negatively correlate with the recall of positive episodic memories that have actually occurred, b) negatively correlate with the recall of positive episodic memories that are imagined, and c) negatively correlate with positive episodic future thoughts

Hypothesis 18a-c: Job-affective wellbeing (emotional state) will a) positively correlate with the recall of positive episodic memories that have actually occurred, b) positively correlate with the recall of positive episodic memories that are imagined, and c) positively correlate with positive episodic future thoughts

Hypothesis 19a-c: Emotional intelligence will a) positively correlate with the recall of positive episodic memories that have actually occurred, b) positively correlate with the recall of positive episodic memories that are imagined, and c) positively correlate with positive episodic future thoughts

Hypothesis 20a-c: Core self-evaluations will a) positively correlate with the recall of positive episodic memories that have actually occurred, b) positively correlate with the recall of positive episodic memories that are imagined, and c) positively correlate with positive episodic future thoughts

Hypothesis 21a-c: Social anxiety will a) negatively correlate with the recall of positive episodic memories that have actually occurred, b) negatively correlate with the recall of positive episodic memories that are imagined, and c) negatively correlate with positive episodic future thoughts 
Hypothesis 22a-c: Depression will a) negatively correlate with the recall of positive episodic memories that have actually occurred, b) negatively correlate with the recall of positive episodic memories that are imagined, and c) negatively correlate with positive episodic future thoughts Hypothesis 23a-c: Job satisfaction will a) positively correlate with the recall of positive episodic memories that have actually occurred, b) positively correlate with the recall of positive episodic memories that are imagined, and c) positively correlate with positive episodic future thoughts Hypothesis 24a-c: Motivation will a) positively correlate with the recall of positive episodic memories that have actually occurred, b) positively correlate with the recall of positive episodic memories that are imagined, and c) positively correlate with positive episodic future thoughts

As Study 2 is qualitative in nature it allows for the categorization of participants responses beyond what a questionnaire might capture, such as: interactions with customers, coworkers, and bosses and dialogue about being hired, promoted, recognized, fired, or quitting. Additionally, I will note the inclusion of experiencing and/or witnessing injuries, yelling, and fighting in participants' responses. These qualitative responses will allow for both quantitative answers (in measuring emotional valence and arousal) exploratory research that could have significant implications for future interdisciplinary research. 


\section{Developing an Integrated Model}

In addition to understanding the correlations between the variables related to memory, work stress, interpersonal differences, and job outcomes, I seek to address the way that these variables may be understood in an integrated model. Existing research on work stress highlights the importance that traits such as personality and psychopathology may have on an employee's ability to process stress and engage in effective coping techniques in the workplace. Additionally, interpersonal differences have been implicated as a factor involved in how an employee may process memories of stressful workplace events. I propose that personality and psychopathology will mediate the relationship between an employee's perception of work stress and their subsequent voluntary, involuntary, and recurrent involuntary memories of stressful work events. Additionally, I believe that personality and psychopathology will mediate the relationship between personality and memories related to mental time travel.

Figure 1: Proposed Model of Work Stress, Episodic Memory, and Interpersonal Differences

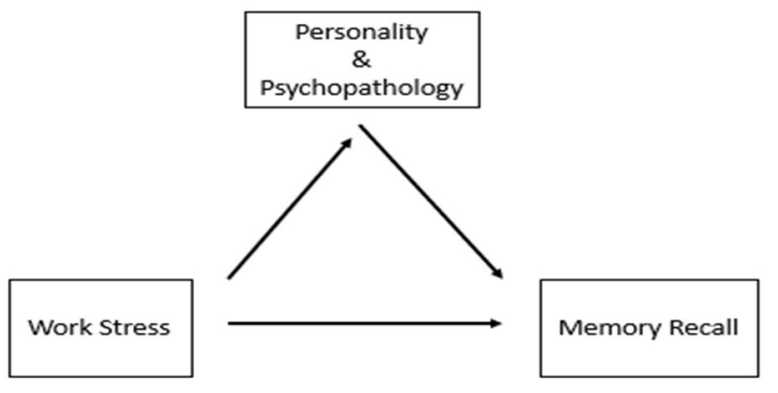


Hypothesis 25a-f: Personality and psychopathology will mediate the relationship between a) work stress and voluntary episodic memory recall of stressful work events, b) work stress and involuntary episodic memory recall of stressful work events, c) work stress and recurrent involuntary episodic memory recall of stressful work events, d) work stress and reports of negative past work experiences, e) work stress and reports of negative imagined past work experiences, and f) work stress and reports of negative imagined future events

When looking at the variables of job satisfaction and motivation, prior research suggests that there will be a significant negative relationship between work stress and these two job outcomes. I propose that the recall of stressful work events (from Study 1) will moderate the relationship between work stress and job satisfaction \& motivation, such that more frequent reports of stressful work memories will strengthen the impact that work stress has on an employee's level of job satisfaction and motivation.

Figure 2: Proposed Model of Work Stress, Episodic Memory, and Job Outcomes

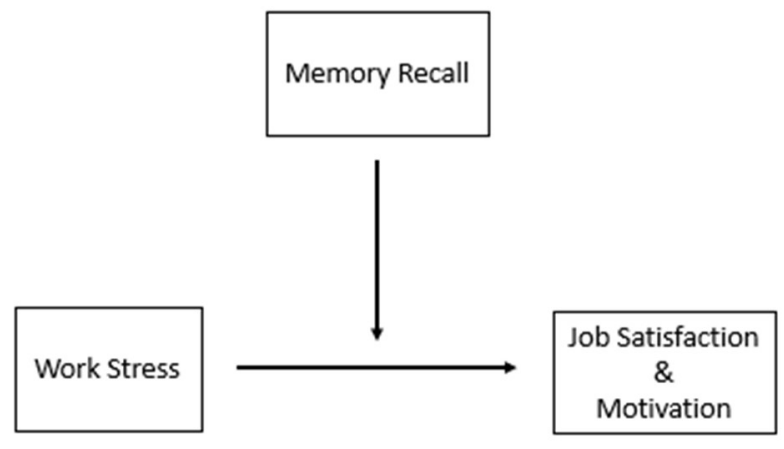


Hypothesis 26a-b: Voluntary recall of stressful work events will moderate the relationship between a) job satisfaction and b) motivation and work stress, such that more frequent voluntary recall of stressful work events will strengthen the relationship between work stress and lower levels of these outcomes

Hypothesis 27a-b: Involuntary recall of stressful work events will moderate the relationship between a) job satisfaction and b) motivation and work stress, such that more frequent involuntary recall of stressful work events will strengthen the relationship between work stress and lower levels of these outcomes

Hypothesis 28a-b: Recurrent involuntary recall of stressful work events will moderate the relationship between a) job satisfaction and b) motivation and work stress, such that more frequent recurrent involuntary recall of stressful work events will strengthen the relationship between work stress and lower levels of these outcomes

When taken together, the proposed mediations and moderations comprise the following model:

Figure 3: Integrated Model of Memory, Stress, Individual Differences, and Job

\section{Outcomes}

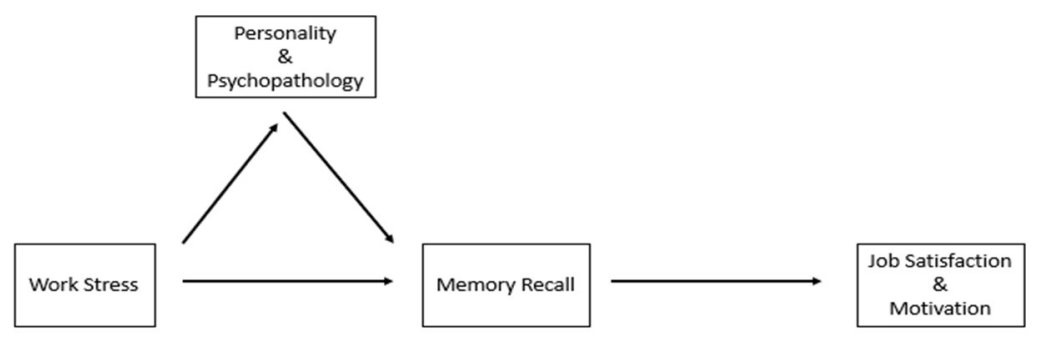




\section{METHODOLOGY}

\section{Study 1 Participants}

The sample consisted of 260 participants who were recruited via SONA Systems at Florida International University. The sample had a mean age of 25.9 years old $(\mathrm{SD}=$ 5.48), was $81.2 \%$ female (17.3\% male and $1.5 \%$ not disclosed), and the ethnic breakdown of the sample was: $60.4 \%$ Hispanic or Latino, $21.5 \%$ Black or African American, $14.2 \%$ White, 3.5\% Asian, and 0.4\% Native Hawaiian or Pacific Islander.

When looking at educational background, 56.9\% of participants held an Associate degree, $17.3 \%$ held a Bachelor degree, $16.2 \%$ had completed some college with no degree, and $8.1 \%$ had a high school diploma (1.5\% did not respond). When looking at hours worked, $22.1 \%$ of participants worked part-time (approximately 20 hours a week), $30.9 \%$ worked $21-30$ hours a week, $36.9 \%$ worked $31-40$ hours a week, and 10.1\% worked $41+$ hours a week. The salary breakdown of the sample was: $54.7 \%$ earning $\$ 20,000$ a year or less, $18 \%$ earning $\$ 20,001$ to $\$ 30,000 /$ year, $13.7 \%$ earning $\$ 30,001$ to $\$ 40,000 /$ year, $5.9 \%$ earning $\$ 40,001$ to $\$ 50,000 /$ year, and $7.8 \%$ earning more than $\$ 50,000 /$ year. With regard to tenure, $15.3 \%$ of participants have been at their current job for less than 6 months, $27.5 \%$ for $6-12$ months, $29.4 \%$ for $1-2$ years, $16.5 \%$ for $3-4$ years, $11 \%$ 5-10 years, and .4\% for $10+$ years. The level of the participants' current positions was $6 \%$ internship, $40.1 \%$ entry level, $42.1 \%$ associate level, $10.7 \%$ mid-senior level, and $1.2 \%$ director.

\section{Study 1 Procedures}

Each participant received the same link to a Qualtrics survey which provided participants with further information about the study (see Appendices), including the 
following eligibility criteria: 18 years or older, and currently working at least part-time (20+ hours a week). Upon the participants' agreement that they met the eligibility requirement, individuals were directed to a consent form to participate in a survey measuring episodic memory in the workplace. In the first section, participants were asked to imagine a stressful event that has happened to them in their workplace over the past six months. The second and third sections asked about the frequency of which stressful past memories and imagined future events came to the participants' minds by themselves (without trying) during a typical workday, measuring involuntary episodic memory recall and recurrent involuntary episodic memory recall respectively. After completing the sections on memory, participants completed a questionnaire comprised of questions measuring work stress, personality traits, psychopathology traits, job satisfaction, and motivation.

Demographic questions were asked at the end of the survey, with the option of non-response to these questions. Participants were made aware that they may stop at any point in the process (see Appendix A), and that completion of the questionnaire was completely voluntary. Completed surveys were scored and entered into SPSS for analysis. Surveys containing more than one incomplete section (e.g., work stress or emotional intelligence) were excluded from further analysis.

\section{Study 2 Participants}

The sample consisted of 227 participants who were recruited via SONA Systems at Florida International University. The sample had a mean age of 25.2 years old ( $\mathrm{SD}=$ 5.7), was $82.4 \%$ female ( $16.7 \%$ male and $.9 \%$ not disclosed), and the ethnic breakdown of the sample was: $65.2 \%$ Hispanic or Latino, $22 \%$ Black or African American, 7.6\% 
White, 4.4\% Asian, 0.4\% American Indian or Alaska Native, and 0.4\% Native Hawaiian or Pacific Islander.

When looking at educational background, $61.3 \%$ of participants held an Associate degree, $17.8 \%$ held a Bachelor degree, $14.7 \%$ had completed some college with no degree, $4.8 \%$ had a high school diploma, and 1.3\% held a Masters degree or higher. When looking at hours worked, $26.8 \%$ of participants worked part-time (approximately 20 hours a week), 29.1\% worked 21-30 hours a week, 30.9\% worked 31-40 hours a week, and $13.2 \%$ worked $41+$ hours a week. The salary breakdown of the sample was: $55.2 \%$ earning $\$ 20,000$ a year or less, $16.6 \%$ earning $\$ 20,001$ to $\$ 30,000 /$ year, $12.6 \%$ earning $\$ 30,001$ to $\$ 40,000 /$ year, $5.4 \%$ earning $\$ 40,001$ to $\$ 50,000 /$ year, and $10.3 \%$ earning more than $\$ 50,000 /$ year. With regard to tenure, $22 \%$ of participants have been at their current job for less than 6 months, $18.8 \%$ for $6-12$ months, $29.6 \%$ for $1-2$ years, $16.1 \%$ for $3-4$ years, $11.7 \%$ 5-10 years, and $1.8 \%$ for $10+$ years. The level of the participants' current positions was $6.8 \%$ internship, $35.1 \%$ entry level, $45 \%$ associate level, $9.9 \%$ mid-senior level, $2.7 \%$ director, and $.5 \%$ executive.

\section{Study 2 Procedures}

Each participant received the same link to a Qualtrics survey which provided participants with further information about the study, including the following eligibility criteria: 18 years or older, and currently working at least part-time (20+ hours a week). Upon the participants' agreement that they met the eligibility requirement, individuals were directed to a consent form to participate in a survey measuring episodic memory in the workplace (see Appendix B). Consenting participants received the following prompt: 
"This is a study about memories and imagined events. On the following pages you will be asked to remember important memories from your workplace. You will also be asked to imagine important events that might happen in future work experiences or might have happened in your past jobs but did not actually occur. Please read the instructions on each page carefully and write down specific memories/imagined events. This means that memories/imagined events you write should belong to a specific time and a specific place and their duration should not exceed a full day -24 hours. Please write a few sentences for each memory/imagined event. After you finish writing each memory/imagined event, please provide a brief title and answer a number of questions about it. All of your answers will remain confidential."

Participants then recorded the following: a summary of a memory from an actual event that has occurred at work over the past one month, one year, and five years; a summary of an imagined past event (an event that might of happened but has not actually happened) over the past one month, one year, and five years; and a summary of an imaginary event that might happen over the next one month, one year, and five years in their career. Upon recording these entries, participants were asked about the phenomenology of the questions related to vividness ("How vivid were the memories"?), emotions ("What were the emotions like that you had upon recalling the following memories"?), intensity ("How intense were the emotions that you felt when recalling the following memories"?), importance ("How important are the following memories to your life"?), voluntary recall ("For the following memories, have you willfully thought back to 
the event in your mind, thinking about or talking about the event that occurred"?), and ease of remembering ("How easy was it to remember the following memories"?).

After completing the sections on memory, participants completed a questionnaire comprised of questions measuring work stress, personality traits, psychopathology traits, job satisfaction, and motivation. Demographic questions were asked at the end of the survey, with the option of non-response to these questions. Participants were made aware that they may stop at any point in the process, and that completion of the questionnaire was completely voluntary.

Completed surveys were scored and entered into SPSS for analysis, where all quantitative data were summed and analyzed. Surveys containing more than one incomplete section (e.g., work stress or emotional intelligence) were excluded from further analysis. The remaining qualitative responses from the nine text entry sections were coded by two raters to determine emotional valence (on a scale of -5 to +5 , with -5 representing the most negative valence score and +5 representing the most positive valence score) and emotional arousal (on a scale of 0 to 5 , with 5 being the highest possible arousal). Additionally, a binary rating of 0 or 1 were assigned to each memory submission to code for the presence of customers or clients, coworkers, supervisors or bosses, promotions or awards, firing or writeups, and fighting or physical altercations. A Cohen's $k$ was run to determine the agreement between the rater's judgment on the participant's responses, with a moderately strong agreement between the rater's judgments: $k=.623(95 \% \mathrm{CI}, .512$ to .785$), p<.01$. 


\section{Measures}

Episodic memory. Episodic memory was measured using O’Toole, Watson, Rosenberg, and Berntsen's (2015) 15-item Autobiographical Memory Questionnaire (previously adapted from Rubin, Schrauf, \& Greenberg, 2003 \& Berntsen \& Rubin, 2006). For the purpose of Study 1, the questionnaire prompted participants to imagine a specific stressful event in their workplace from the past six months (as opposed to a general life event, as the survey would originally prompt for). Each question addressed a unique component of episodic memory, with one question per each of the following: reliving, visual, olfactory, surroundings, vividness, bodily sensations, emotions, valence, current intensity, perspective, belief, words, worry, voluntary recall, and involuntary recall of the memory.

Twelve of the questions (e.g. "This memory is vivid" and "When I recall the event, it comes to me in words") used a 7-point Likert scale to assess the extent of which and individual agreed with the statement given in the question, with 1 being "not at all" and 7 being "to a very high degree." The question on valence ("The emotions I have when I recall the episode are...") used a 7-point Likert scale to assess the positive versus negative emotions related to one's memory, with -3 being "extremely negative," 3 being "extremely positive," and 0 being neutral. The question on perspective ("When I recall the event, I primarily see what happened from a perspective as seen through...”) used a 7-point Likert scale to access the degree to which a memory is experienced in the firstperson, with 1 being "my own eyes" and 7 being "an observers eyes." Lastly, the question on belief ("I believe that the event really took place the way I remember it, and that I did not imagine anything or invent anything that did not take place") used a 7-point Likert 
scale to assess an individual's confidence on the reality of the event their remembering, with 1 being " $100 \%$ fantasy" and 7 being “ $100 \%$ real."

Each facet of autobiographical memory was measured separately when conducting hypothesis testing. A summed measure of episodic memory included all components except for valence (positive versus negative emotions), intensity, and worry, which were measured independently when addressing each hypothesis. A high score on the summed measure of episodic memory indicated a higher degree of recall of the stressful event that the participant chose to reflect on, and a low score indicated a lower degree of recall. The Cronbach's alpha for the 15-Item Questionnaire items ranged between .80 and .91 for Study 1 .

Involuntary autobiographical memory. Involuntary autobiographical memory was measured with an adapted version of the Involuntary Autobiographical Memory Inventory (IAMI; Berntsen, Rubin, \& Salgado, 2015). The IAMI consisted of 20 items that addressed how frequently imagined and future events came to mind on a day-to-day basis, without the participant actively trying to recall these memories (e.g., "Memories of personal events pop into my mind by themselves - without me consciously trying to remember them" and "When I am bored, imaginary future events come to my mind by themselves - without me consciously trying to evoke them"). I adapted the IAMI for the current study by editing the wording to reflect stressful workplace events (e.g. "Memories of stressful workplace events pop into my mind by themselves - without me consciously trying to remember them" and "When I am bored, I imagine future stressful workplace events without consciously trying to evoke them"). All items used a 5-point Likert scale to address the frequency of involuntary memories experienced, with $0=$ "never" and $4=$ 
"once an hour or more." When summed, a low score on the IAMI reflected infrequent involuntary episodic memories and a high score reflected more frequent involuntary stressful episodic memories. The adapted IAMI for involuntary memory in the workplace had a Cronbach's alpha of .92 for Study 1.

Recurrent involuntary autobiographical memory. Recurrent involuntary autobiographical memory was measured by adapting the 20 -item IAMI scale to assess whether a participant's involuntary memory was experienced more than once. Participants received a second IAMI after completing the original scale with slight revisions, such as "I have experienced recurrent memories of stressful workplace that have popped up into my mind by themselves - without me consciously trying to evoke them" and "When I am bored, the same imagined future stressful events reoccur in my mind by themselves, without me consciously trying to evoke them"). The revision of the recurrent IAMI used the same 5-point Likert scale as the IAMI to address the frequency of recurrent involuntary memories, with $0=$ "never" and through $4=$ "once an hour or more." When summed, a low score on the revised IAMI reflected infrequent recurrent involuntary autobiographical memories and a high score reflected more frequent recurrent involuntary autobiographical memories. The adapted IAMI for recurrent involuntary memory in the workplace had a Cronbach's alpha of .90 for Study 1.

Mental time travel. I measured mental time travel by asking three blocks of questions related to past and future memories. Prior to answering the memory questions, participants received the following statement:

"This is a study about memories and imagined events. On the following pages you will be asked to remember important memories from your workplace. You will 
also be asked to imagine important events that might happen in future work experiences or might have happened in your past jobs but did not actually occur. Please read the instructions on each page carefully and write down specific memories/imagined events. This means that memories/imagined events you write should belong to a specific time and a specific place and their duration should not exceed a full day -24 hours. Please write a few sentences for each memory/imagined event. After you finish writing each memory/imagined event, please provide a brief title and answer a number of questions about it. All of your answers will remain confidential."

The first block of questions pertained to past events that were actually experienced by the participants, and consisted of "Please write a brief summary of your memory of an important event that has happened within the past month," "Please write a brief summary of your memory of an important event that has happened in the past year," and "Please write a brief summary of your memory of an important event that has happened within the past $5+$ years." The second block of questions was identical to the questions about past events, but was worded to ask about imagined past events as opposed to past events that actually happened (e.g. "Please write a brief summary of your memory of an important event that could have happened within the past month, but has not actually happened.").

The third block of questions pertained to episodic future thinking and included the prompts of "Imagine an important event that may happen in your workplace over the next month. Briefly describe this imagined future event," "Imagine an important event that may happen in your workplace over the next year. Briefly describe this imagined future 
event," and "Imagine an important event that may happen in your workplace over the next five or more years. Briefly describe this imagined future event."

Phenomenology questions were asked after the participants completed the nine memory responses. Participants were asked how vivid the memories were, what the emotions were like that they had upon recalling these memories, how intense the emotions were that were felt upon recall, how important the memories were to the participant's life, how easy it was to remember the memory, and whether or not the participant had willfully thought back to the event in their mind since the event initially occurred.

All qualitative variables were coded by two raters for the following information: emotional valence (from -5 to +5 ), emotional intensity (from 0 to 5 ), inclusion of clients or customers ( 0 or 1$)$, inclusion of coworkers ( 0 or 1$)$, inclusion of bosses or supervisors ( 0 or 1$)$, mention of praise or promotion ( 0 or 1$)$, mention of reprimand or being fired ( 0 to 1), mention of yelling, fighting, or injury (0 to 1), and mention of an episodic memory that was not related to work tasks (e.g., birthday parties, 0 to 1 ).

Workplace stress. Workplace stress was measured with the Work-Related Stress Questionnaire - an adaptation of the HSE Management Standards Indicator Tool 2019. The questionnaire was composed of 39 items assessing an employee's feelings about their work environment over the past six months (e.g., "I am subject to personal harassment in the form of unkind words or behavior," "I am clear about the goals and objectives for my department," "I have unachievable deadlines," and "I can rely on my line manager to help me out with a work problem.”). The workplace stress measure was assessed with a 5-point Likert scale that determined the frequency of an employee's 
stressful experiences, with anchors of $1=$ "never" and $5=$ "always." When summed, a high score on the Work-Related Stress Questionnaire reflected higher levels of stress than low scores on this questionnaire. The Work-Related Stress Questionnaire had a Cronbach's alpha of .94 for Study 1 and .93 for Study 2.

Positive and negative affect. I measured positive and negative affect with the 20 item Positive and Negative Affect Schedule (PANAS; Watson et al., 1988). Ten items represented positive affect, and ten items represented negative affect. The PANAS scale consisted of words to describe feelings and emotions (e.g., guilty, strong, ashamed, determined). A 5-point Likert scale was used to assess the extent of which an individual associates with each word in the present moment, with $1=$ "very slightly or not at all" through $5=$ "extremely." When items from the NA section were summed, a high score was associated with high negative affectivity and a low score was associated with low negative affectivity. When items from the PA section were summed, a high score was associated with high positive affectivity and a low score was associated with low positive affectivity. No items were reverse coded in this scale. The PANAS scale had a Cronbach's alpha of .94 (PA) and .90 (NA) for Study 1 and .93 (PA) and .89 (NA) for Study 2.

Emotional state. I measured emotional state with the 20-item Job-related Affective Well-being Scale (JAWS; Van Katwyk, Fox, Spector, \& Kelloway, 1999). The JAWS described different emotions (e.g., "My job made me feel angry," "My job made me feel calm," "My job made me feel depressed") and participants were advised to indicate the extent to which any aspect of their job has elicited that emotion in the past 30 days. The JAWS was modified to use a 5-point Likert scale, with $1=$ "never" through 5 
= "extremely often." Negatively worded items (i.e., depressed, fatigued, frightened) were reverse-coded. After the reverse-coded items were scored and reversed, and all items were then summed, a high score on the JAWS was associated with high wellbeing and positive emotional states, and a low score was associated with low wellbeing and negative emotional states. The JAWS had a Cronbach's alpha of .92 for Study 1 and Study 2 .

Emotional intelligence. Emotional intelligence was measured using Schutte, Malouff, Hall, Haggerty, Cooper, Golden, \& Dornheim's (1998) 33-item Emotional Intelligence and Reading Scale (EIRS, based on Salovey \& Mayer's model of emotional intelligence). Each item was assessed on a 5-point Likert scale, with $1=$ "strongly disagree" and 5 = "strongly agree." Example items included "I know when to speak about my personal problems to others," "I am aware of my emotions as I experience them," and "I am aware of the nonverbal messages I send to others." After the reversecoded items (e.g., "It is difficult for me to understand why people feel the way they do") were scored and reversed, and all items were then summed, a high score on the EIRS was associated with a high level of emotional intelligence and a low score was associated with a low level of emotional intelligence. The EIRS had a Cronbach's alpha of .94 for Study 1 and .93 for Study 2.

Core self-evaluations. I measured core self-evaluations using the Judge, Bono, and Thorensen's (2003) 12-item Core Self-Evaluations Scale (CSES). Each item was measured on a 5-point Likert Scale with 1 = "strongly disagree" and 5 = "strongly agree." Example items included "I am confident I get the success I deserve in life", "Sometimes I do not feel in control of my own work," and "I am capable of coping with 
most of my problems." Once negatively worded items were reverse coded, a high score on the CSES was associated with high (or positive) core self-evaluations and a low score was associated with low (or negative) core self-evaluations. The CSES had a Cronbach's alpha of .89 for Study 1 and .84 for Study 2 .

Trait social anxiety. I measured social anxiety using Mattick and Clarke's (1989) 20-item Social Interaction Anxiety Scale (SIAS). Each item was assessed on a 5-point Likert scale, with $1=$ "not at all characteristic or true of me" through $5=$ "extremely characteristic or true of me." Example items included "I find it difficult to mix comfortably with the people I work with," "I find myself worrying I won't know what to say in social situations," and "I am tense mixing in a group." The SIAS included both positively and negatively keyed items. After the reverse-coded items were scored and reversed, and all items were then summed, a high score on the SIAS was associated with a high level of social anxiety, and a low score was associated with a low level of anxiety. The SIAS had a Cronbach's alpha of .94 for Study 1 and Study 2.

Depression. Depression was measured using the Beck Depression Inventory $-2^{\text {nd }}$ edition (BDI-II; Beck, Steer, \& Brown, 1996). The BDI-II was a 21-item self-reported scale that looked at depression experienced within the last two weeks in a participant's life. Each item was rated on a 4-point scale, ranging from 0 to 3, depending on the severity of each item (e.g., sadness has responses of 0 "I don't feel sad" to 3 "I am so sad or unhappy that I can't stand it"). When summed, a score of 0-13 indicated minimal depression, 14-19 indicated mild depression, 20-28 indicated moderate depression, and 29-63 indicated severe depression. The BDI-II had a Cronbach's alpha of .91 for Study 1 and .90 for Study 2. 
Job satisfaction. I used Spector's (1994) 36-item Job Satisfaction Survey to measure job satisfaction at nine facet levels, four items per facet. Example items included "My supervisor shows too little interest in the feeling of subordinates," "I often feel that I do not know what is going on in my organization," and "I feel a sense of pride in doing my job." A 6-point Likert scale was used with $1=$ "disagree very much" through $6=$ "agree very much." Negatively worded items (i.e. "I sometimes feel my job is meaningless," or "The goals of this organization are not clear to me") were reversecoded. After the reverse-coded items were scored and reversed, and all items were then summed, a high score on the JSS was associated with high job satisfaction, and a low score was associated with low job satisfaction. The JSS has a Cronbach's alpha of .92 for Study 1 and .93 for Study 2 .

Motivation. I measured motivation using Tremblay, Blanchard, Taylor, Pelletier, and Villeneuve's (2009) 18-item Work Extrinsic and Intrinsic Motivation Scale (WEIMS). Though the scale can be broken down into intrinsic motivation, integrated regulation, identified regulation, introjected regulation, external regulation, and amotivation, I looked at a summed measure of motivation by combining these subscales (and reverse coding the measures of amotivation). Example items included "Because this is the type of work I choose to do to attain a certain lifestyle," "Because it allows me to earn money," and "I don't know why, we are provided with unrealistic working conditions." A 7-point Likert scale will be used with $1=$ "does not correspond at all" and $7=$ "corresponds exactly." A high score on the WEIMS was associated with higher levels of work motivation and a lower score on the WEIMS was associated with lower levels of 
work motivation. The Cronbach's alpha for the WEIMS was .91 for Study 1 and .90 for Study 2 .

\section{RESULTS}

\section{Correlations}

The hypotheses that pertained to correlations between variables were calculated using the Pearson ( $r$ ) Correlation. A Bonferroni correction was used for all correlation analysis to compensate for the possibility of a Type 1 error that may occur when analyzing several variables at once. Table 2 depicts the inter-correlations among all primary variables measured in Study 1 and Table 4 depicts the inter-correlations among all primary variables measured in Study 2.

Hypotheses 1a-b explored the relationship between workplace stress and episodic memory recall of a stressful workplace event, with H1a predicting a positive correlation between stress and negative aspects of episodic recall and $\mathrm{H} 1 \mathrm{~b}$ predicting a negative correlation between stress and positive aspects of episodic recall. Study 1 measured fifteen components of general episodic memory recall, with nine components (reliving, olfaction, perception of surroundings, vividness, bodily feelings, emotion, words, voluntary recall, and valence) having a nonsignificant relationship with workplace stress (see Table 3 for complete sub-measure correlations). Additionally, workplace stress was not significantly correlated with the summed measure of voluntary episodic memory recall. Three components of episodic memory recall, however, were moderately positively correlated with workplace stress: emotional intensity $(r=.14, p<.05)$, worry of memory reoccurrence $(r=.13, p<.05)$, and involuntary recall $(r=.18, p<.01)$. The 
results show partial support for H1a; higher levels of workplace stress are significantly positively correlated with an employee's experience of intense emotions when recalling stressful events, an employee's worry about memories of stressful events reoccurring, and the involuntary recall of stressful memories related to an employee's workplace.

Three components of episodic memory recall were negatively correlated with workplace stress: visualization $(r=-.17, p<.01)$, perspective $(r=-.19, p<.01)$, and belief $(r=-.14, p<.01)$. At the component level of episodic memory recall there was partial support for $\mathrm{H} 1 \mathrm{~b}$; higher levels of workplace stress are significantly negatively correlated with an employee's ability to visualize a memory in their minds, with an employee's ability to perceive stressful memories from a third person versus first person perspective, and an employee's correspondence between what they believe happened in the event they recalled and what actually happened in their workplace.

Hypotheses 2a-b explored the relationship between workplace stress and reports of involuntary episodic memory recall (H2a) and recurrent involuntary episodic memory recall $(\mathrm{H} 2 \mathrm{~b})$. Hypotheses 2a-b were fully supported; workplace stress had a moderate positive correlation with involuntary memory recall $(r=.26, p<.01)$ and a moderate positive correlation with recurrent involuntary memory recall $(r=.34, p<.01)$. The results show that although stress may not play a significant role in all aspects of voluntary episodic memory recall, higher levels of workplace stress are important in understanding employees' involuntary recall of stressful memories, whether they are single episodes or reoccurring stressful memories of workplace events.

Hypotheses 3a-b explored the relationship between workplace stress and positive (H3a) and negative (H3b) affect. Hypotheses 3a-b were fully supported; positive affect 
had a moderate negative correlation with workplace stress $(r=-.27, p<.01)$ and negative affect had a moderate positive correlation with workplace stress $(r=.37, p<.01)$. The correlations related to positive and negative affect implicate the importance of looking at affect in relation to workplace stressors, as employees higher in positive affect report less workplace stress and employees higher in negative affect report higher levels of workplace stress.

Hypotheses 4a-f examined the potential relationship between positive and negative affect and voluntary episodic memory recall (H4a \& H4d), involuntary episodic memory recall $(\mathrm{H} 4 \mathrm{~b} \& \mathrm{H} 4 \mathrm{e})$, and recurrent involuntary episodic memory recall $(\mathrm{H} 4 \mathrm{c} \&$ H4e). Hypotheses 4a-e was partially supported regarding negative affect (H4d-e). Positive affect (H4a-c) was not significantly correlated with the summed measure of voluntary episodic memory recall, involuntary recall, or recurrent involuntary recall. When looking at the components of episodic memory recall individually, positive affect is only positively correlated with olfaction (smelling or tasting an event in one's mind; $r$ $=.22, p<.01)$ and positive emotions $(r=.19, p<.01)$

Negative affect was significantly moderately positively correlated with the summed measure of voluntary episodic memory recall $(r=.13, p<.05)$, and strongly positively correlated with involuntary episodic memory recall $(r=.51, p<.01)$ and recurrent involuntary episodic memory recall $(r=.48, p<.01)$. When looking at the individual components of voluntary recall, negative affect was positively correlated with eight of the fifteen measures: reliving the original stressful event $(r=.13, p<.05)$, the vividness of the stressful event remembered $(r=.16, p<.01)$, the reexperience of bodily sensations from the original stressful event $(r=.14, p<.05)$, the reexperience of the 
stressful emotions from the event $(r=.17, p<.01)$, the intensity of the stressful emotions from the event $(r=.18, p<.01)$, worry that the stressful event will occur again $(r=.24, p$ $<.01)$, deliberately choosing to think about the stressful event $(r=.29, p<.01)$, and involuntary recall $(r=.18, p<.01)$.

The results of $\mathrm{H} 4$ in relation to positive affect suggest that the most important way that this personality trait may be involved in relation to memory recall is regarding the recall of positive over negative emotions, even when asked to recall a stressful event in the workplace. Negative affect emerged as a much more prominent personality trait involved in memory recall, tied to intense, vivid, and emotional recall of events. Additionally, individuals high in negative affect are more likely than individuals low in negative affect to voluntarily recall stressful events. The results pertaining to negative affect highlight how individuals high in negative affect tend to engage in ruminative behaviors, whether in an isolated experience or in a recurrent nature.

Hypotheses 5a-c examined the relationship between workplace stress and job affective wellbeing (or emotional state at work; H5a), emotional intelligence (H5b), and core self-evaluations (H5c). Hypotheses 5a-c were fully supported; job affective wellbeing was strongly negatively correlated with workplace stress $(r=-.56, p<.01)$, emotional intelligence was strongly negatively correlated with workplace stress $(r=-.44$, $p<.01$ ), and core self-evaluations was moderately negatively correlated with workplace stress $(r=-.34, p<.01)$. These results suggest one of two things: either individuals with more positive personality traits experience less stress in the workplace in general, or that individuals with more positive personality traits have stronger coping mechanisms to deal with the stress that they do experience at work. 
Hypotheses 6a-c elaborated on job affective wellbeing (emotional state) and its relationship with voluntary episodic memory recall (H6a), involuntary episodic memory recall (H6b), and recurrent involuntary episodic memory recall. The summed measure of voluntary episodic memory recall was not significantly correlated with job affective wellbeing. There was, however, partial support for H6a via the significant negative correlation between job affective wellbeing and the following components of voluntary episodic recall: vividness of the stressful memory $(r=-.15, p<.05)$, the reexperience of stressful emotions from the event $(r=-.16, p<.01)$, the intensity of the reexperience of the stressful event $(r=-.16, p<.01)$, worrying about reoccurrence of the stressful event $(r=-.17, p<.01)$, and deliberately recalling the stressful event after the initial occurrence $(r=-.21, p<.01)$. There was full support for H6b and H6c; job affective wellbeing was moderately negatively correlated with involuntary episodic memory recall $(r=-.27, p<$ $.01)$ and recurrent involuntary episodic memory recall $(r=-.28, p<.01)$.

The analysis of job affective wellbeing in relation to episodic memory recall suggests that an employee's emotional state at work can buffer the vividness, intensity, and emotions involved with stressful workplace events. Employees high in job affective wellbeing (positive emotional states) also worry less about the experience of recalling stressful events, and do not deliberately recall stressful events as much as individuals who have lower job affective wellbeing. Additionally, employees high in job affective wellbeing are less likely than individuals low in job affective wellbeing to have involuntary and recurrent involuntary recall of stressful events related to the workplace.

Hypotheses 7a-c elaborated on emotional intelligence and its relationship with voluntary episodic memory recall (H7a), involuntary episodic memory recall (H7b), and 
recurrent involuntary episodic memory recall $(\mathrm{H} 7 \mathrm{c})$. Hypotheses $7 \mathrm{~b}-\mathrm{c}$ were fully supported; emotional intelligence was moderately negatively correlated with involuntary episodic memory recall $(r=-.14, p<.05)$ and recurrent involuntary episodic memory recall $(r=-.16, p<.01)$. Though there was a significant correlation between emotional intelligence and voluntary memory recall $(\mathrm{H} 7 \mathrm{a})$, it was in the opposite direction as expected; emotional intelligence was moderately positively correlated with (the summed measure of) voluntary episodic memory recall $(r=.29, p<.01)$. When looking at the components of the voluntary recall measure, emotional intelligence was positively correlated with eleven of the fifteen sub-measures: reliving the original event $(r=.30, p<$ $.01)$, seeing the original event in one's mind $(r=.13, p<.05)$, recalling the physical surroundings of the event $(r=.30, p<.01)$, the vividness of the event $(r=.24, p<.01)$, the bodily sensations originally felt in the event $(r=.14, p<.05)$, the emotions felt in the original event $(r=.19, p<.01)$, the intensity of the emotions felt when recalling the event $(r=.13, p<.05)$, the ability to put the event into words $(r=.14, p<.05)$, and the perceived correspondence between the original event and the memory recalled $(r=.28, p$ $<.01)$.

The unique results related to emotional intelligence highlight the importance of an employee's emotional intelligence as a potentially more impactful personality trait than positive/negative emotional disposition (positive/negative affect) and job affective wellbeing. Employees who are high in emotional intelligence can relive a stressful workplace experience - seeing and feeling what happened in the initial event with precision, as shown by the correlations with the sub-measures of voluntary recall without reporting worry or negative emotions when doing so. Additionally, employees 
higher in emotional intelligence do not report involuntary or recurrent involuntary recall of these stressful memories, demonstrating the ability to process stressful events without ruminating and reexperiencing negative memories.

Hypotheses 8a-c examined the role of core self-evaluations (self-efficacy, selfesteem, locus of control, and neuroticism) in relation to voluntary episodic memory recall (H8a), involuntary episodic memory recall (H8b), and recurrent involuntary episodic memory recall (H8c). There was no significant relationship between core self-evaluations and the summed measure of voluntary memory recall. Three of the fifteen sub-measures, however, were significantly negatively correlated with core self-evaluations: worry $(r=-$ $.28, p<.01)$, voluntary recall $(r=-.16, p<.01)$, and involuntary recall $(r=-.12, p<.05)$. Hypotheses H8b and H8c were fully supported; core self-evaluations were moderately to strongly negatively correlated with involuntary episodic memory recall $(r=-.31, p<.01)$ and recurrent involuntary episodic memory recall $(r=-.31, p<.01)$. According to these results, employees who have higher self-efficacy, higher self-esteem, an internal (versus external) locus of control, and low levels of neuroticism are less likely to worry about the reoccurrence of stressful memories, less likely to deliberately recall stressful memories, less likely to have stressful involuntary episodic memory recall, and less likely to experience recurrent episodic memories of stressful workplace events.

Hypotheses 9a-b explored the psychopathology traits of social anxiety and depression in relation to workplace stress. Hypotheses $9 \mathrm{a}-\mathrm{b}$ were fully supported; social anxiety and depression both had a positive correlation with workplace stress $(r=.27, p<$ .01 and $r=.17, p<.01)$. An employee with higher levels of social anxiety and 
depression, therefore, is more likely to experience workplace stress than an individual low in these psychopathology traits.

Hypotheses 10a-c examined the role of social anxiety in relation to voluntary episodic memory recall (H10a), involuntary episodic memory recall (H10b), and recurrent involuntary episodic memory recall (H10c). There was no significant relationship between social anxiety and the summed measure of voluntary episodic memory recall, though the relationship approached significance $(p=.08)$. Seven of the fifteen sub-measures, however, were positively correlated with social anxiety: reliving ( $r$ $=.14, p<.05)$, bodily sensations $(r=.23, p<.01)$, emotions $(r=.15, p<.05)$, intensity $(r=.17, p<.01)$, worry about reoccurrence $(r=.25, p<.01)$, voluntary recall $(r=.16, p$ $<.01)$, and involuntary recall $(r=.21, p<.01)$. The analysis of the components of the episodic memory measure shows partial support for H10a. Additionally, H10b and H10c were fully supported, with social anxiety having a moderate to strong positive correlation with involuntary episodic memory recall $(r=.37, p<.01)$ and with recurrent involuntary episodic memory recall $(r=.39, p<.01)$.

The correlations of social anxiety and memory recall suggest that though there may not be a significant correlation between social anxiety and voluntary recall of stressful episodic memories in general, there are components of stressful memory recall that impact individuals with social anxiety more than those low in social anxiety. Employees with high social anxiety are more likely than employees with low social anxiety to feel that they are reexperiencing the actual event (mentally and physically), to experience the resurgence of feelings of intensity and worry, and to engage in voluntary and involuntary recall of these stressful memories more frequently. Additionally, an 
employee with high social anxiety also experiences more frequent involuntary and recurrent involuntary episodic memories of stressful events in their workplace than those with low levels of anxiety.

Hypotheses 11a-c explored the relationship between depression and voluntary episodic memory recall (H11a), involuntary episodic memory recall (H11b), and recurrent involuntary episodic memory recall (H11c). Hypothesis 11a was fully supported: depression had a positive correlation with voluntary episodic memory recall ( $r$ $=.17, p<.01)$. When looking at voluntary recall by the sub-measures of episodic memory, depression was positively correlated with reliving $(r=.17, p<.01)$, visualizing $(r=.19, p<.01)$, physical surroundings $(r=.16, p<.01)$, vividness $(r=.12, p<.05)$, bodily sensations $(r=.14, p<.05)$, emotions $(r=.16, p<.01)$, intensity $(r=.15, p<$ $.05)$, worry about reoccurrence $(r=.17, p<.01)$, voluntary recall $(r=.18, p<.01)$, and involuntary recall $(r=.20, p<.01)$. Additionally, depression was negatively correlated with the valence of the emotions recalled $(r=-.21, p<.01)$. Hypothesis $11 \mathrm{~b}$ and $11 \mathrm{c}$ were also fully supported, with depression having a moderate positive correlation with involuntary episodic memory recall $(r=.31, p<.01)$ and recurrent involuntary episodic memory recall $(r=.28, p<.01)$.

Employees with high levels of depression also have more voluntary, involuntary, and recurrent involuntary episodic memories of stressful workplace events than employees with low levels of depression. Apart from the measures of olfaction, wording, perspective, and one's belief that the event truly happened, there is a significant connection between depression and the frequency of these memories. The relationship between depression and valence suggests that aspects of memory like vividness and 
visualizing the original event are experienced through a negative, ruminative lens. Depressed employees are also more likely than non-depressed employees to have negative or stressful involuntary and recurrent involuntary memories pop up in their minds while at work.

Hypotheses 12a-c explored the relationship between the outcome of job satisfaction and voluntary episodic memory recall (H12a), involuntary episodic memory recall (H12b), and recurrent involuntary episodic memory recall (H12c). There was little to no support found for H12a; job satisfaction was not significantly correlated with the summed measure of voluntary episodic memory recall, and was only significantly correlated with four of the sub-measures of voluntary memory: intensity $(r=-.13, p<$ $.05)$, worry of reoccurrence $(r=-.15, p<.05)$, voluntary recall $(r=-.16, p<.01)$, and perspective $(r=.14, p<.05)$. Full support was found for H12b and H12c, with job satisfaction having a moderate negative correlation with involuntary episodic memory recall $(r=-.27, p<.01)$ and recurrent involuntary episodic memory recall $(r=-.31, p<$ $.01)$.

These results suggest that employees who experience stressful memories less frequently have higher levels of job satisfaction than employees who experience stressful memories more frequently. Job satisfaction is also positively correlated with a stronger first-person perspective (as opposed to viewing a personal memory from third-person). Additionally, intense memories, worry about stressful events reoccurring, and voluntary recall of stressful memories were all associated with an employee feeling lower levels of job satisfaction. 
Hypotheses 13a-c examined the relationship between the outcome of job motivation and voluntary episodic memory recall (H13a), involuntary episodic memory recall (H13b), and recurrent involuntary episodic memory recall (H13c). There was little to no support for $\mathrm{H} 13 \mathrm{a}$; there was no relationship between motivation and voluntary memory recall, and the only sub-measure with a significant relationship was motivation and reliving the event in one's mind $(r=.20, p<.01)$. Hypotheses $13 \mathrm{~b}$ and $13 \mathrm{c}$ were fully supported as motivation had a significant negative correlation with involuntary memory recall $(r=-.18, p<.01)$. and recurrent involuntary memory recall $(r=-.18, p<$ .01). Though motivation is significantly correlated with involuntary and recurrent involuntary recall of negative episodic memories in the workplace, the correlation was weaker between motivation and memory than with any of the previously analyzed variables. The results related to motivation and episodic memory may indicate that employees who experience workplace stressors less severely have higher levels of motivation. There may also be differences between extrinsic and intrinsic motivators that is not captured by the current study.

Hypotheses 14a-c explored the relationship between workplace stress and mental time travel, with H14a pertaining to episodic memories that have previously occurred in an employee's workplace, $\mathrm{H} 14 \mathrm{~b}$ pertaining to imaginary episodic memories of what could have occurred in an employee's workplace, and H14c pertaining to imaginary episodic future thinking about the workplace. Each of these hypotheses posited that work stress would be negatively correlated with the recall of positive memories. H14a was partially supported, with a significant negative correlation between work stress and memories recalled from one month in the past $(r=-.20, p<.01)$ and five or more years in 
the past $(r=-.23, p<.01)$. H14b was fully supported, with a significant negative correlation between work stress and imagined memories at one month in the past $(r=-$ $.15, p<.05)$, one year in the past $(r=-.16, p<.05)$, and five years in the past $(r=-.19, p$ $<.01)$. H14c was also fully supported, with a significant negative correlation between work stress and future memories at one month in the future $(r=-.18, p<.01)$, one year in the future $(r=-.17, p<.05)$, and five years in the future $(r=-.21, p<.01)$.

When looking at H14a-c, work stress appears to have a significant impact on an employee's mental time travel. Employee's with higher levels of stress report fewer positive memories when reflecting on the past within their current workplace, when reflecting on hypothetical events that might have happened in their current workplace, and when imagining future events that may occur in their careers.

Hypotheses $15 \mathrm{a}-\mathrm{f}$ examined the relationship between work stress and the six phenomenology questions of vividness, emotions, importance, intensity, frequency, and ease of remembering. H15a posited that work stress would be positively correlated with higher levels of vividness at memory recall. Though there was a significant relationship between vividness of memories and work stress, the relationship was in the opposite direction than was predicted. Vividness was significantly negatively correlated with work stress $(r=-.19, p<.01)$, indicating that higher stress levels result in less vivid memories. The negative correlation between vividness and work stress suggests that as opposed to the initial belief that experiences of stress would evoke more vivid memories than nonstressful memories, employees with higher levels of stress may have more suppressed thoughts of negative events. This decrease in vivid memories could be related to active suppression by employees as a function of coping, which would indicate the utilization of 
positive coping techniques. The decrease could also, however, be a negative symptom related to the depletion of the cognitive resources necessary to (voluntarily) recreate a detailed narrative of a stressful memory.

Hypothesis $15 \mathrm{~b}$ looked at the emotions the participants felt when recalling the memories and suggested that employees with higher levels of work stress would experience lower levels of positive emotions at recall. Hypothesis $15 \mathrm{~b}$ was fully supported, with positive emotions being moderately to strongly negatively correlated with work stress $(r=-.38, p<.01)$. Employees with higher work stress levels have more negative emotions when recalling events related to the workplace.

Hypothesis $15 \mathrm{c}$ pertained to the perceived importance of the event and was not supported; there was no significant positive correlation between perceived importance of actual, imaginary, or future events and work stress. There was, however, a significant negative relationship between the perceived importance of imaginary future events and the experience of work stress $(r=-.14, p<.05)$. This suggests that as opposed to stress serving as a signal of an important event in the workplace (as evolutionary theories of stress would posit), higher levels of work stress lead an employee to regard episodic future thoughts as less important than those who have lower levels of stress.

Hypothesis $15 \mathrm{~d}$ looked at the intensity of emotions during memory recall and was not supported; there was no significant relationship between work stress and the intensity of actual past memories, imagined past memories, or imagined future events. Hypothesis $15 \mathrm{e}$ looked at the frequency of retrospection about memory recall and was not supported; there was no significant relationship between work stress and willful thinking about actual past memories, imagined past memories, or imagined future events. 
Hypothesis $15 \mathrm{f}$ concluded the phenomenology questions by determining the relationship between ease of remembering and work stress. Hypothesis $15 \mathrm{f}$ was partially supported, with the ease of remembering both actual past memories $(r=.18, p<.01)$ and imagined future events $(r=.14, p<.05)$ having a significant positive relationship with work stress. An employee who is experiencing higher levels of work stress will have a greater ease of remembering memories of events that have happened to them and imagining the kinds of events that could potentially happen in their future. Given that stress is also positively correlated with negative personality traits, psychopathology traits, and involuntary memory recall, a greater ease in remembering may not necessarily be a good thing for employees who are experiencing high levels of stress.

Hypotheses 16a-c through Hypotheses 22a-c focused on the relationship between mental time travel and job-affective wellbeing (H16a-c), emotional intelligence (H17a-c), core self-evaluations (H18a-c), social anxiety (H19a-c), depression (H20a-c), job satisfaction (H21a-c), and motivation (H22a-c). Each of these hypotheses was analyzed in comparison with the corresponding hypothesis from Study 1. The following relationships were significant: positive affect and actual past memories $(r=.24, p<.01)$, imagined past memories $(r=.28, p<.01)$, and imagined future thoughts $(r=.23, p<$ $.01)$; negative affect and imagined past memories $(r=.16, p<.05)$ and imagined future thoughts $(r=.17, p<.05)$; job-affective wellbeing and actual past memories $(r=.17, p<$ $.01)$, imagined past memories $(r=.22, p<.01)$, and imagined future thoughts $(r=.14, p$ $<.05)$; emotional intelligence and imagined future thoughts $(r=.15, p<.05)$; and depression and imagined future thoughts $(r=-.15, p<.05)$. All other correlations were non-significant. 


\section{Mediation Analysis}

Hypotheses 25a-f analyzed the mediation effects of personality (positive affect, negative affect, job-affective wellbeing, emotional intelligence, and core self-evaluations) and psychopathology (social anxiety and depression) on the relationship between work stress (causal variable) and six outcome variables: voluntary recall of stressful episodic memories $(\mathrm{H} 25 \mathrm{a})$, involuntary recall of stressful episodic memories $(\mathrm{H} 25 \mathrm{~b})$, recurrent involuntary recall of stressful episodic memories (H25c), recall of actual past memories $(\mathrm{H} 25 \mathrm{~d})$, recall of imagined past memories $(\mathrm{H} 25 \mathrm{e})$, and imaginary future thoughts $(\mathrm{H} 25 \mathrm{f})$. To test these relationships and establish mediation, the four-step process modeled by Baron and Kenny (1986; see also James \& Brett, 1984; Judd \& Kenny, 1982) was used.

Step 1 of this process is to show that the causal variables are correlated with the outcome (that work stress is correlated with the six memory variables). Step 2 of this process is to show that the causal variable is correlated with the mediator (personality and psychopathology), treating the mediator as if it was an outcome and confirming that work stress is correlated with personality and psychopathology. Step 3 of this process is to show that the outcome variables are correlated with the mediator (that the six memory variables are correlated with personality and psychopathology). Step 4 involves showing that the mediator affects the outcome variable, and establishing that the mediator completely mediates the relationship between the causal variable and the outcome after controlling for the direct effects (does personality or psychopathology, when added to the model, decrease the significance of the relationship between work stress and memory?; does the coefficient between work stress and memory reduce to non-significance?). As I am measuring multiple potential mediators, it is expected that no one trait will fully 
mediate the relationship between work stress and memory, and that instead each trait will show partial mediation of this relationship (e.g. the coefficient will reduce to nonsignificance at $p<.05$ but may not drastically reduce).

To test the first step of mediation, six regressions were conducted to determine the correlation between work stress and a) voluntary memory recall from Study 1, b) involuntary memory recall from Study 1, c) recurrent involuntary memory recall from Study 1, d) negative actual past events from Study 2, e) negative imagined past events from Study 2, and f) negative imaginary future events from Study 2. The results showed that higher levels of work stress were associated with an increased frequency of involuntary memory recall of stressful events $(\beta=.19, p<.01)$ and recurrent involuntary memory recall of stressful events $(\beta=-.25, p<.01)$. Additionally, higher levels of work stress were associated with recall of negative actual past events $(\beta=-.18, p<.01)$, of negative imagined past events $(\beta=-.17, p<.05)$, and of negative imaginary future events $(\beta=-.12, p<.05)$. There was not a significant relationship between voluntary recall of stressful events and work stress, disqualifying voluntary recall from inclusion in Step 2.

To test the second step of mediation, a regression was conducted to determine the correlation between the five remaining memory variables and each of the personality and psychopathology variables. For involuntary memory of stressful events, the results showed that more frequent reports of stressful memories were correlated with negative affect $(\beta=.50, p<.01)$, job-affective wellbeing $(\beta=-.29, p<.05)$, emotional intelligence $(\beta=-.21, p<.05)$, core self-evaluations $(\beta=-.42, p<.01)$, social anxiety $(\beta=.35, p<$ $.01)$, and depression $(\beta=.03, p<.01)$. There was not a significant relationship between involuntary memory of stressful events and positive affect. For recurrent involuntary 
memory of stressful events, the results showed that more frequent reports of stressful memories were correlated with negative affect $(\beta=.47, p<.01)$, job-affective wellbeing $(\beta=-.30, p<.01)$, emotional intelligence $(\beta=-.25, p<.01)$, core self-evaluations $(\beta=-$ $.42, p<.01)$, social anxiety $(\beta=.38, p<.01)$, and depression $(\beta=-.03, p<.01)$. There was also not a significant relationship between positive affect and recurrent involuntary memory of stressful workplace events.

When looking at the variables related to mental time travel, actually experienced past events were correlated with positive affect $(\beta=.16, p<.01)$, negative affect $(\beta=.09$, $p<.05)$, and job-affective wellbeing $(\beta=.15, p<.05)$. There was not a significant relationship between actually experienced past events and emotional intelligence, core self-evaluations, social anxiety, and depression. For imagined past events, memory reports were correlated with positive affect $(\beta=.17, p<.01)$, negative affect $(\beta=.12, p<$ $.05)$, job-affective wellbeing $(\beta=.18, p<.01)$, and depression $(\beta=-.01, p<.05)$. Imagined past events were not significantly correlated with emotional intelligence, core self-evaluations, and social anxiety. The final regressions in Step 2 look at imaginary future events, which had a significant relationship with positive affect $(\beta=.17, p<.01)$, negative affect $(\beta=.14, p<.05)$, job-affective wellbeing $(\beta=.13, p<.05)$, and emotional intelligence $(\beta=.22, p<.05)$. Core self-evaluations, social anxiety, and depression were not significantly correlated with reports of imaginary future memories.

Regressions were conducted in Step 3 between work stress and each of the personality and psychopathology traits, as each of these variables was significant in one or more of the relationships tested in Step 2. In Study 1, work stress was significantly correlated with positive affect $(\beta=-.17, p<.01)$, negative affect $(\beta=.26, p<.01)$, job- 
affective wellbeing $(\beta=-.43, p<.01)$, emotional intelligence $(\beta=-.50, p<.01)$, core self-evaluations $(\beta=-.33, p<.01)$, social anxiety $(\beta=.18, p<.01)$, and depression $(\beta=$ $.01, p<.01)$. In Study 2, work stress was also significantly correlated with positive affect $(\beta=-.29, p<.01)$, negative affect $(\beta=.21, p<.01)$, job-affective wellbeing $(\beta=-.58, p<$ $.01)$, emotional intelligence $(\beta=-.53, p<.01)$, core self-evaluations $(\beta=-.45, p<.01)$, social anxiety $(\beta=.21, p<.01)$, and depression $(\beta=.02, p<.01)$.

For each of the relationships that met the first three criteria for mediation, hierarchical regressions were conducted to determine the change in the relationships established between work stress and memory reports. In step one of each regression the respective memory variable was entered as the dependent and work stress as the independent variable for the analysis. In step two the respective personality or psychopathology trait was added with work stress to the list of independent variables. Support was found for a mediating effect of negative affect on the relationship between work stress and involuntary memory recall $(\beta=.37, p<.01$ to $\beta=.12, p=.13$; see Table 6). Though work stress did not decrease to insignificant, the $\mathrm{R}^{2}$ increased when accounting for job-affective wellbeing, core self-evaluations, social anxiety, and depression in the model testing work stress and involuntary memory. The $\mathrm{R}^{2}$ change supports the idea that personality may have a cumulative effect in impacting relationship between stress and memory that is not able to be identified when looking at individual traits in a single mediation analysis. Emotional intelligence emerged as a completely insignificant factor in the relationship between work stress and involuntary memory recall. 
When looking at recurrent involuntary memory recall, none of the personality or psychopathology traits decreased the relationship between work stress and memory to non-significance. Much like involuntary memory recall, however, the $\mathrm{R}^{2}$ did increase in each of the models (along with a decrease in the coefficient $\beta$ ), indicating that I am measuring more of the relationship between work stress and memory when I include these personality and psychopathology traits in the model than I do when I include work stress and memory alone.

When looking at the traits related to mental time travel, support was found for a mediating effect of positive affect $(\beta=-.28, p<.01$ to $\beta=-.05, p=.54)$ and job-affective wellbeing $(\beta=-.28, p<.01$ to $\beta=-.09, p=.35$ ) on the relationship between work stress and actually occurring past events. Support was also found for a mediating effect of positive affect $(\beta=-.17, p<.01$ to $\beta=.06, p=.44)$ and job-affective wellbeing $(\beta=-.17$, $p<.01$ to $\beta=-.04, p=.67$ ) on the relationship between work stress and imagined past events in the workplace. Additionally, there was a mediating effect of positive affect $(\beta=$ $-.17, p<.01$ to $\beta=-.06, p=.47)$ and emotional intelligence $(\beta=-.17, p<.01$ to $\beta=-.11$, $p=.19)$ on the relationship between work stress and imaginary future thoughts of workplace events (see Tables 7-9 for full results).

The results of the mediation analysis indicate that there are differences in episodic memories recalled when the participant is asked to remember something stressful versus asked to remember (or predict) a general episodic memory. Negative affect was the only variable to emerge as a mediator when looking at voluntary recall of stressful workplace events, whereas positive affect, job-affective wellbeing (emotional state), and emotional 
intelligence had a mediating role in the relationship between work stress and the mental time travel memories that could have been positive or negative.

\section{Moderation Analysis}

The final hypotheses of the study examine the potential moderating role of voluntary recall of stressful events (H26a-b), involuntary recall of stressful events (H27ab), and recurrent involuntary recall of stressful events (H28a-b) on the outcomes of job satisfaction and motivation. For standardization of results and to avoid multicollinearity of the predictor variables, each variable was centered prior to analysis. Additionally, interaction variables (stress*memory recall) were created for each of the moderations tested. See Table 10 for full results.

To test the hypotheses that job satisfaction and motivation are a function of one's work stress, and more specifically whether memory of stressful work events moderates the relationship between satisfaction \& motivation and stress, six hierarchical multiple regressions were conducted using the PROCESS procedure for SPSS (Hayes, 2019), with a confidence interval of $95 \%$ and a bootstrap for indirect effects of 1,000 samples. The three analyses related to memory and job satisfaction yielded non-significant results; the interaction of voluntary recall and stress $\left(\Delta R^{2}=.004, \Delta F(1,262)=1.80, p=.18\right)$, involuntary recall and stress $\left(\Delta R^{2}=.001, \Delta F(1,262)=.42, p=.52\right)$, and recurrent involuntary recall and stress $\left(\Delta R^{2}=.000, \Delta F(1,262)=.08, p=.77\right)$ did not account for a significant amount of variance in the experience of job satisfaction.

More promising results, however, were found when looking at the relationship between work stress and motivation. Voluntary recall $\left(\Delta R^{2}=.02, \Delta F(1,256)=5.02, p<\right.$ $.05)$, involuntary recall $\left(\Delta R^{2}=.02, \Delta F(1,256)=4.14, p<.05\right)$, and recurrent involuntary 
recall $\left(\Delta R^{2}=.02, \Delta F(1,262)=5.03, p<.05\right)$ had a significant interaction in the relationship between work stress and motivation, accounting for a significant proportion of the variance in motivation. Simple slopes were tested for each memory category to understand the relationship between stress and motivation at low (-1 SD below the mean), moderate (mean), and high $(+1 \mathrm{SD}$ above the mean) frequencies of these memory reports. Voluntary memory recall of stressful events in the workplace had significant slopes at each of the three frequencies. Involuntary and recurrent involuntary memory recall of stressful events in the workplace had significant slopes at two of the three frequencies: the mean and +1 SD from the mean. Each of the slopes at -1 SD approached significance with a $p$-value of .09 .

The results of the probing for the simple slopes of voluntary memory recall as a moderator were: $b=-.89, S E_{b}=-.38, t(260)=-2.95, p<.01$ for $-1 \mathrm{SD}$ from the mean, $b=$ $.11, S E_{b}=-.60, t(260)=-5.55, p<.01$ at the mean, and $b=.95, S E_{b}=-.78, t(260)=-5.30$, $p<.01$ for $+1 \mathrm{SD}$ from the mean (See Figure 4). These slopes suggest that an employee with more frequent reports of voluntary memory recall of stressful work events will report lower levels of motivation under conditions of high work stress.

The results of the probing for the simple slopes of involuntary memory recall as a moderator were: $b=-.87, S E_{b}=-.26, t(260)=-1.70, p=.09$ for $-1 \mathrm{SD}$ from the mean, $b=$ $-.04, S E_{b}=-.50, t(260)=-4.53, p<.01$ at the mean, and $b=.81, S E_{b}=-.70, t(260)=-$ $4.56, p<.01$ for $+1 \mathrm{SD}$ from the mean (See Figure 5). Additionally, the simple slopes for recurrent involuntary memory recall as a moderator were: $b=-.94, S E_{b}=-.28, t(260)=-$ $1.71, p=.09$ for $-1 \mathrm{SD}$ from the mean, $b=-.17, S E_{b}=-.47, t(260)=-4.17, p<.01$ at the mean, and $b=.90, S E_{b}=-.79, t(260)=-4.68, p<.01$ for +1 SD from the mean (See 
Figure 6). Like voluntary memory recall, involuntary and recurrent involuntary memory reports of stressful work events will correspond with lower levels of motivation under conditions of work stress (when looking at employees who report mean and +1 SD frequencies of stressful event recall).

\section{Exploratory Data Analysis (Study 2)}

Though there were no official hypotheses regarding the qualitative aspects of the data from Study 2, there are several results worth noting regarding the workplace memories that the participants wrote about. Each text entry was rated on valence ( -5 to $+5)$ and intensity (0 to 5) and categorized by the inclusion of the following in the narrative: clients/patients/customers, coworkers, boss/supervisors, promotion/reward/recognition, quitting/getting fired/getting reprimanded, and witnessing or experiencing injury/fighting/yelling. Tables 11-13 report the means and frequencies by actual past events, imagined past events, and imaginary future events. Table 14 shows the average of each of these groups and notes the trend between groups.

When looking at the valence (positivity versus negativity) of the memories reported, memories of actual past events were slightly less positive than any other events but were also less intense on average than the imagined/imaginary memories. The only category of memories that had a negative average valence was memory reports of actual events that occurred within the past one month (the category that was also the least intense on average). The group of memory reports with the most notable difference in average valence was those related to imaginary future events, averaging 1.9 out of 5 compared to .20 for actual past events and .39 for imagined past events. These memory reports suggest that when looking into the future, employees are markedly more positive 
or optimistic about the events they predict will happen than they are when reflecting on events that have or could have occurred to them in the past.

The intensity of an event, however, did not seem to vary as drastically between groups; the average intensity was 2.43 for actual past events, 2.86 for imagined past events, and 2.83 for imaginary future events. What these numbers do reflect is that regardless of whether the events reported were positive or negative, events (on average) were at least mildly intense (between 2-3 out of 5) to be recalled by employees who are prompted to think of important workplace memories.

Another aspect of the qualitative data that was measured was the inclusion of others in the memory narrations - namely clients or customers, coworkers, and bosses or supervisors. The highest frequency of reports of others was in the actual past events category, with peak numbers of clients or customers (38.4\% of all reports), coworkers (21.8\% of all reports), and bosses or supervisors ( $28.4 \%$ of all reports) occurring in memory reports one month in the past. For each of the three groups (actual past, imagined past, and imaginary future), mentions of others in the memory reports tended to decrease as participants reported memories further in the past. For example, in the actual past events category, reports of clients or customers went from $38.4 \%$ at one month in the past to $26.4 \%$ at one year in the past and $19.3 \%$ at $5+$ years in the past. This phenomenon occurred in each of the three memory categories (e.g. in the imaginary future events category, reports of coworkers went from $8.9 \%$ at one month in the future to $3.3 \%$ at one year in the future and $0.1 \%$ at $5+$ years in the future). These outcomes suggest that as an employee engages in mental time travel further into the past and future, the episodic 
memories that emerge as the most prominent or important are more self-centered than other-centered.

Components of episodic memory related to actions taken or experience were also coded in each of the memory responses; frequencies of receiving praise or being promoted, being reprimanded or fired, and witnessing or experiencing fighting, injuries, or yelling were all computed. Additionally, reports of non-task related episodic events (e.g. birthday parties and other office gatherings) were calculated for each of the memory categories. Narratives involving praise, recognition, and promotion rose drastically when looking at future events, averaging mention in $36.4 \%$ of reports in the future as opposed to $27.1 \%$ of actual past and $28.7 \%$ of imagined past events. The highest reports of praise and promotion were at one year in the future where $40.2 \%$ of respondents reported a memory that involved recognition for their work, whether through being acknowledged for hard work, receiving raises, or climbing the corporate ladder within their careers.

Though the highest reports of being fired, written up, or reprimanded occurred in the imagined past category ( $15.3 \%$ of all reports), there was a noticeable increase in the averages of these reports between the actual past ( $9 \%$ of all reports) and imaginary future $(14.7 \%)$ memories of the workplace. Memories of fighting, injury, or yelling (15\% vs. $2.8 \%)$ and non-task related episodic memories ( $8 \%$ to $1.7 \%)$ both decreased when looking at past and future memories.

When looking at actual past events and the potential relationship between the categorical variables and the overall variables measured in the study, the following relationships were significant: valence was negatively correlated with work stress $(r=$ $.27, p<.01)$; coworkers were negatively correlated with positive affect $(r=-.18, p<.05)$; 
bosses/supervisors were negatively correlated with positive affect $(r=-.23, p<.01)$, jobaffective wellbeing $(r=-.25, p<.01)$, and job satisfaction $(r=-.16, p<.05)$ and positively correlated with work stress $(r=.15, p<.05)$; praise/promotion was positively correlated with positive affect $(r=.19, p<.05)$; and reprimands/being fired was negatively correlated with job-affective wellbeing $(r=-.24, p<.01)$, job satisfaction $(r=$ $-.21, p<.05)$, and motivation $(r=-.19, p<.05)$ and positively correlated with negative $\operatorname{affect}(r=.22, p<.05)$, depression $(r=.25, p<.01)$, and stress $(r=.25, p<.01)$.

\section{Figure 7: Frequencies of Exploratory Analyses Variables}

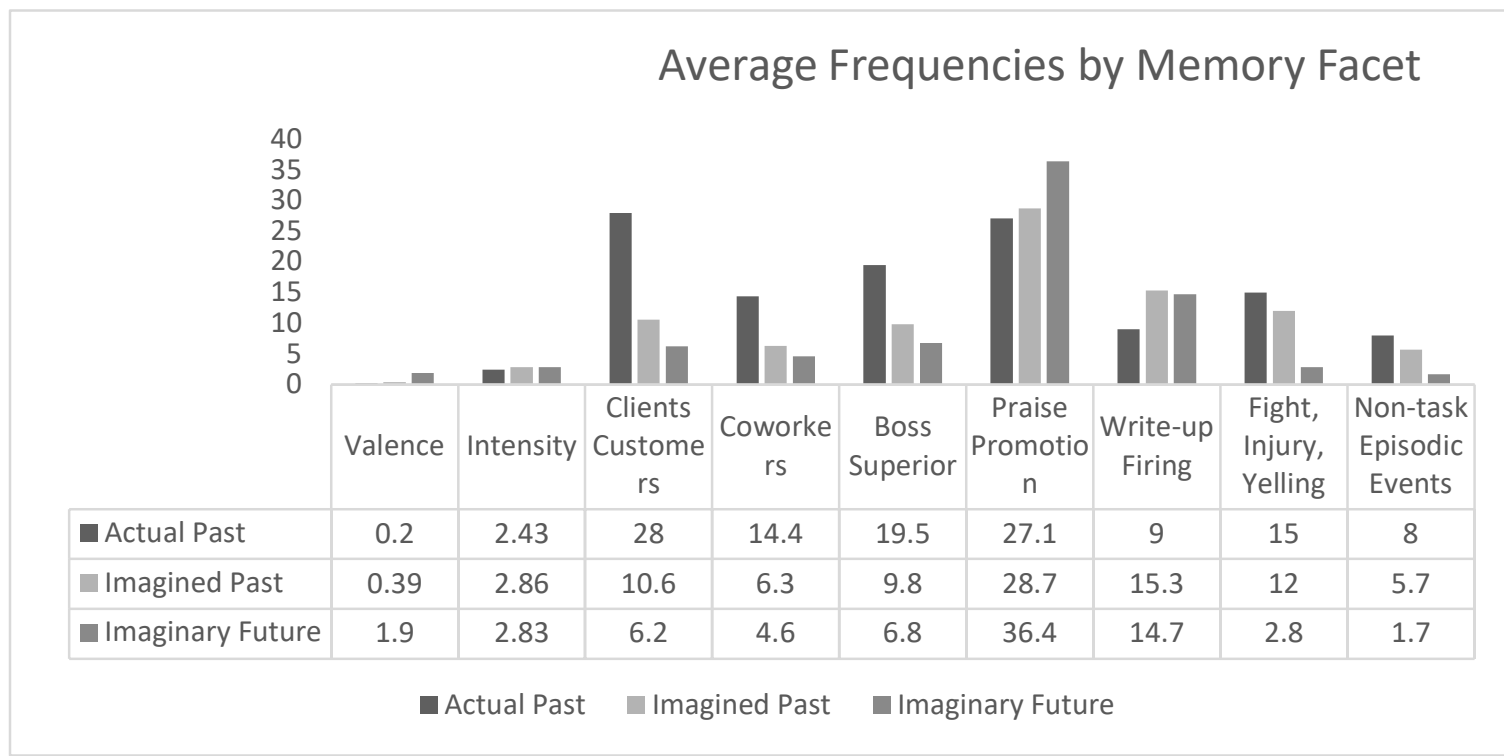

Imagined past events did not yield significant correlations with these variables.

Imaginary future events, however, yielded the following significant relationships: stress was negatively correlated with valence $(r=-.15, p<.05)$; praise/promotion was negatively correlated with negative affect $(r=-.15, p<.05)$ and depression $(r=-.18, p<$ $.05)$; and reprimands/being fired was negatively correlated with job-affective wellbeing ( $r$ $=-.20, p<.05)$, emotional intelligence $(r=-.18, p<.05)$, job satisfaction $(r=-.21, p<$ 
$.05)$, and motivation $(r=-.31, p<.01)$ and positively correlated with work stress $(r=.29$, $p<.01)$ and social anxiety $(r=.30, p<.01)$.

Overall, the qualitative data from Study 2 is filled with opportunities for analysis and offers a unique perspective into the memories of the participants that quantitative data cannot afford.

\section{DISCUSSION}

There were several underlying purposes of this dissertation. Firstly, I sought to understand how employees in an organization encode and retrieve memories of workplace experiences - namely, how the experience of workplace stressors might impact an employee's episodic memory system. Secondly, I hoped to elucidate upon the personality and psychopathology traits linked with emotional regulation and determine how an employee's experience of stress is linked with these interpersonal characteristics. Thirdly, I aimed to examine how differences in the ways that employees perceive and manage their work-related stress impacts both their episodic memory processing and the work-related outcomes of job satisfaction and motivation. Lastly, the overarching goal of this dissertation was to bridge the gap between research in cognitive and I/O psychology by identifying the interconnectedness between each of the concepts and variables related to memory, stress, interpersonal differences, and work-related outcomes.

\section{Work Stress and the Experience of Voluntary vs. Involuntary Memory}

At the heart of this dissertation is the question of whether there is a cause for studying memory from the perspective of an employee, and if the experience of stress in the workplace will yield as significant of an impact on memory processes as other more 
well-studied types of stressors do. Prior research on memory encoding of stressful events suggested that traumatic experiences result in the encoding of tunnel memories: highly salient memories with a focus on the gist of an event and lack of peripheral details. In the first study, employees were asked to recall a memory of a stressful event that had occurred within the workplace. A cursory glance at the non-significant correlation between this voluntary recall of stressful memories and the participants' levels of work stress might indicate that tunnel memories of workplace events - if they exist - are not as related with post-traumatic stress symptoms as hypothesized.

A closer look at the sub-measures of episodic memory indicate that work stress is related to memory intensity, rumination about the reoccurrence of the stressful memory, and an inability to control when the stressful memory is recalled. Additionally, stress led to less visualization, less of a first-person perspective when recalling memories, and less certainty about whether the event that was recalled was an event that really happened. The relationship between stress and the sub-measures of episodic memory is consistent with previous research on trauma memory which specified issues for trauma survivors with relation to memory specificity, fragmented memories and dissociation of selfidentity, and reliving memories from an outside as opposed to first-person perspective (Berntsen et. al, 2003; Berntsen \& Rubin, 2007; Finnbogadottir, 2011; Hall et al., 2018; Thomsen \& Berntsen, 2009; Tulving, 2002).

With only some aspects of memories supported regarding stressful memory recall, there are still several unanswered questions about the overall relationship between work stress and episodic memories of the workplace. Are isolated incidents of stressful recall not traumatic enough to evoke a true tunnel memory of a workplace event? Is this 
because some employees do not have tunnel memories related to the workplace, or is there a fundamental difference between stressful memories that are voluntarily recalled versus the memories that are prone to involuntarily come to mind? Or are workplace memories not central enough to one's life story to trigger post-traumatic stress? Perhaps the answer is that memories that are prompted by a non-work experience (e.g., a questionnaire that can be taken in the comfort of one's home) allow an employee to utilize cognitive resources that they may not have while on the job, buffering the impact of the memory and resulting in lower reports of stress.

The link between stress and involuntary recall (as reported as a measure of general episodic memory), and the reaffirming confirmation of this link via the correlation between work stress and both involuntary and recurrent involuntary episodic memories as independent measures, supports the idea of a distinction between voluntary and involuntary memories of workplace events. Previous research implicated the importance of general disposition, mood, emotional reactiveness, ruminative tendencies, positivity biases, self-identity, and overall wellbeing as influences on the frequency and intensity of involuntary and recurrent involuntary memories. The impact mood may have on memory was reiterated by the current study via the positive correlation between negative affect (disposition and mood), social anxiety (rumination), and depression (overall mental wellbeing) and involuntary \& recurrent involuntary memories of stressful events. Additionally, job-affective wellbeing (positive emotional state at work), emotional intelligence (positive emotional reactiveness), and core self-evaluations (positive self-identity) were all associated with a reduced frequency in reliving memories of stressful events. In addition to confirming previous theories on the causes and effects 
of involuntary and recurrent involuntary episodic memories, it integrates and supports prior theories of personality from I/O literature as well.

\section{Work Stress and Mental Time Travel}

In the second study, participants were asked to record brief qualitative entries of their memories at different time periods in their careers to examine the process of remembering past events, speculating on events that could have happened, and engaging in episodic future thinking of what could happen in the workplace. Unlike the first study, these employees were not prompted to deliberately remember stressful events. Work stress was consistently negatively correlated with positive memories, whether past or present, actual or imagined. The consistent negative impact of work stress on memory in the second study may support the previous idea that prompted recall of a negative event may not be as significant of a representation of the stress-memory relationship as an employee selectively recalling a negative workplace event might be. Additionally, the configuration of study 2 allowed for a clearer delineation between employees who recall positive versus negative memories regarding interpersonal differences impacting memory valence.

When comparing the three categories of memories - actual past events, imagined past events, and imaginary future events - employees reported a more negative average valence when referring to past events (.20 for actual and .39 for imagined, on a scale of -5 to 5) than when they engaged in episodic future thinking (an average valence of 1.9). In each of the three memory categories, positive memory reports were negatively correlated with the inclusion of clients or customers, coworkers, and bosses or superiors. The inclusion of other people from the workplace was also the most prominent when 
employees were reporting on actual past events. This suggests that positive versus negative emotions experienced when reflecting on the workplace have some social determinants, and that memories involving others related to one's workplace can be inherently more stressful than memories that are self-focused.

The social influence on work stress and memory processes is consistent with prior research on social memory, self-identity, and creating and maintaining relationships with others. Theories such as emotional contagion (mood transmission between employees) might also be supported, as these results might also suggest that interacting with others who are suffering from workplace stressors might cause secondhand stress symptoms to someone who is experiencing a negative event vicariously as opposed to directly. Employees who included witnessing or experiencing fighting, yelling, or injuries also reported less positive memories and heightened experiences of work stress, as did employees who reported being reprimanded or fired - an experience that employees reported more frequently when imagining events in the past or future than when reporting actual past events. Those who reported memories on being praised or promoted did not have these same levels of stress, and employees who reported praise and promotion reported more self-focused memories and fewer memories of others. The memory reports of future events included less frequent memories involving bosses or supervisors, who would be the assumed individuals giving the praise or promotion to these employees.

Overall, the results related to imagined future events suggest that there are multiple components from the workplace that impact an employee's ability to engage in mental time travel. The most optimistic of these findings may be the trends related to an employee's memory regarding future episodic projections. Employees, overall, tend to 
focus less on others when thinking about their futures, and there is an increase in positive valence and the frequency of hopeful memories about future workplace outcomes.

\section{Interpersonal Differences, Memory Processes, and Work Stress}

Developing an understanding of how personality and psychopathology traits influence an employee's episodic memory processes and their perceptions of workplace stress were important goals of this dissertation. Each of the traits measured yielded significant and interesting results that support the current interdisciplinary studies and warrant future studies like them.

Positive affect. Considering the importance of one's emotional disposition in mentally processing stress, it was expected that positive affect would provide an emotional buffer and/or bolster an employee's ability to engage in emotion-focused coping techniques in the current studies. Subsequently, employee's high in positive affect were expected to report lower levels of work stress and more positive episodic memories. In the first study, positive affect did have a negative correlation with work stress, but did not have any significant correlations with voluntary, involuntary, or recurrent involuntary memory recall. At the sub-measure level, positive affect's main (and only) emerging significant relationship was a positive correlation with more positive emotions during voluntary memory recall.

In the second study, positive affect had much more significant results, with a positive correlation with positive actual past events, imagined past events, and imaginary future thinking. Positive affect was also negatively correlated with inclusions of bosses or supervisors in their narratives, and positively correlated with inclusions of experiences of praise or promotion. Above and beyond simple correlations, mediation analysis showed 
that positive affect significantly affected or altered the relationship between work stress and each of the mental time travel phenomena of actual past events, imagined past events, and imaginary future thoughts. This is a significant finding supporting the interrelationship between common I/O personality variables and concepts of episodic memory via cognitive psychology research. The significance of this mediation effect, and the mediation effects between other personality traits, work stress, and memory phenomena support the development of an integrative model including each of these different variables.

The lack of relationship with the Study 1 memory variables and the significant relationship with the Study 2 ones may be due to similar reasons as the non-significant relationship between voluntary memory and work stress. When prompted to think of negative events, positive affect may not play as significant of a role in the emotional regulation involved in memory recall. When given an open prompt and allowed to recall memories freely, however, positive affect appears to illicit the kind of positivity bias that previous research links with this personality trait. This provides the evidence that positive affect is an important trait when looking at the day-to-day relationship between workplace stressors and episodic memory recall, and that employees higher in positive affect will experience stress and stressful memory recall less frequently and severely than employees lower in positive affect.

Negative affect. Negative affect emerged as a much more significant personality trait than positive affect in the first of the two studies. When looking at recall of stressful events, negative affect was positively correlated with voluntary, involuntary, and recurrent involuntary recall. Though negative affect was significantly correlated with 
eight of the fifteen measures of voluntary memory, the correlations between NA and both involuntary measures was much stronger than with voluntary recall (.13 with voluntary memory versus .51 and .48 with involuntary and recurrent involuntary respectively). In fact, the relationship between involuntary and recurrent involuntary memory recall and negative affect was the most significant relationships that these memory processes had with any variable, including work stress. Additionally, negative affect was the only variable that had a mediational effect on the relationship between work stress and memory, accounting for a significant portion of the relationship that emerged between work stress and involuntary memory recall. The relationship between affect work stress, and memory signify the importance that negative mood can have on the predisposition of an employee to engage in negative thought processes in the workplace, and to experience workplace stressors more severely than employees lower in negative affect.

In the second study on mental time travel, negative affect was significantly positively correlated with actual past events and imaginary future thinking. It was expected that negative affect would be negatively correlated with the mental time travel phenomena, as each of the memories types was measured on a scale of positive to negative valence. Additionally, when looking at the qualitative responses, negative affect was significantly positively correlated with the inclusion of being reprimanded or fired. This data, taken together, suggests that employees high in negative affect are reporting negative situations in a positive light. It is possible that employees who are high in negative affect are expecting to experience stress and other unfavorable outcomes in the workplace. When they do experience events that are in line with their cognitive bias as inherent targets for scrutiny, perhaps this affirmation to preexisting schema related to 
their self-identity provides a sense of security. It is also possible, albeit a morbid thought, that the positive emotions employees high in negative affect report are when recalling bad experiences that have happened to those around them.

Job-affective wellbeing. Job-affective wellbeing measured an employee's predisposition to experience positive or negative emotional states and is a measure that directly looks at personality in the scope of the workplace. This personality measure was strongly negatively correlated with job stress across both studies (-.56 in Study 1 and -.70 in Study 2), suggesting that an employee's emotional state plays a pivotal role in how they experience and respond to negative workplace events. Regarding the stressful episodic memories in Study 1, job-affective wellbeing was only significantly (negatively) correlated with involuntary and recurrent involuntary memories. Though the summed measure of voluntary recall only approached significance, job-affective wellbeing was significantly correlated with ten of the fifteen sub-measures of general episodic memory. Positive emotions, the ability to relive an event as it actually occurred, appraisal of the physical surroundings involved in the memory, positive wording, vividness, belief in the reality of the events occurrence, and a lack of worry of reoccurrence were all associated with job-affective wellbeing.

In the second study, job-affective wellbeing had a significant positive correlation with the raters (coders) measure of qualitative valence and was also significantly positively correlated with the (employee-rated) valence of imagined past and imaginary future events. Like Study 1, job-affective wellbeing was positively correlated with the vividness of memories, the experience of positive emotions when remembering, and how important the memory was to the employee. Additionally, employees higher in job- 
affective wellbeing reported fewer memories involving others from the workplace, and fewer instances of being reprimanded or fired across all memories. One of the most notable results in Study 2 was the mediation of job-affective wellbeing on the relationship between work stress and both actual past events and imagined past events in the workplace. This mediation determined that job-affective wellbeing has a significant impact in the relationship that is seen between work stress and aspects of mental time travel.

Taken together with Study 1, this data provides evidence that positive emotional states in the workplace - an employee's context-specific affective responses to workplace experiences - is an important part of how an employee processes stress and regulates their emotions.

Emotional intelligence. Emotional intelligence, or an employee's awareness of their feelings, of others' feelings, and of how to control their own emotions and feelings, was expected to play a similar role as job-affective wellbeing in mitigating workplace stress. It's important to note that emotional intelligence was measured as an overall trait without looking at the sub-facets (emotional regulation and management, understanding, perception, etcetera). Though emotional intelligence may be similar in scope to other emotion-focused traits, this overall measure of emotional intelligence yielded results unlike any other personality trait.

In Study 1, emotional intelligence was negatively correlated with involuntary and recurrent involuntary memories as were expected, suggesting that individuals who are higher in emotional intelligence experience less frequent involuntary and recurrent involuntary stressful memories. The unexpected result was the positive correlation 
between emotional intelligence and voluntary recall of stressful events. Not only was it the only positive personality and psychopathology trait to positively correlate with stressful memory recall, but it was more significantly correlated with voluntary recall of workplace stress than any other variable measured. This is despite a strong negative correlation between emotional intelligence and the measure of work stress

The results from Study 1 implies that emotional intelligence is a personality trait that allows an employee to go above and beyond mitigating stress or determining mood. Higher levels of emotional intelligence allow an employee to attending to and process information and events regardless of their positive or negative nature without incurring negative repercussions for reliving potentially stressful or traumatic experiences. The negative correlation between emotional intelligence and involuntary and recurrent involuntary memory shows that this trait allows an employee to process stressful events without subsequent rumination. When looking at the general episodic sub-measures, employees higher in emotional intelligence are still reporting negative emotions when reliving stressful events, but they are also reporting less intensity, less vividness, less worry of reoccurrence, and less involuntary recall than is associated with any of the other personality and psychopathology traits.

In contrast, Study 2 did not yield as remarkable of results about the trait. Emotional intelligence was only positively correlated with imaginary future thoughts, vividness of memories, and positive emotions associated with the phenomenology questions. There was a significantly negative relationship between emotional intelligence and work stress, and between EI and the inclusion of being reprimanded or fired in the memory narratives. The most notable finding related to emotional intelligence in Study 2 
was the slight mediation of emotional intelligence on the relationship between work stress and imaginary future thoughts of the workplace, signifying that some of the relationship that is seen between work stress and imaginary future thinking is accounted for by an employee's emotional intelligence.

The accumulation of data (from Study 1 and Study 2) on emotional intelligence suggests that emotional intelligence is distinct from the other positive personality traits when both dealing with stressful events and when an employee is prompted to remember a general memory. Emotional intelligence allows an employee to buffer against negativity when willfully recollecting an episode of stress but does not necessarily have a significant relationship with the day-to-day recall of workplace memories.

Core self-evaluations. Core self-evaluations, within the scope of these studies, was predicted to gauge emotional stability, capability to adjust, and an employee's overall self-confidence in the workplace. The results related to core self-evaluations were like that of job-affective wellbeing; there was no significant relationship with voluntary recall, but a significant negative correlation with core self-evaluations and involuntary and recurrent involuntary stressful memories. The difference between core selfevaluations and job-affective wellbeing is that CSE's were only associated with less worry of reoccurrence on the sub-measures of episodic memory. The one thing that can be noted is that employees with higher core self-evaluations reported less worry of reoccurring a stressful workplace memory than employees with any other personality trait. This is consistent with an employee feeling capable to adjust to unfavorable workplace situations and is likely in part because of an internal locus of control. Prior results have implicated the social nature of dealing with workplace stressors, and an 
internal locus of control paired with higher self-esteem and self-efficacy could be buffering employees from the worry of negative things happening on the job.

With regards to Study 2, core self-evaluations did not have a significant relationship with mental time travel (though there was a positive correlation with positive emotions and memory intensity). Looking at the qualitative data, there was still no significant relationship between core self-evaluations and these memories. One possibility is that CSE's are not as relevant of a variable as the other personality traits regarding job-related memories.

In both studies, tenure was positively correlated with higher levels of core selfevaluations. This suggests a secondary explanation for the non-significant relationship between core self-evaluations and mental time travel, which is that individuals who have been in their careers longer may not have the need to engage in mental time travel in order to visualize where they are going or where they have been in their careers. In running an exploratory correlation analysis with tenure and the qualitative data from Study 2, employees who have been in their careers longer are less likely to mention others in the workplace in their narratives, less likely to mention fighting or yelling, and more frequently mention receiving praise and promotion.

Social anxiety. Previous research on social anxiety suggests that employee's high in social anxiety will have skewed social appraisals, negative distortions and selfopinions, ruminative behaviors, and memory biases. This implied that employees in the current study who were higher in social anxiety should report higher levels of work stress, more frequent negative episodic memories, and more negative memories with regards to mental time travel. As expected, social anxiety was significantly positively 
correlated with work stress in both studies conducted. In the first study, social anxiety was positively correlated with more detailed reliving, stronger bodily sensations, heightened intensity, and heightened worry about the reoccurrence of stressful memories. Social anxiety was also positively correlated with involuntary and recurrent involuntary memories. The findings related to social anxiety and memory are consistent with what is known about social anxiety within the context of both memory and I/O literature. Employees who are more socially anxious, especially in social situations such as the workplace, are prone to engaging in more ruminative behaviors about the stressful situations that have already happened to them and to have intrusive thoughts about negative events that have yet to occur.

In the second study, higher levels of social anxiety were associated with less vivid mental time travel, more negative emotions when engaging in mental time travel, an increased frequency of negative memories, and greater ease in remembering negative memories. Anxiety was also the most strongly correlated trait with the mention of being reprimanded or fired. Overall, it looks as if individuals higher in social anxiety have some predispositions towards the experience of negative memories, and that anxiety may guide an employee's thoughts when they are attempting to engage in mental time travel. It does not seem, however, that social anxiety is as much of a determining factor as other personality traits. Social anxiety and negative affect share many commonalities with regards to cyclical negative thinking and ruminative behavior, however negative affect seems to be a stronger factor of the work stress-episodic memory relationship.

Depression. Depression, the last of the interpersonal traits measured, is typified by a general decrease in wellbeing and mental functioning related to work stress and 
memory processes. In addition to being positively correlated with work stress in both studies, depression was one of only two traits that had the expected relationship with recall of stressful work events in Study 1. Depression was positively correlated with voluntary, involuntary, and recurrent involuntary memory akin to negative affect. At the sub-measure level of voluntary episodic memory, depression was correlated with a record twelve of fifteen measures; depression positively correlated with reliving the original event, visualizing the original event, feeling the same physical surroundings and bodily sensations as the original event, vividness, high emotionality, intensity, worry of reoccurrence, voluntary and involuntary recall, and was the only trait to be negatively correlated with self-reports of valence. The overall results from the first study support the idea that employees with higher levels of depression may suffer from memory problems, decreased ability to cope with stress, more specific recall of information tied to stronger emotions and heightened physical reactions to the memory of their experiences (see Watson et al., 2012).

In the second study, depression was only significantly (negatively) correlated with the element of mental time travel dealing with projections into the future. The results of the phenomenology questions showed that the predominant way that depression impacts the memories involved with mental time travel is through heightened experiences of negative emotions in reliving these memories. This was supported by the quantitative reports of the memory narratives, with depression being significantly negatively correlated with positive moods during mental time travel. Depression was also correlated with more intense memories, less mention of promotion or praise, and greater mention of being reprimanded or fired. Unlike some of the other traits, depressed employees do not 
seem to be particularly influences by others in the workplace. Instead they deal with substantially more negative emotions across all aspects of mental time travel and seem to have a bleaker outlook about their past and future careers.

\section{The Implications and Impacts on Job Outcomes}

As the workplace outcomes of job satisfaction and motivation have already been well-researched regarding each of the personality and psychopathology traits, the main objective of the current studies was to determine the potential interrelationships that might exist between these variables and the different measures of workplace memory. Job satisfaction and motivation were both negatively correlated with measures of involuntary and recurrent involuntary memory, suggesting that more frequent spontaneous recall of stressful work events results in less satisfied, less motivated employees. Neither outcome had noteworthy relationships with voluntary memory recall or any of the sub-measures (except for lower levels of intensity and less worry of reoccurrence being slightly positively correlated with job satisfaction). Additionally, neither outcome was significantly correlated with memories related to mental time travel. Job satisfaction and motivation were both positively correlated with vividness, positive emotions, and less ease of remembering when looking at the impact of the phenomenology measures.

The most notable results regarding job outcomes in the current studies was the exploratory moderation analysis conducted between the three types of stressful memory recall and the outcome of motivation. Each of these analyses showed a significant moderation of memory (voluntary recall, involuntary recall, and recurrent involuntary recall) under conditions of heightened work stress, which supported the development of 
an integrated model between memory, work stress, and job outcomes. These results mean that more frequent reports of stressful memory recall account for a significant amount of the variance in the relationship between higher levels of work stress and lower levels of motivation (via the interaction between work stress and memory recall). These moderations, aside from basic correlation analyses, lend the most support to the interdisciplinary idea of a relationship between work stress, memory processes, and jobrelated outcomes. This is a significant step towards determining directions for future research regarding these interrelationships.

\section{The Highlights of Other Exploratory Findings}

There were a variety of unique findings discovered when looking at elements of the study such as demographic variables and trends with the qualitative data.

Gender. Gender differences emerged when looking at personality and psychopathology traits and the different measures of memory. Women have higher levels of emotional intelligence than men but suffer from lower positive affect and higher levels of social anxiety and depression. Additionally, women experience more negative emotions during memory recall. This is another example of how emotional intelligence allows an individual to process what might be stressful or negative emotions while still maintaining some element of positivity. Despite being more anxious and depression, and having more negative emotions, women were more likely to have vivid memories, more likely to experience positive emotions, more likely to recall important memories, and report more positive actual past memories and imaginary future thoughts when engaging in mental time travel. 
Income. Income was another variable that had relationships with personality, psychopathology, and memory traits. Higher income was tied to the positive personality traits of positive affect and core-self evaluations. It was also negatively correlated with social anxiety in both studies. Additionally, income seems to have a role in whether an employee engages in positive mental time travel, with higher income employees having more (positively) vivid memories, a greater tendency to willfully think about workrelated memories, and more positive mental time travel across all three memory categories. This seems to support the idea that money, to some degree, can buy you happiness when you are being paid well for the job you do. It also may be evidence for the idea that individuals high in traits such as negative affect create self-fulfilling prophecies of negative experiences, and that positive personality traits promote the opposite regarding personal successes.

Time worked. The amount of time an employee spends on the job also has implications regarding a variety of variables, whether time is categorized by hours per week or by years an employee has worked with their current company. Employees who work more hours in a week have higher positive affect, emotional intelligence, core selfevaluations, and reports of motivation, and have less social anxiety than those who work fewer hours. The number of years worked in one's current job is also positively correlated with core self-evaluations. More time on the job was also associated with many of the memory phenomena including the aspects of mental time travel, which all yielded more positive memories. Overall, these are interesting findings considering larger workloads (hours per week) are typically associated with burnout and negative symptoms related to an employee's wellbeing and work-life balance. Other (positive and negative) 
factors are possible that might yield these findings, such as high work engagement levels or workaholism.

Sexual orientation. Though an employee's sexual orientation was not correlated with an abundance of variables, the correlations that did emerge are important to note regarding the overall mental health and wellbeing of non-heterosexual employees. Employees who identified as homosexual, bisexual, or other non-heteronormative orientations reported higher levels of depression across both studies. In Study 2, nonheterosexual employees reported higher levels of work stress, more negative emotional states, less positive core self-evaluations, less job satisfaction, and less positive recall of actual past memories when engaging in mental time travel. These findings suggest that non-heterosexual employees are a population at risk in the workplace of developing and perpetuating negative self-images and views of the workplace that may come from a lack of open-mindedness and acceptance from one's peers.

Exploring the qualitative data. Many of the notable findings from the qualitative data in Study 2 have already been reported throughout this discussion, however there are other important things to note when reflecting upon these memory narratives. Memories of praise, recognition, or promotion in the workplace were the most prominent types of memories recorded, being a subject of approximately $1 / 3$ of all memory narratives. There are, however, many entries across the three types of mental time travel that both the existence of tunnel memories of workplace events and employees' fear of these situations reoccurring.

When examining the most extreme memories ( -5 for valence and 5 for intensity), many included severe belittling and beratement, intense physical violence and fighting, 
public humiliation, severe injury to one's self or coworkers, witnessing or trying to prevent a death, and police interventions. One of the most common fears among employees reporting negative imaginary future events is the experience of a mass shooting - something that was mentioned several times across a variety of scenarios. Employees who work with the public (places with crowds, schools, malls, etcetera) are reporting significant fears when thinking about what could happen to them at work. This is something that stands to get worse as mass shootings turn into daily occurrences that become more and more plausible as potential experiences employees may have when going to work.

Memory reports that were highly positive usually involved major promotions or other sensationalized events that are not everyday occurrences (such as being proposed to while at work). When reflecting on actual past experiences, many employees included parties and events unrelated to their work tasks and spoke about them with great excitement. While it is arguable that an office baby shower or Thanksgiving potluck is an accurate reflection of what an employee experiences at work, the inclusion of events like this throughout the work year appear to be of great importance to many employees. The deliberate planning of these events, which undoubtedly provides employees with a temporary respite from their day-to-day stressors, might allow an organization to have some control in decreasing work stress and subsequently minimizing negative memories of the workplace.

\section{Limitations of the Current Study}

Though the current studies were successful in at least partially supporting many of the hypotheses I sought to investigate in this dissertation, there were a few major 
limitations that surfaced throughout this study that are important to note when interpreting these findings.

One of the most major limitations is conducting these studies through one-time questionnaires as opposed to being able to utilize diary studies. The surveys used in both studies were employed in order to maximize the amount of information collected while minimizing the costs that would have come with services such as Amazon Turk. I do believe, however, that future studies should measure longitudinal data and include a sample that is more representative of a working population, such that paid statistical services could provide. This type of longitudinal data collection would allow for spontaneous measures of involuntary and recurrent involuntary memories as well as instances of mental time travel with a working sample that extends beyond workers enrolled in college. Additionally, it's possible that balancing the responsibility of being a student with being a worker could skew the levels of stress reported with the population used in the current studies.

There are other underlying methodological issues in the types of questionnaires that were used to measure the data. As the current studies were merging two very different fields of psychology, several measures had to be modified in order to accommodate both the cognitive and I/O research questions. Each of the measures used in both studies had an acceptable validity when looking at the measure of Cronbach's alpha, but only a few of the measures are widely recognized, accepted, and frequently used in psychology research. The most difficult measures to adapt to the current studies were the memory scales, and the development of a work-specific measure of memory (as 
opposed to the adaptation of more general scales) might provide clearer insight into the encoding and retrieval processes of episodic workplace memories.

The lack of existing research juxtaposing the subject areas of I/O psychology and cognitive (memory) psychology is also somewhat of a limitation for the current study as there is not substantial contextual evidence yet to create more well-founded theories about memory in the workplace. One way that this can be addressed in future research is through more thoroughly and comprehensively defining workplace memory as a construct. Additionally, creating more work-related criteria for examining episodic workplace memories and mental time travel related to one's career would be helpful in determining work-specific memory phenomena and utilizing future findings in practically applying research outcomes to the workplace.

\section{Implications for Future Research}

There are several topics for future research that I believe have emerged from this dissertation, including the following:

I. Determining the differences between voluntary, involuntary, and recurrent involuntary memories in the workplace by developing and utilizing a unified measure of episodic memory of stressful events (that is potentially workplacespecific). Additionally, future research examining qualitative over quantitative responses of these types of memories may yield important findings that have yet to be discovered in $\mathrm{I} / \mathrm{O}$ or cognitive research.

II. The inclusion of different personality variables to determine if non-emotion focused personality traits yield similar results to the ones from this study and breaking down the core self-evaluations trait and looking at self-efficacy, self- 
esteem, and locus of control as independent personality variables. There may be interesting relationships between work stress, memory, and personality measures such as the Big 5 (openness to experience, conscientiousness, extraversion, agreeableness, and neuroticism). It would also be interesting to examine the relationship between employee creativity and memory narratives of workplace events.

III. The inclusion of the sub-facets of emotional intelligence to further determine the significance of the relationship between emotional intelligence, workplace stress, and memory.

IV. Expanding upon the types of job outcomes studied, especially given the relationships found between stress. memory, and motivation in moderation analyses. Organizational commitment, organizational justice, involvement, engagement, and perceived organizational support are all potential variables that could be significant when looking at work stress and memory processes.

V. Accounting for the social relationships in the workplace in future studies, given the distinctive findings in the qualitative data on mental time travel. Further exploration could identify the interpersonal versus self-related impact of workplace experiences on memory processes.

VI. The interesting findings related to tenure, hours and years worked, gender, and sexual orientation suggest that demographic variables are important to include in the development of future research questions and included in the primary analysis of future studies. Future research could look at gender differences and include different types of workplaces. These are areas that could substantially contribute 
to the existing body of knowledge on memory processes, in general and regarding work-focused episodic memories.

VII. Focusing on a sample that is more proportionate to the general population (e.g., more equal participation by males and females or a more group regarding ethnicity), and considering a sample composed solely of a working population (as opposed to student base) could yield results that are better applied to general working populations.

Overall, the relationships in this study (be they significant or non-significant) brings light to the idea that a wide variety of factors play a role in the interaction between who an employee is and a) how that influences the perceptions of stress, b) how that stress impacts workplace memory, and c) how those memories might influence job outcomes. The current research also provides enough evidence to pave the way in a variety of interdisciplinary areas that will aid in the understanding of employee experiences of their workplace.

\section{Conclusion}

This dissertation was successful in supporting many hypotheses that elucidated upon memory processes in the context of workplace stress. Even the hypotheses that were not supported allowed for a greater understanding of how stress is perceived and processed in via an employee's episodic memory system, and highlighted areas of future research that would fill the gaps that still exist in the current I/O and cognitive literature. Though work-specific memory is still a novel concept in both fields of psychology, the results of this study show promise for the theory that workplace stress is relevant in memory research related to post-traumatic stress and event processing. These results also 
showed that emotion, specifically tied to personality and psychopathology, play a significant role in the stress-memory relationship, and that there are still areas regarding an employee's temperament and disposition that warrant research and exploration by I/O and cognitive psychologists. Despite its limitations, this dissertation has shown evidence that the work stress-episodic memory relationship exists and is far more complex than an A to B relationship. In doing such, this dissertation has met the goal of contributing to existing stress and memory research and beginning to create new channels of dialogue for more innovative and interdisciplinary ideas to follow. 


\section{REFERENCES}

Aiken, L. S., \& West, S. G. (1991). Multiple regression: Testing and interpreting interactions. Newbury Park, London, Sage.

Attance, C. M., \& O’Neill, D. K. (2001). Episodic future thinking. Trends in Cognitive Sciences, 5 (12), 533-539.

Attman, D. G. (1999). Practical statistics for medical research. New York, NY: Chapman \& Hall/CRC Press.

Ball, C. T., \& Little, J. R. (2006). A comparison of involuntary memory retrievals. Applied Cognitive Psychology, 20, 1167-1179.

Bandura, A. (1986). Social foundations of thought and action: A social cognitive theory. Englewood Cliffs, NJ: Prentice Hall

Bandura, A. (1997). Self-efficacy: The exercise of control. Chapter ix, 604 Pages. New York, NY. W H Freemen/Times Books/Henry Holt \& Co.

Bandura, A., Barbaranelli, C., Vittorio Caprara, G., Pastorelli, C. (2001). Self-efficacy beliefs as shapers of children's aspirations and career trajectories. Child Development, 72 (1), 187-206.

Baron, R. M., \& Kenny, D. A. (1986). The moderator-mediator variable distinction in social psychological research: Conceptual, strategic, and statistical considerations Journal of Personality and Social Psychology, 51, 1173-1182.

Becker, E. S., Andrich, M., Roth, W. T., \& Margraf, J. (1999). Explicit memory in anxiety disorders. Journal of Abnormal Psychology, 108, 153-163.

Beehr, T. A., \& Newman, J. E. (1978) Job stress, employee health, and organizational effectiveness: a facet analysis, model, and literature review. Personnel Psychology, 31, 665-699.

Bergdahl, J., Larsson, A., Nilsson, L-G., Ahlstrom, K. R., \& Nyberg, L. (2005). Treatment of chronic stress in employees: Subjective, cognitive and neural correlates. Scandinavian Journal of Psychology, 46 (5), 395-402.

Berntsen, D. (1996). Involuntary autobiographical memories. Applied Cognitive Psychology, 10, 435-454.

Berntsen, D. (1998). Voluntary and involuntary access to autobiographical memory. Memory, 6, 113-141. 
Berntsen, D. (2001). Involuntary memories of emotional events. Do memories of traumas and extremely happy events differ? Applied Cognitive Psychology, 15, 135-158.

Berntsen, D. (2002). Tunnel memories for autobiographical events: central details are remembered more frequently from shocking than from happy experiences. Memory \& Cognition, 30, 1010-1020.

Berntsen, D., \& Bohn, A. (2010). Remembering and forecasting: the relation between autobiographical memory and episodic future thinking. Memory \& Cognition, 38, 265-278.

Berntsen, D. \& Hall, N. M. (2004). The episodic nature of involuntary autobiographical memories. Memory and Cognition, 32, 789-803.

Berntsen, D. \& Jacobsen, A. S. (2008). Involuntary (spontaneous) mental time travel into the past and future. Consciousness and Cognition, 17, 1093-1104.

Berntsen, D., \& Rubin, D. C. (2002). Emotionally charged memories across the life span: the recall of happy, sad, traumatic, and involuntary memories. Psychology of Aging, 17, 636-652.

Berntsen, D., \& Rubin, D. C. (2006). The centrality of event scale: A measure of integrating trauma into one's identity and its relation to post-traumatic stress disorder. Behaviour Research and Therapy, 44, 219-231.

Berntsen, D., \& Rubin, D. C. (2007). When a trauma becomes key to identity: enhanced integration of trauma memories predicts posttraumatic stress disorder symptoms. Applied Cognitive Psychology, 21, 417-431.

Berntsen, D., \& Rbin, D. C. (2008). The reappearance hypothesis revisited: recurrent involuntary memories after traumatic events in everyday life. Memory \& Cognition, 36 (2), 449-460.

Berntsen, D., Rubin, D. C., \& Salgado, S. (2015). The frequency of involuntary autobiographical memories and future thoughts in relation to daydreaming, emotional distress, and age. Consciousness and Cognition, 36, 352-372.

Berntsen, D., Willert, M., \& Rubin, D. C. (2003). Splintered memories of vivid landmarks? Qualities and organization of traumatic memories with and without PTSD. Applied Cognitive Psychology, 17, 675-693.

Bluck, S. (2003). Autobiographical memory: Exploring its functions in everyday life. Memory, 11, 113-123. 
Bono, J. E., \& Judge, T.A. (2003). Core self-evaluations: A review of the trait and its role in job satisfaction and job performance. European Journal of Personality, 17 (S5S18).

Botzung, A., Ekaterina, D., \& Manning, L. (2007). Experiencing past and future personal events: Functional neuroimaging evidence on the neural bases of mental time travel. Brain and Cognition, 66, 202-212.

Bower, G. H., Black, J. B., \& Turner, T. J. (1979). Scripts in memory for text. Cognitive Psychology, 11, 117-220.

Bracket, M. A., \& Mayer, J. D. (2003). Convergent, discriminant, and incremental validity of comparing measures of emotional intelligence. Personality and Social Psychology Bulletin, 29 (9), 1147-1158.

Brief, A. P., Burke, M. J., George, J. M., Robinson, B. S., \& Webster, J. (1988). Should negative affectivity remain an unmeasured variable in the study of job stress? Journal of Applied Psychology, 73, 193-198.

Burke, M. J., Brief, A. P., \& George, J. M. (1993). The role of negative affectivity in understanding relations between self-reports of stressors and strains: a comment on the applied psychology literature. Journal of Applied Psychology, 78, 402-412.

Burton, J. P., \& Hoobler, J. M. (2006). Subordinate self-esteem and abusive supervision. Journal of Managerial Issues, 17, 340-355.

Burton, J. P., \& Hoobler, J. M. (2011). Aggressive reactions to abusive supervision: The role of interactional justice and narcissism. Scandinavian Journal of Psychology, 52, 389-398.

Champoux, J. E. (1991). A multivariate test of the job characteristics theory of work motivation. Journal of Organizational Behavior, 12 (5), 431-446.

Chen, P. Y., \& Spector, P. E. (1991). Negative affectivity as the underlying cause of correlations between stressors and strains. Journal of Applied Psychology, 76, 398-407.

Christianson, S. A., \& Loftus, E. F. (1987). Memory for traumatic events. Applied Cognitive Psychology, 1, 225-239.

Christianson, S. A., \& Loftus, E. F. (1991). Remembering emotional events: the face of detailed information. Cognition and Emotion, 5, 81-108.

Clark, D. M, \& McManus, F. (2002). Information processing in social phobia. Society of Biological Psychiatry, 51, 92-100. 
Clore, G. L., \& Gasper, K. (2000). Feeling is believing: Some affective influences on belief. In N. H. Frijda, A. S. R. Manstead, \& S. Bem (Eds.), Emotions and beliefs: How do emotions influence beliefs? (pp. 10-44). Cambridge, England: Cambridge University Press.

Clore, G. L., \& Storbeck, J. (2006). Affect as information about liking, efficacy, and importance. In J. Forgas (Ed.) Hearts and minds: Affective influences on social cognition and behavior (pp. 123-142). New York, NY: Psychology Press.

Clore, G. L., Wyer, R. S., Dienes, B., Gasper, K., Gohm, C., \& Isbell, L. (2001). Affective feelings as feedback: Some cognitive consequences. In L. L. Martin \& G. L. Clore (Eds.) Theories of mood and cognition: A user's handbook (pp. 2762). Mahwah, NJ. Lawrence Erbaum Associates, Inc.

Cody, M. W., \& Teachman, B. A. (2010). Post-event processing and memory bias for performance feedback in social anxiety. Journal of Anxiety Disorders, 24, 468479 .

Conway, M. A. (2005). Memory and the self. Journal of Memory and Language, 53, 594628.

Conway, M. A., \& Bekerian, D. A. (1988) Characteristics of vivid memories. In R. N. Sykes (Ed.) Practical aspects of memory: Current research and issues (Vol. 1., pp. 519-524). New York, NY: Wiley.

Conway, M. A., \& Pleydell-Peace, C. W. (2000). The construction of autobiographical memories in the self-memory system. Psychological Review, 107, 261-288.

Cote, S. (2005). A social interaction model of the effects of emotion regulation on work strain. The Academy of Management Review, 30, 509-530.

Cropanzano, R., James, K., \& Konovsky, M. A. (1993). Dispositional affectivity as a predictor of work attitudes and job performance. Journal of organizational Behavior, 14, 595-606.

Deci, E. L., \& Ryan, R. M. (1985). Intrinsic motivation and self-determination in human behavior. New York: Plenum.

Duffy, M. K., Ganster, D. C., \& Pagon, M. (2001). Social undermining and social support in the workplace. Academy of Management Journal, 45, 331-351.

Duffy, M. K., Ganster, D. C., \& Shaw, J. D. (1998). Positive affectivity and negative outcomes: The role of tenure and job satisfaction. Journal of Applied Psychology, $83,930-959$. 
Duffy, M. K., Shaw, J. D., Scott, K. L., \& Tepper, B. J. (2006). The moderating roles of self-esteem and neuroticism in the relationship between group and individual undermining behavior. Journal of Applied Psychology, 91, 1066-1077.

Edwards, J. R. (1992). A cybernetic theory of stress, coping, and well-being in organizations. Academy of Management Review, 17, 238-274.

Ehlers, A., \& Clark, D. M. (2000). A cognitive model of posttraumatic stress disorder. Behaviour Research and Therapy, 38, 319-345.

Ehlers, A., Hackmann, A., \& Michael, T. (2004). Intrusive reexperiencing in posttraumatic stress disorder: Phenomenology, theory, and therapy. Memory, 12, 403415.

Ehlers, A., Michael, T., Chen, Y. P., Payne, E., \& Shan, S. (2006). Enhanced perceptual Priming for neutral stimuli in a traumatic context: A pathway to intrusive memories? Memory, 14, 316-328.

Elkin, A. J., \& Rosch, P. J. (1990). Promoting mental health at the workplace: The prevention side of stress management. Occupational Medicine: State of the Art Reviews, 5 (4).

Elliot, T. R., Sherwin, E., Harkins, S. W., \& Marmarosh, C. (1995). Self-appraised problem-solving ability, affective states, and psychological distress. Journal of Counseling Psychology, 42, 105-115.

Fiedler, K. (2001). Affective states trigger processes of assimilation and accommodation. In L. L. Martin \& G. L. Clore (Eds.). Theories of mood and cognition: A user's guidebook (pp. 85-98). Mahwah, NJ: Lawrence Erlbaum Associates, Inc.

Finklestein, R., Minibas-Poussard, J., \& Bastounis, M. (2009). The moderating role of seeking social support on coping styles and perceptions of organizational justice: A study with French and Turkish Students. Social Behavior and Personality, 37, 845-862.

Finnbogadottir, H. \& Berntsen, D. (2011). Involuntary and voluntary mental time travel in high and low worriers. Memory, 19, 625-640.

Finnbogadottir, H. \& Berntsen, D. (2013). Involuntary future projections are as frequent as involuntary memories, but more positive. Consciousness and Cognition, 23, 272-280.

Folkman, S., \& Lazarus, R. S. (1988). Coping as a mediator of emotion. Journal of Personality and Social Psychology, 3, 466-475. 
Fontaine, J. R. J., Scherer, K. R., Roesch, E. B., \& Ellsworth, P. C. (2007). The world of emotions is not two-dimensional. Pscyhol Sci, 18 (12), 1050-1157.

Ford, J. H., Addis, D. R., \& Giovanello, K. S. (2011). Differential neural activity during search of specific and general autobiographical memories elicited by musical cues. Neuropsychologia, 49, 2514-2526.

Forgas, J. P. (1995). On seeing a bear that isn't there: Affect and perception. Contemporary Psychology, 40 (11), 1057-1058.

Fredrickson, B. L. (1998). What good are positive emotions? Review of General Psychology, 2, 300-319.

Frese, M. (1989). Human computer interaction within an industrial psychology framework. Applied Psychology: An Interactional Review, 38 (1), 29-44.

Frese, M., \& Zapf, D. (1994) In Handbook of industrial and organizational psychology (Vol. 4, 2nd ed.), by Triandis, Harry C (ed.); Dunnette, Marvin D (ed.); Hough, Leaetta M (ed.). 271-340, Chapter xxv, 869 Pages. 2nd ed. Palo Alto, CA, US: Consulting Psychologists Press, 1994.

Goleman, D. (1995). Emotional Intelligence. New York, NY, England: Bantam Books, Etc.

Grandey, A. A., Cordeiro, B. L., \& Crouter, A. C. (2005). A longitudinal and multisource test of the work-family conflict and job satisfaction relationship. Journal of Occupational and Organizational Psychology, 78 (3), 305-323.

Griffin, M. A., \& Clarke, S. (2010). In APA handbook of industrial and organizational psychology, Vol 3: Maintaining, expanding, and contracting the organization, by Zedeck, Sheldon (ed.). 359-397, Chapter viii, 960 Pages. Washington, DC, US: American Psychological Association.

Gross, J. J. (1998). The emerging field of emotion regulation: An integrative review. Review of General Psychology, 2 (3), 271-299.

Hackman, J. R., \& Oldham, G. R. (1975). Development of the job diagnostic survey. Journal of Applied Psychology, 60, 159-170.

Halbesleban, J. R. B., \& Buckley, M. R. (2004). Burnout in organizational life. Journal of Management, 30, 859-879.

Hall, N. M., \& Berntsen, D. (2008). The effect of emotional stress on involuntary and voluntary conscious memories. Memory, 16, 48-57. 
Hall, S. A., Brodar, K. E., LaBar, K. S., Berntsen, D., \& Rubin, D.C. (2018). Neural responses to emotional involuntary memories in posttraumatic stress disorder: Differences in timing and activity. NeuroImage: Clinical, 19, 793-804.

Harris, K. J, Harvey, P., Harris, R. B., \& Cast, M. (2013). An investigation of abusive supervision, vicarious abusive supervision, and their joint impacts. The Journal of Social Psychology, 153, 38-50.

Harris, C. B., Rasmussen, A. S., \& Berntsen, D. (2014). The functions of autobiographical memory: an integrative approach. Memory, 22 (5), 559-581.

Hart, P. M., \& Cooper, C. L. (2001). Occupational stress: toward a more integrated framework. In N. Anderson, D. S. Ones, H. K. Sinangil, \& C. Viswesvaran (Eds.), Handbook of Industrial, Work, and Organizational Psychology (vol 2: Personnel Psychology). London: Sage.

Harvey, P., Stoner, J., Hochwarter, W., \& Kacmar, C. (2007). Coping with abusive supervision: The neutralizing effects of ingratiation and positive affect on negative employee outcomes. Leadership Quarterly, 18, 264-280.

Hayes, A. F. (2018). Introduction to mediation, moderation, and conditional process analysis. (2nd Ed.). New York: The Guilford Press.

Heinrichs, N., \& Hofmann, S. G. (2001). Information processing in social phobia: a critical review. Clinical Psychology Review, 21, 751-770.

Hofstede, G. H. (1979). Culture's consequences: International differences in work-related values. London: Sage Publications.

Holland, A. C., \& Kensinger, E. A. (2010). Emotion and autobiographical memory. Phys Life Review, 7 (1), 88-131.

Hoobler, J. M., \& Hu, J. (2013). A model of injustice, abusive supervision, and negative affect. The Leadership Quarterly, 24, 256-269.

Horowitz, M. J., \& Reidbord, S. P. (1992). Memory, emotion, and response to trauma. In S.-A Christianson (Ed.). The handbook of emotion and memory: Research and theory (pp.343-357). Hillsdale, NJ: Erlbaum.

Hurrell, J. J., Nelson, D. L., \& Simmons, B. L. (1998). Measuring job stressors and strains: where we have been, where we are, and where we need to go. Journal of Occupational Health Psychology, 3 (4), 368-389.

Ilgen, D. R., Fisher, C. D., \& Taylor, S. M. (1979). Consequences of individual feedback on behavior in organizations. Journal of Applied Psychology, 64, 349-371. 
Janoff-Bulman, R. (1988). Assumptive worlds and the stress of traumatic events: applications of the schema construct. Social Cognition,7, 113-136.

James, L. R., \& Brett, J. M. (1984) Mediators, moderators, and tests for mediation. Journal of Applied Psychology, 69, 307-321.

James, L. R., \& Tetrick, L. E. (1986) Confirmatory analytic tests of three causal models relating job perceptions to job satisfaction. Journal of Applied Psychology, 71, 7782.

Janovics, J., \& Christiansen, N. D. (2001, April). Emotional intelligence in the workplace. Paper presented at the 16th Annual Conference of the Society of Industrial and Organizational Psychology, San Diego, CA.

Jex, S. M. (1998). Stress and Job Performance. Sage Publications, London.

Jex, S. M., \& Elacqua, T. C. (1999). Time management as a moderator of relations between stressors and employee strain. Work \& Stress, 13, 182-191.

Jhean-Larose, S., Leveau, N., \& Denhiere, G. (2014). Influence of emotional valence and arousal on the spread of activation memory. Cognitive Processes, 15, 515-522.

Judge, T.A., \& Bono, J. E. (2001). Relationship of core self-evaluations traits - selfesteem, generalized self-efficacy, locus of control, and emotional stability - with job satisfaction and job performance: a meta-analysis. Journal of Applied Psychology, 86, 80-92.

Judge, T.A., Bono, J. E., Erez, A., \& Locke, E. A. (2005). Core self-evaluations and job and life satisfaction: The role of self-concordance and goal attainment. Journal of Applied Psychology, 90 (2), 257-268.

Judge, T. A., Locke, E. A., \& Durham, C. C. (1997). The dispositional causes of job satisfaction: A core evaluations approach. Research in Organizational Behavior, 19, 151-188.

Kahn, R. L., \& Byosiere, P. (1992). Stress in organizations. In M. D. Dunnette \& L. M. Hough (Eds.), Handbook of industrial and organizational psychology (pp. 571650). Palo Alto, CA, US: Consulting Psychologists Press.

Kanfer, R. (1990). Motivation theory and industrial and organizational psychology. In book: Handbook of industrial and organizational psychology (Vol. 1), Chapter: Motivation theory and Industrial/Organizational Psychology, Publisher: Consulting Psychologists Press, Editors: M. D. Dunnette \& L. Hough, pp.75-170. 
Kanfer, R., \& Ackerman, P. L. (1989). Motivation and cognitive abilities: An integrative/aptitude-treatment interaction approach to skill acquisition. Journal of Applied Psychology, 74(4), 657-690.

Kashdan, T. B., \& Collins, R. L. (2010). Social anxiety and the experience of positive emotion and anger in everyday life: an ecological momentary assessment approach. Anxiety, Stress, \& Coping, 23, 259-272.

Keenan, A., \& Newton, T. J. (1985). Stressful events, stressors, and psychological strains in young professional engineers. Journal of Occupational Behaviour, 6, 151-156.

Kensinger, E. A., \& Schacter, D. L. (2006). When the Red Sox shocked the Yankees: Comparing negative and positive memories. Psychometric Bulletin and Review, $13,757-763$.

Kobasa, S. C., Maddi, S. R., \& Kahn, S. (1982). Hardiness and health: A prospective study. Journal of Personality and Social Psychology, 42(1), 168-177.

Kocovski, N. L., Endler, N. S., Rector, N. A., \& Flett, G. L. (2005). Ruminative coping and post-event processing in social anxiety. Behaviour and Research Therapy, 43, 971-984.

Kong, F., Zhao, J, \& You, X. (2012). Trait emotional intelligence and mental distress: the mediating role of positive and negative affect. International Journal of Psychology, 47, 460-466.

Koppel, J., \& Berntsen, D. (2014). The cultural life script as cognitive schema: How the life script shapes memory for fictional life stories. Memory, 22 (8), 949-971.

Larson, R. J., \& Ketelaar, T. (1991). Personality and susceptibility to positive and negative emotional states. Journal of Personality and Social Psychology, 61, 132140.

Lazarus, R. S., \& Folkman, S. (1984). Stress, appraisal, and coping. New York, NY: Springer.

Lazarus, R. S., Kanner, A. D., \& Folkman, S. (1980). Emotions: A cognitivephenomenological analysis. In R. Plutchik \& H. Kellerman (Eds.) Theories of emotion (pp. 189-217). New York, Academic Press.

Lee-Baggley, D., Preece, M., \& DeLongis, A. (2005). Coping with interpersonal stress: Role of the Big Five traits. Journal of Personality, 73, 1142-1177. 
Lepine, J. A., Podsakoff, N. P., \& Lepine, M. A. (2005). A meta-analytic test of the challenge stressor-hindrance stressor framework: An explanation for inconsistent relationships among stressors and performance. Academy of Management Journal, 48(5), 764-775.

Levin, I., \& Stokes, J. P. (1989). Dispositional approach to job satisfaction: role of negative affectivity. Journal of Applied Psychology, 5, 752-758.

Levine, L. J., \& Pizarro, D. A. (2006). Emotional valence, discrete emotions, and memory. In B. Uttl, N. Ohta, \& A. L. Siegenthaler (Eds.), Memory and emotion: Interdisciplinary perspectives (pp. 37-58). Malden: Blackwell Publishing.

Locke, E. A. (1976). The nature and causes of job satisfaction. The Handbook of Industrial and Organizational Psychology, 31.

Locke, E. A. (1969). What is job satisfaction? Organizational Behavior \& Human Performance, 4(4), 309-336.

Loftus, E. F., Loftus, G. R., \& Messo, J. (1987). Some facts about "weapon focus". Law and Human Behavior, 11 (1).

Maslach, C. (1982). Burnout: The Cost of Caring. Englewood Cliffs, NJ: Prentice-Hall.

Maslach, C., \& Jackson, S. E. (1981). The measurement of experienced burnout. Journal of Occupational Behaviour, 2, 99-113.

Maslow, A. H. (1943). A theory of human motivation. Psychological Review, 50(4), 370396.

Mattick, R. P., \& Clarke, J. C. (1998). Development and validation of measures of social Phobia scrutiny fear and social interaction anxiety. Behaviour Research and Therapy, 36, 455-470.

McCrae, R. R., Costa, P. T. (1991). Adding Liebe und Arbeit: The full five-factor model and well-being. Personality and Social Psychology Bulletin, 17 (2), 227-232.

Milich, R., \& Dodge, K. A. (1984). Social information processing in child psychiatric populations. Journal of Abnormal Child Psychology, 47, 1-490.

Moreno, L. L., Garcia, J. M., Diaz, M. J., \& Diaz Ramiro, E. (2006). Psycho-social risks and trait anxiety as predictors of stress and job satisfaction. Ansiedad y Estres, 12, 89-97. 
Moskowitz, J. T., Shmueli-Blumberg, D., Acree, M., \& Folkman, S. (2012). Positive affect in the midst of distress: implications for role functioning. Journal of Community \& Applied Social Psychology, 22, 502-518.

Nepon, T., Flett, G.L., Hewitt, P. L., \& Molnar, D. S. (2011). Perfectionism, Negative Social Feedback, and Interpersonal Rumination in Depression and Social Anxiety. Canadian Journal of Behavioral Science, 43, 297-308.

Nijenhuis, E. R. S., \& van der Hart, O. (1999). Forgetting and reexperiencing trauma. In J. Goodwin, \& R. Cittias (Eds.), Splintered reflections: Images of the body in trauma (pp. 3 9-65). New York: Basic Books.

Niziurski, J. A., \& Berntsen, D. (2019). Involuntary versus voluntary episodic memories: The effects of encoding factors and emotion. Psychology of Consciousness: Theory, Research, and Practice. Advance online publication. http://dx.doi.org/10.1037/cns0000190

O’Toole, M. S., Watson, L. A., Rosenberg, N. K., \& Berntsen, D. (2016). Negative autobiographical memories in social anxiety disorder: A comparison with panic disorder and healthy controls. Journal of Behavior Therapy and Experimental Psychiatry, 50, 223-230.

Palacio-Gonzalez, A., Watson, L. A., \& Berntsen, D. (2018). Autobiographical memory functions and posttraumatic stress symptoms across adulthood. Memory, 26 (7), 985-992.

Pekrun, R., \& Frese, M. (1992). Emotions in work and achievement. In C. L. Cooper \& I. T. Robertson (Eds.). International review of industrial and organizational psychology (Vol 7, pp. 153-200). Chichester, England: Wiley.

Penney, L. M., \& Spector, P. E. (2005). Job stress, incivility, and counterproductive work behavior (CWB): the moderating role of negative affectivity. Journal of Organizational Behavior, 26, 777-796.

Perrewe, P. L., \& Zellars, K. L. (1999). An examination of attributions and emotions in the transactional approach to the organizational stress process. Journal of Organizational Behavior, 20, 739-752.

Pillemer, D. B., Ivcevic, Z., Gooze, R. A., \& Collins, K. A. (2007). Self-esteem memories: feeling good about achievement success, feeling bad about relationship distress. Personality and Social Psychology Bulletin, 33 (9), 1292-1305.

Plimpton, B., Patel, P., \& Kvalvilashvili, L. (2015). Role of triggers and dysphoria in mind-wandering about past, present, and future: a laboratory study.

Consciousness and Cognition, 33, 261-276. 
Quoidbach, J., Hansenne, M., \& Mottet, C. (2008). Personality and mental time travel: a differential approach to autonoetic consciousness. Consciousness and Cognition, 17, 1082-1092.

Rasmussen, A. S., \& Berntsen, D. (2010). Personality traits and autobiographical memory: Openness is positively related to the experience and usage of recollections. Memory, 18, 774-786.

Rook, K. C. (1992). Detrimental aspects of social relationships: Taking stock of an emerging literature. In H. Veil \& U. Baumann (Eds.), The meaning and measurement of social support: 157-169. New York: Hemisphere.

Rotter, J. B. (1966). Generalized expectancies for internal versus external control of reinforcement. Psychological Monographs: General and Applied, 80(1), 1-28.

Rubin, D. C., Berntsen, D., Deffler, S. A., \& Brodar, K. (2019). Self-narrative focus in autobiographical events: The effect of time, emotion, and individual differences. Memory \& Cognition, 47, 63-75.

Rubin, D. C., Schrauf, R. W., \& Greenberg, D. L. (2003). Belief and recollection of autobiographical memories. Memory and Cognition, 31, 877-886.

Russel, J. A. (1980). A circumplex model of affect. Journal of Personality and Social Psychology, 39, 1161-1178.

Ryan, R. M., \& Deci, E. L. (2000). Self-determination theory and the facilitation of intrinsic motivation, social development, and well-being. American Psychologist, $55,68-78$.

Safer, M. A., Christianson, S., Autry, M. W., \& Osterlund, K. (1998). Tunnel memory for traumatic events. Applied Cognitive Psychology, 12, 99-117.

Schat, A. C. H., \& Kelloway, E. K. (2003). Reducing the adverse consequences of workplace aggression and violence: the buffering effects of organizational support. Journal of Occupational Health Psychology, 8, 110-122.

Schulkind, M. D., \& Woldorf, G. M. (2005). Emotional organization of autobiographical memory. Memory and Cognition, 33, 1025-1035.

Schunk, D. H., \& Usher, E. L. (2012). Social cognitive theory and motivation. In R. M. Ryan (Ed.), Oxford library of psychology. The Oxford handbook of human motivation (pp. 13-27). New York, NY, US: Oxford University Press. 
Schutte, N. S., Malouff, J. M., Hall, L. E., Haggerty, D. J., Cooper, J. T., Golden, C. J., \& Dornheim, L. (1998). Development and validation of a measure of emotional intelligence. Personality and Individual Differences, 25, 167-177.

Sheth, B. R., \& Tham, T. (2008). How emotional arousal and valence influence access to awareness. Vision Research, 48, 2415-2424.

Sonnentag, S. (2000). Expertise at work: Experience and excellent performance. In C. L. Cooper \& I. T. Robertson (Eds.), International Review of Industrial and Organizational Psychology (pp. 223-264). Chichester: Wiley.

Sonnentag, S., \& Frese, M. (2003). Stress in organizations. In W. C. Borman, D. R. Ilgen, \& R. J. Klimoski (Eds.), Handbook of psychology: Industrial and organizational psychology, Vol. 12, pp. 453-491). Hoboken, NJ, US: John Wiley \& Sons Inc.

Spector, P. E. (1997). Advanced topics in organizational behavior. Job satisfaction: Application, assessment, causes, and consequences. Thousand Oaks, CA, US: Sage Publications, Inc.

Spector, P. E. (1998). A control theory of the job stress process.

Spector, P. E., Dwyer, D. J., \& Jex, S. M. (1988). Relation of job stressors to affective, health, and performance outcomes: a comparison of multiple data sources. Journal of Applied Psychology, 73, 11-19.

Spence, D. P. (1998). Passive remembering. In U. Neisser \& E. Winograd (Eds.). Remembering reconsidered: Ecological and traditional approaches to the study of memory (pp. 627-643). New York: Cambridge University Press.

Steinmetz, K. R. M., Addis, D. R., \& Kensinger, E. A. (2010). The effect of arousal on the emotional memory network depends on valence. NeuroImage, 53, 318-324.

Stopa, L., \& Clark, D. M. (2000). Social phobia and interpretation of social events. Behaviour and Research Therapy, 38, 273-283.

Suddendorf, T., \& Corballis, M. C. (2007). The evolution of foresignt: What is mental time travel and is it unique to humans? Behavioral and Brain Sciences, 30, 299 313.

Talarico, J. M., Berntsen, D., \& Rubin, D. C. (2009). Positive emotions enhance recall of peripheral details. Cognition and Emotion, 23 (2), 380-398.

Tellegan, A. (1985). Structures of mood and personality and their relevance to assessing anxiety, with an emphasis on self-report. In A. H. Tuman \& J. D. Maser (Eds.) Anxiety and Anxiety Disorders, 681-706. 
Tepper, B. J. (2000). Consequences of abusive supervision. Academy of Management Journal, 43, 178-190.

Tepper, B. J., Duffy, M. K., Henle, C. A., \& Lambert, L. S. (2006). Procedural injustice, victim precipitation, and abusive supervision. Personnel Psychology, 59, 101-123.

Thomsen, D. K., \& Berntsen, D. (2005). The end point effect in autobiographical memory: more than a calendar is needed. Memory, 13, 846-861.

Tremblay, M. A., Blanchard, C. M., Taylor, S., Pelletier, L. G., \& Villenueve, M. (2009). Work extrinsic and intrinsic motivation scale: its value for organizational psychology research. Canadian Journal of Behavioral Science, 41 (4), 213-226.

Tulving, E. (2002). Episodic memory: From mind to brain. Annual Review of Psychology, 53 (1), 1-25.

Van Katwyk, P. T., Spector, P. E., Fox, S., \& Kelloway, E. K. (2000). Using the jobrelated affective well-being scale (JAWS) to investigate affective responses to work stressors. Journal of Occupational Health Psychology, 2, 219-230.

Van Rooy, D. L., Viswesvaran, C., \& Pluta, P. (2005). An Evaluation of Construct Validity: What Is This Thing Called Emotional Intelligence? Human Performance, 18(4), 445-462.

Walker, W. R., Skowronksi, J. J., \& Thompson, C. F. (2003). Life is pleasant - and memory helps to keep it that way! Review of General Psychology, 7, 203-210.

Watson, L. A., Berntsen, D., Kuyken, W., \& Watkins, E. B. (2012). The characteristics of involuntary and voluntary autobiographical memories in depressed and never depressed individuals. Consciousness and Cognition, 21, 1382-1392.

Watson, L. A., Berntsen, D., Kuyken, W., \& Watkins, E. B. (2013). Involuntary and voluntary autobiographical memory specificity as a function of depression. Journal of Behavior Therapy and Experimental Psychiatry, 44, 7-13.

Watson, D., Clark, L. A., \& Tellegen, A. (1988). Development and validation of brief measures of positive and negative affect: the PANAS scales. Journal of Personality and Social Psychology, 54, 1063-1070.

Watson, D., \& Slack, A. K. (1993). General factors of affective temperament and their relation to job satisfaction over time. Organizational Behavior and Human Decision Processes, 54(2), 181-202.

Watson, D., \& Tellegen, A. (1985). Toward a consensual structure of mood. Psychological Bulletin, 98, 219-235. 
Webb, T. L., Ononaiye, M. S. P., Sheeran, P., Reidy, J. G., \& Lavda, A. (2010) “Using implementation intentions to overcome the effects of social anxiety on attention and appraisals of performance" Personality and Social Psychology Bulletin, 36, 612-627.

Williams, J. M. G., Barnhofer, T. Crane, C. Hermans, D., Raes, F., Watkins, E., et al. (2007). Autobiographical memory specificity and emotional disorder. Psychological Bulletin, 113, 112-148.

Winstanley, S. \& Whittington, R. (2002). Anxiety, burnout and coping styles in general hospital staff exposed to workplace aggression: a cyclical model of burnout and vulnerability to aggression. Work \& Stress, 16, 302-315. 


\section{TABLES}

Table 1: Summary of Support for All Hypotheses

\begin{tabular}{|c|c|c|}
\hline Hypothesis & & Support \\
\hline $1 \mathbf{a}$ & $\begin{array}{l}\text { Workplace stress will positively correlate with } \\
\text { measures of negative episodic memory recall }\end{array}$ & Partial \\
\hline $1 \mathrm{~b}$ & $\begin{array}{l}\text { Workplace stress will negatively correlate with } \\
\text { measures of positive episodic memory recall }\end{array}$ & Partial \\
\hline $2 a$ & $\begin{array}{l}\text { Workplace stress will positively correlate with } \\
\text { involuntary episodic memory recall of stressful work } \\
\text { events }\end{array}$ & Full \\
\hline $2 b$ & $\begin{array}{l}\text { Workplace stress will positively correlate with } \\
\text { recurrent involuntary episodic memory recall of } \\
\text { stressful work events }\end{array}$ & Full \\
\hline $\mathbf{3 a}$ & $\begin{array}{l}\text { Positive affect will negatively correlate with workplace } \\
\text { stress }\end{array}$ & Full \\
\hline $3 \mathbf{b}$ & $\begin{array}{l}\text { Negative affect will positively correlate with } \\
\text { workplace stress }\end{array}$ & Full \\
\hline $4 a$ & $\begin{array}{l}\text { Positive affect will negatively correlate with voluntary } \\
\text { episodic memory recall of stressful work events }\end{array}$ & Partial \\
\hline $4 b$ & $\begin{array}{l}\text { Positive affect will negatively correlate with } \\
\text { involuntary episodic memory recall of stressful work } \\
\text { events }\end{array}$ & None \\
\hline $4 c$ & $\begin{array}{l}\text { Positive affect will negatively correlate with recurrent } \\
\text { involuntary episodic memory recall of stressful work } \\
\text { events }\end{array}$ & None \\
\hline $4 d$ & $\begin{array}{l}\text { Negative affect will positively correlate with voluntary } \\
\text { episodic memory recall of stressful work events }\end{array}$ & Full \\
\hline $4 e$ & $\begin{array}{l}\text { Negative affect will positively correlate with } \\
\text { involuntary episodic memory recall of stressful work } \\
\text { events }\end{array}$ & Full \\
\hline $4 f$ & $\begin{array}{l}\text { Negative affect will positively correlate with recurrent } \\
\text { involuntary episodic memory recall of stressful work } \\
\text { events }\end{array}$ & Full \\
\hline $5 \mathbf{a}$ & $\begin{array}{l}\text { Job-affective wellbeing (emotional state) will } \\
\text { negatively correlate with workplace stress }\end{array}$ & Full \\
\hline $5 \mathbf{b}$ & $\begin{array}{l}\text { Emotional intelligence will negatively correlate with } \\
\text { workplace stress }\end{array}$ & Full \\
\hline $5 c$ & $\begin{array}{l}\text { Core self-evaluations will negatively correlate with } \\
\text { workplace stress }\end{array}$ & Full \\
\hline 6a & $\begin{array}{l}\text { Job-affective wellbeing (emotional state) will } \\
\text { negatively correlate with voluntary episodic memory } \\
\text { recall of stressful events }\end{array}$ & Partial \\
\hline $6 b$ & $\begin{array}{l}\text { Job-affective wellbeing (emotional state) will } \\
\text { negatively correlate with involuntary episodic memory } \\
\text { recall of stressful events }\end{array}$ & Full \\
\hline $6 c$ & $\begin{array}{l}\text { Job-affective wellbeing (emotional state) will } \\
\text { negatively correlate with recurrent involuntary episodic } \\
\text { memory recall of stressful events }\end{array}$ & Full \\
\hline
\end{tabular}




\begin{tabular}{|c|c|c|}
\hline $7 a$ & $\begin{array}{l}\text { Emotional intelligence will negatively correlate with } \\
\text { voluntary episodic memory recall of stressful events }\end{array}$ & Full \\
\hline $7 b$ & $\begin{array}{l}\text { Emotional intelligence will negatively correlate with } \\
\text { involuntary episodic memory recall of stressful events }\end{array}$ & Full \\
\hline $7 c$ & $\begin{array}{l}\text { Emotional intelligence will negatively correlate with } \\
\text { recurrent involuntary episodic memory recall of } \\
\text { stressful events }\end{array}$ & Full \\
\hline $8 a$ & $\begin{array}{l}\text { Core self-evaluations will negatively correlate with } \\
\text { voluntary episodic memory recall of stressful events }\end{array}$ & Partial \\
\hline $8 b$ & $\begin{array}{l}\text { Core self-evaluations will negatively correlate with } \\
\text { involuntary episodic memory recall of stressful events }\end{array}$ & Full \\
\hline $8 c$ & $\begin{array}{l}\text { Core self-evaluations will negatively correlate with } \\
\text { recurrent involuntary episodic memory recall of } \\
\text { stressful events }\end{array}$ & Full \\
\hline $9 a$ & $\begin{array}{l}\text { Social anxiety will be positively correlated with work } \\
\text { stress }\end{array}$ & Full \\
\hline $9 \mathrm{~b}$ & $\begin{array}{l}\text { Depression will be positively correlated with work } \\
\text { stress }\end{array}$ & Full \\
\hline $10 a$ & $\begin{array}{l}\text { Social anxiety will be positively correlated with } \\
\text { voluntary episodic memory recall of stressful events }\end{array}$ & Partial \\
\hline $10 b$ & $\begin{array}{l}\text { Social anxiety will be positively correlated with } \\
\text { involuntary episodic memory recall of stressful events }\end{array}$ & Full \\
\hline $10 \mathrm{c}$ & $\begin{array}{l}\text { Social anxiety will be positively correlated with } \\
\text { recurrent involuntary episodic memory recall of } \\
\text { stressful events }\end{array}$ & Full \\
\hline 11a & $\begin{array}{l}\text { Depression will be positively correlated with voluntary } \\
\text { episodic memory recall of stressful events }\end{array}$ & Full \\
\hline 11b & $\begin{array}{l}\text { Depression will be positively correlated with } \\
\text { involuntary episodic memory recall of stressful events }\end{array}$ & Full \\
\hline $11 \mathrm{c}$ & $\begin{array}{l}\text { Depression will be positively correlated with recurrent } \\
\text { involuntary episodic memory recall of stressful events }\end{array}$ & Full \\
\hline $12 a$ & $\begin{array}{l}\text { Job satisfaction will be negatively correlated with } \\
\text { voluntary episodic memory recall of stressful events }\end{array}$ & Partial \\
\hline $12 b$ & $\begin{array}{l}\text { Job satisfaction will be negatively correlated with } \\
\text { involuntary episodic memory recall of stressful events }\end{array}$ & Full \\
\hline $12 \mathrm{c}$ & $\begin{array}{l}\text { Job satisfaction will be negatively correlated with } \\
\text { recurrent involuntary episodic memory recall of } \\
\text { stressful events }\end{array}$ & Full \\
\hline 13a & $\begin{array}{l}\text { Motivation will be negatively correlated with voluntary } \\
\text { episodic memory recall of stressful events }\end{array}$ & None \\
\hline $13 b$ & $\begin{array}{l}\text { Motivation will be negatively correlated with } \\
\text { involuntary episodic memory recall of stressful events }\end{array}$ & Full \\
\hline $13 c$ & $\begin{array}{l}\text { Motivation will be negatively correlated with recurrent } \\
\text { involuntary episodic memory recall of stressful events }\end{array}$ & Full \\
\hline
\end{tabular}




\begin{tabular}{|c|c|c|}
\hline $14 a$ & $\begin{array}{l}\text { Workplace stress will positively correlate with } \\
\text { measures of negative episodic memories of actual past } \\
\text { events }\end{array}$ & Partial \\
\hline $14 b$ & $\begin{array}{l}\text { Workplace stress will positively correlate with } \\
\text { measures of negative episodic memories of imagined } \\
\text { past events }\end{array}$ & Full \\
\hline $14 c$ & $\begin{array}{l}\text { Workplace stress will positively correlate with } \\
\text { measures of negative episodic future thoughts }\end{array}$ & Full \\
\hline $15 a$ & $\begin{array}{l}\text { Workplace stress will positively correlate with the } \\
\text { vividness of episodic memories }\end{array}$ & None \\
\hline $15 b$ & $\begin{array}{l}\text { Workplace stress will negatively correlate with the } \\
\text { emotions experienced during episodic memories }\end{array}$ & Full \\
\hline $15 \mathrm{c}$ & $\begin{array}{l}\text { Workplace stress will positively correlate with the } \\
\text { perceived importance of episodic memories }\end{array}$ & None \\
\hline 15d & $\begin{array}{l}\text { Workplace stress will positively correlate with the } \\
\text { intensity of episodic memories }\end{array}$ & None \\
\hline $15 e$ & $\begin{array}{l}\text { Workplace stress will positively correlate with the } \\
\text { frequency of episodic memories }\end{array}$ & None \\
\hline $15 f$ & $\begin{array}{l}\text { Workplace stress will positively correlate with the ease } \\
\text { of remembering episodic memories }\end{array}$ & Partial \\
\hline $16 a$ & $\begin{array}{l}\text { Positive affect will be positively correlated with actual } \\
\text { past memories }\end{array}$ & Full \\
\hline $16 \mathrm{~b}$ & $\begin{array}{l}\text { Positive affect will be positively correlated with } \\
\text { imagined past memories }\end{array}$ & Full \\
\hline $16 c$ & $\begin{array}{l}\text { Positive affect will be positively correlated with } \\
\text { imaginary future thoughts }\end{array}$ & Full \\
\hline $17 \mathbf{a}$ & $\begin{array}{l}\text { Negative affect will be negatively correlated with } \\
\text { actual past memories }\end{array}$ & None \\
\hline $17 \mathrm{~b}$ & $\begin{array}{l}\text { Negative affect will be negatively correlated with } \\
\text { imagined past memories }\end{array}$ & None \\
\hline $17 \mathrm{c}$ & $\begin{array}{l}\text { Negative affect will be negatively correlated with } \\
\text { imaginary future events }\end{array}$ & None \\
\hline 18a & $\begin{array}{l}\text { Job-affective wellbeing will be positively correlated } \\
\text { with actual past memories }\end{array}$ & Full \\
\hline $18 \mathrm{~b}$ & $\begin{array}{l}\text { Job-affective wellbeing will be positively correlated } \\
\text { with imagined past memories }\end{array}$ & Full \\
\hline $18 \mathrm{c}$ & $\begin{array}{l}\text { Job-affective wellbeing will be positively correlated } \\
\text { with imaginary future thoughts }\end{array}$ & Full \\
\hline 19a & $\begin{array}{l}\text { Emotional intelligence will be positively correlated } \\
\text { with actual past memories }\end{array}$ & None \\
\hline $19 b$ & $\begin{array}{l}\text { Emotional intelligence will be positively correlated } \\
\text { with imagined past memories }\end{array}$ & None \\
\hline
\end{tabular}




\begin{tabular}{|c|c|c|}
\hline $19 \mathrm{c}$ & $\begin{array}{l}\text { Emotional intelligence will be positively correlated } \\
\text { with imaginary future thoughts }\end{array}$ & Full \\
\hline $20 \mathrm{a}$ & $\begin{array}{l}\text { Core self-evaluations will be positively correlated with } \\
\text { actual past memories }\end{array}$ & None \\
\hline $20 \mathrm{~b}$ & $\begin{array}{l}\text { Core self-evaluations will be positively correlated with } \\
\text { imagined past memories }\end{array}$ & None \\
\hline $20 \mathrm{c}$ & $\begin{array}{l}\text { Core self-evaluations will be positively correlated with } \\
\text { imaginary future thoughts }\end{array}$ & None \\
\hline $21 \mathrm{a}$ & $\begin{array}{l}\text { Social anxiety will be negatively correlated with actual } \\
\text { past memories }\end{array}$ & None \\
\hline $21 b$ & $\begin{array}{l}\text { Social anxiety will be negatively correlated with } \\
\text { imagined past memories }\end{array}$ & None \\
\hline 21c & $\begin{array}{l}\text { Social anxiety will be negatively correlated with } \\
\text { imaginary future events }\end{array}$ & None \\
\hline $22 a$ & $\begin{array}{l}\text { Depression will be negatively correlated with actual } \\
\text { past memories }\end{array}$ & None \\
\hline $22 b$ & $\begin{array}{l}\text { Depression will be negatively correlated with imagined } \\
\text { past memories }\end{array}$ & Full \\
\hline $22 c$ & $\begin{array}{l}\text { Depression will be negatively correlated with } \\
\text { imaginary future events }\end{array}$ & None \\
\hline $23 a$ & $\begin{array}{l}\text { Job satisfaction will be positively correlated with } \\
\text { actual past memories }\end{array}$ & None \\
\hline $23 b$ & $\begin{array}{l}\text { Job satisfaction will be positively correlated with } \\
\text { imagined past memories }\end{array}$ & None \\
\hline $23 \mathrm{c}$ & $\begin{array}{l}\text { Job satisfaction will be positively correlated with } \\
\text { imaginary future thoughts }\end{array}$ & None \\
\hline $24 a$ & $\begin{array}{l}\text { Motivation will be positively correlated with actual } \\
\text { past memories }\end{array}$ & None \\
\hline $24 b$ & $\begin{array}{l}\text { Motivation will be positively correlated with imagined } \\
\text { past memories }\end{array}$ & None \\
\hline $24 c$ & $\begin{array}{l}\text { Motivation will be positively correlated with imaginary } \\
\text { future thoughts }\end{array}$ & None \\
\hline $25 a$ & $\begin{array}{l}\text { Personality and psychopathology will mediate the } \\
\text { relationship between work stress and voluntary } \\
\text { episodic memory recall of stressful work events }\end{array}$ & Partia \\
\hline $25 b$ & $\begin{array}{l}\text { Personality and psychopathology will mediate the } \\
\text { relationship between work stress and involuntary } \\
\text { episodic memory recall of stressful work events }\end{array}$ & None \\
\hline $25 c$ & $\begin{array}{l}\text { Personality and psychopathology will mediate the } \\
\text { relationship between work stress and recurrent } \\
\text { involuntary episodic memory recall of stressful work } \\
\text { events }\end{array}$ & None \\
\hline $25 d$ & $\begin{array}{l}\text { Personality and psychopathology will mediate the } \\
\text { relationship between work stress and voluntary } \\
\text { episodic memory recall of stressful work events and } \\
\text { negative actual past experiences }\end{array}$ & Partia \\
\hline
\end{tabular}




\begin{tabular}{lll}
\hline 25e & $\begin{array}{l}\text { Personality and psychopathology will mediate the } \\
\text { relationship between work stress and voluntary } \\
\text { episodic memory recall of stressful work events and } \\
\text { negative imagined past experiences }\end{array}$ & \\
\hline $\mathbf{2 5 f}$ & $\begin{array}{l}\text { Personality and psychopathology will mediate the } \\
\text { relationship between work stress and voluntary } \\
\text { episodic memory recall of stressful work events and } \\
\text { negative imaginary future events }\end{array}$ & Partial \\
\hline 26a & $\begin{array}{l}\text { Voluntary recall of stressful work events will moderate } \\
\text { the relationship between motivation and work stress, }\end{array}$ & None \\
& $\begin{array}{l}\text { such that more frequent voluntary recall of stressful } \\
\text { work events will strengthen the relationship between } \\
\text { work stress and lower levels of these outcomes }\end{array}$ & \\
\hline $\mathbf{2 6 b}$ & $\begin{array}{l}\text { Voluntary recall of stressful work events will moderate } \\
\text { the relationship between job satisfaction and work } \\
\text { stress such that more frequent voluntary recall of } \\
\text { stressful work events will strengthen the relationship } \\
\text { between work stress and lower levels of these } \\
\text { outcomes }\end{array}$ & \\
\hline Involuntary recall of stressful work events will \\
moderate the relationship between job satisfaction and \\
work stress, such that more frequent involuntary recall \\
of stressful work events will strengthen the relationship \\
between work stress and lower levels of these \\
outcomes
\end{tabular}


Table 2: Means, Standard Deviations, and Correlations (Study1)

\begin{tabular}{|c|c|c|c|c|c|c|c|c|c|c|}
\hline Variables & $M$ & $S D$ & 1 & 2 & 3 & 4 & 5 & 6 & 7 & 8 \\
\hline 1. Age & 25.01 & 5.48 & - & & & & & & & \\
\hline 2. Gender & 1.82 & 0.39 & -.022 & - & & & & & & \\
\hline $\begin{array}{l}\text { 3. Education } \\
\text { Level }\end{array}$ & 3.91 & 0.91 & $.319 * *$ & -.092 & - & & & & & \\
\hline 4. Salary & 2.86 & 1.96 & $.403 * *$ & $-.173 * *$ & $.182 * *$ & - & & & & \\
\hline 5. Tenure & 2.83 & 1.22 & $.439 * *$ & .037 & $.134^{*}$ & $.219 * *$ & - & & & \\
\hline $\begin{array}{l}\text { 6. Voluntary } \\
\text { Episodic } \\
\text { Memory }\end{array}$ & 4.90 & 0.99 & .057 & .078 & .021 & .042 & .006 & - & & \\
\hline $\begin{array}{l}\text { 7. Involuntary } \\
\text { Episodic } \\
\text { Memory }\end{array}$ & 2.49 & 0.81 & -.091 & .002 & .066 & -.005 & -.097 & $.289 * *$ & - & \\
\hline $\begin{array}{l}\text { 8. Recurrent } \\
\text { Involuntary } \\
\text { Episodic } \\
\text { Memory }\end{array}$ & 2.31 & 0.81 & -.083 & -.024 & .056 & .015 & -.054 & $.247 * *$ & $.862 * *$ & - \\
\hline 9. Work Stress & 2.35 & 0.58 & -.046 & .062 & .019 & .009 & .013 & -.065 & $.263 * *$ & $.339 * *$ \\
\hline $\begin{array}{l}\text { 10. Positive } \\
\text { Affect }\end{array}$ & 3.36 & 0.93 & .021 & $-.176 * *$ & .097 & $.164 * *$ & .049 & .067 & .006 & -.005 \\
\hline $\begin{array}{l}\text { 11. Negative } \\
\text { Affect }\end{array}$ & 2.14 & 0.83 & $-.173 * *$ & .091 & -.027 & -.055 & -.088 & $.125^{*}$ & $.512 * *$ & $.477 * *$ \\
\hline $\begin{array}{l}\text { 12. Job- } \\
\text { Affective } \\
\text { Wellbeing }\end{array}$ & 3.35 & 0.76 & .075 & -.108 & .050 & .036 & -.046 & -.087 & $-.217 * *$ & $-.280 * *$ \\
\hline $\begin{array}{l}\text { 13. Emotional } \\
\text { Intelligence }\end{array}$ & 3.75 & 0.52 & .083 & .018 & -.022 & .106 & .076 & $.289 * *$ & $-.135^{*}$ & $-.162 * *$ \\
\hline $\begin{array}{l}\text { 14. Core Self- } \\
\text { Evaluations }\end{array}$ & 3.50 & 0.61 & $.127^{*}$ & -.118 & .015 & $.114^{*}$ & $\begin{array}{c}.160 * \\
*\end{array}$ & .039 & $-.313 * *$ & $-.314 * *$ \\
\hline $\begin{array}{l}\text { 15. Social } \\
\text { Anxiety }\end{array}$ & 2.44 & 0.84 & $-.146^{*}$ & $.131 *$ & -.023 & $-.132 *$ & -.092 & .104 & $.368 * *$ & $.394^{* *}$ \\
\hline $\begin{array}{l}16 . \\
\text { Depression }\end{array}$ & 28.69 & 8.71 & -.048 & $.127^{*}$ & -.069 & $-.132 *$ & -.068 & $.166^{* *}$ & $.306 * *$ & $.284 * *$ \\
\hline $\begin{array}{l}\text { 17. Job } \\
\text { Satisfaction }\end{array}$ & 3.88 & 0.76 & .008 & -.055 & .006 & .001 & -.081 & -.009 & $-.271 * *$ & $-.311 * *$ \\
\hline $\begin{array}{l}\text { 18. Job } \\
\text { Motivation }\end{array}$ & 4.61 & 1.04 & .065 & -.083 & .008 & .096 & .043 & .085 & $-.175 * *$ & $-.176^{* *}$ \\
\hline
\end{tabular}


Table 2, Continued

\begin{tabular}{|c|c|c|c|c|c|c|c|c|c|}
\hline Variables & 9 & 10 & 11 & 12 & 13 & 14 & 15 & 16 & 17 \\
\hline 1. Age & & & & & & & & & \\
\hline 2. Gender & & & & & & & & & \\
\hline $\begin{array}{l}\text { 3. Education } \\
\text { Level }\end{array}$ & & & & & & & & & \\
\hline 4. Salary & & & & & & & & & \\
\hline 5. Tenure & & & & & & & & & \\
\hline $\begin{array}{l}\text { 6. Voluntary } \\
\text { Episodic } \\
\text { Memory }\end{array}$ & & & & & & & & & \\
\hline $\begin{array}{l}\text { 7. Involuntary } \\
\text { Episodic } \\
\text { Memory }\end{array}$ & & & & & & & & & \\
\hline $\begin{array}{l}\text { 8. Recurrent } \\
\text { Involuntary } \\
\text { Episodic } \\
\text { Memory }\end{array}$ & & & & & & & & & \\
\hline 9. Work Stress & - & & & & & & & & \\
\hline $\begin{array}{l}\text { 10. Positive } \\
\text { Affect }\end{array}$ & $-.271 * *$ & - & & & & & & & \\
\hline $\begin{array}{l}\text { 11. Negative } \\
\text { Affect }\end{array}$ & $.371^{* *}$ & -.116 & - & & & & & & \\
\hline $\begin{array}{l}\text { 12. Job-Affective } \\
\text { Wellbeing }\end{array}$ & $-.559^{* *}$ & $.502 * *$ & $-.490 * *$ & - & & & & & \\
\hline $\begin{array}{l}\text { 13. Emotional } \\
\text { Intelligence }\end{array}$ & $-.440 * *$ & $.368 * *$ & $-.162 * *$ & $.244 * *$ & - & & & & \\
\hline $\begin{array}{l}\text { 14. Core Self- } \\
\text { Evaluations }\end{array}$ & $-.339 * *$ & $.394 * *$ & $-.391 * *$ & $.397 * *$ & $.506^{* *}$ & - & & & \\
\hline $\begin{array}{l}\text { 15. Social } \\
\text { Anxiety }\end{array}$ & $.266^{*}$ & $-.217^{* *}$ & $.406^{* *}$ & $-.329 * *$ & $-.368 * *$ & $-.525^{* *}$ & - & & \\
\hline 16. Depression & $.169^{* *}$ & $-.422 * *$ & $.387 * *$ & $-.422 * *$ & $-.196^{* *}$ & $-.497 * *$ & $.369 * *$ & - & \\
\hline $\begin{array}{l}\text { 17. Job } \\
\text { Satisfaction }\end{array}$ & $-.696^{* *}$ & $.324 * *$ & $-.361^{* *}$ & $.669 * *$ & $.290 * *$ & $.331 * *$ & $-.290^{* *}$ & $-.289 * *$ & - \\
\hline $\begin{array}{l}\text { 18. Job } \\
\text { Motivation }\end{array}$ & $-.310 * *$ & $.228 * *$ & $-.278^{* *}$ & $.388^{* *}$ & $.324 * *$ & $.270^{* *}$ & $-.281 * *$ & -.121 & $.403 * *$ \\
\hline
\end{tabular}


Table 3: Correlations - Individual Variables \& Episodic Memory Sub-Measures

\begin{tabular}{|c|c|c|c|c|c|c|c|c|c|c|}
\hline Variables & Stress & PA & NA & EI & JAWS & CSES & SIAS & BDII & JSS & WEIMS \\
\hline 1. Reliving & -.012 & .011 & $.130^{*}$ & -.052 & $.129^{*}$ & .010 & $.144^{*}$ & $.165^{* *}$ & .012 & .017 \\
\hline 2. Visual & $-.167 * *$ & .057 & .006 & -.037 & $.297 * *$ & .096 & -.009 & $.185^{* *}$ & .066 & $.204 * *$ \\
\hline 3. Olfactory & .000 & $.220 * *$ & .035 & .077 & $.130^{*}$ & .058 & .008 & .005 & .023 & .038 \\
\hline $\begin{array}{l}\text { 4. Physical } \\
\text { Surroundings }\end{array}$ & -.046 & .050 & .072 & -.053 & $.304 * *$ & .107 & -.041 & $.162 * *$ & .016 & .117 \\
\hline 5. Vividness & -.026 & .030 & $.160^{* *}$ & $-.147 *$ & $.238^{* *}$ & .069 & .071 & $.121^{*}$ & -.044 & .021 \\
\hline $\begin{array}{l}\text { 6. Bodily } \\
\text { Sensations }\end{array}$ & .014 & .056 & $.194 * *$ & -.101 & $-.136^{*}$ & -.069 & $.233 * *$ & $.139 *$ & -.055 & -.002 \\
\hline 7. Emotions & .023 & -.020 & $.167^{* *}$ & $-.164 * *$ & $.188^{* *}$ & -.104 & $.146^{*}$ & $.159^{* *}$ & -.069 & .051 \\
\hline 8. Intensity & $.140^{*}$ & .020 & $.181 * *$ & $-.158^{* *}$ & $.127^{*}$ & -.014 & $.173^{* *}$ & $.147^{*}$ & $-.134^{*}$ & .024 \\
\hline 9. Wording & .029 & -.023 & .051 & -.031 & $.139^{*}$ & -.048 & .105 & .079 & -.104 & .055 \\
\hline $\begin{array}{l}10 . \text { Worry of } \\
\text { Reoccurrence }\end{array}$ & $.128^{*}$ & -.080 & $.238^{* *}$ & $-.171^{* *}$ & -.026 & $-.283^{* *}$ & $.248^{* *}$ & $.168^{* *}$ & $-.148^{*}$ & .021 \\
\hline $\begin{array}{l}\text { 11. Voluntary } \\
\text { Recall }\end{array}$ & .108 & -.003 & $.286^{* *}$ & -.100 & -.079 & $-.161^{* *}$ & $.163^{* *}$ & $.183 * *$ & -.099 & .088 \\
\hline $\begin{array}{l}\text { 12. Involuntary } \\
\text { Recall }\end{array}$ & $.178^{* *}$ & -.083 & $.181^{* *}$ & $-.212 * *$ & -.014 & $-.121^{*}$ & $.211 * *$ & $.204 * *$ & $-.162^{* *}$ & -.024 \\
\hline 13. Valence & .043 & $.188^{* *}$ & .037 & .118 & -.073 & .028 & -.013 & $-.209^{* *}$ & .009 & -.088 \\
\hline 14. Perspective & $-.190 * *$ & -.031 & -.079 & .038 & .120 & .104 & -.105 & .024 & $.143^{*}$ & .061 \\
\hline 15. Belief & $-.173 * *$ & .107 & -.041 & -.006 & $.275^{* *}$ & .065 & .003 & -.010 & .061 & .032 \\
\hline
\end{tabular}


Table 4: Means, Standard Deviations, and Correlations (Study 2)

\begin{tabular}{|c|c|c|c|c|c|c|c|c|c|c|}
\hline Variables & $M$ & $S D$ & 1 & 2 & 3 & 4 & 5 & 6 & 7 & 8 \\
\hline 1. Age & 25.11 & 5.69 & - & & & & & & & \\
\hline 2. Gender & 1.83 & 0.38 & .015 & - & & & & & & \\
\hline 3. Education Level & 3.96 & 0.79 & $.330^{* *}$ & -.114 & - & & & & & \\
\hline 4. Salary & 2.86 & 2.01 & $.428^{* *}$ & -.115 & $.164 *$ & - & & & & \\
\hline 5. Tenure & 2.68 & 0.88 & $.270 * *$ & .016 & $.211^{* *}$ & $.431^{* *}$ & - & & & \\
\hline 6. Hours Worked & .238 & 1.18 & $.332 * *$ & -.038 & $.195^{* *}$ & $.331^{* *}$ & $.357^{* *}$ & - & & \\
\hline $\begin{array}{l}\text { 7.Actual Episodic } \\
\text { Memory }\end{array}$ & 3.06 & 0.63 & .104 & $.208^{* *}$ & .092 & $.142 *$ & $.162 *$ & $.134^{*}$ & - & \\
\hline $\begin{array}{l}\text { 8. Imagined Episodic } \\
\text { Memory }\end{array}$ & 3.21 & 0.61 & .114 & .124 & .017 & $.161^{*}$ & .088 & $.154^{*}$ & $.679^{* *}$ & - \\
\hline $\begin{array}{l}\text { 9. Imagined Future } \\
\text { Event }\end{array}$ & 3.26 & 0.71 & .121 & $.143^{*}$ & .042 & $.148^{*}$ & $.145^{*}$ & $.182^{* *}$ & $.668^{* *}$ & $.767^{* *}$ \\
\hline 10. Work Stress & 2.36 & 0.62 & -.043 & -.043 & -.079 & .034 & .048 & .023 & $-.178^{* *}$ & $-.175^{*}$ \\
\hline 11. Positive Affect & 3.35 & 0.96 & -.015 & .049 & .069 & -.023 & .079 & .027 & $.243^{* *}$ & $.278^{* *}$ \\
\hline 12. Negative Affect & 2.16 & 0.85 & $-.184^{* *}$ & .017 & -.011 & -.054 & -.013 & .089 & .121 & $.164^{*}$ \\
\hline $\begin{array}{l}\text { 13. Job-Affective } \\
\text { Wellbeing }\end{array}$ & 3.34 & 0.73 & .053 & .075 & .016 & -.042 & -.008 & -.083 & $.174^{* *}$ & $.222 * *$ \\
\hline $\begin{array}{l}\text { 14. Emotional } \\
\text { Intelligence }\end{array}$ & 3.85 & 0.50 & .080 & $.186^{* *}$ & .052 & .089 & $.147^{*}$ & .004 & .031 & .092 \\
\hline $\begin{array}{l}\text { 15. Core Self- } \\
\text { Evaluations }\end{array}$ & 3.52 & 0.61 & .081 & .124 & .057 & .104 & $.244^{* *}$ & .025 & .076 & .120 \\
\hline 16. Social Anxiety & 2.45 & 0.86 & $-.194 * *$ & -.016 & -.101 & $-.142^{*}$ & $-.199 * *$ & -.081 & -.002 & -.003 \\
\hline 17. Depression & 29.19 & 7.91 & -.002 & -.051 & -.041 & -.064 & -.068 & .059 & -.100 & $-.152 *$ \\
\hline 18. Job Satisfaction & 3.86 & 0.59 & -.028 & .054 & .031 & -.044 & -.128 & -.097 & .057 & .116 \\
\hline 19. Job Motivation & 4.63 & 1.04 & .122 & .005 & $.210^{* *}$ & .111 & .049 & .001 & .080 & .000 \\
\hline
\end{tabular}


Table 4, Continued

\begin{tabular}{|c|c|c|c|c|c|c|c|c|c|c|}
\hline Variables & 9 & 10 & 11 & 12 & 13 & 14 & 15 & 16 & 17 & 18 \\
\hline \multicolumn{11}{|l|}{ 1. Age } \\
\hline \multicolumn{11}{|l|}{ 2. Gender } \\
\hline \multicolumn{11}{|l|}{$\begin{array}{l}\text { 3. Education } \\
\text { Level }\end{array}$} \\
\hline \multicolumn{11}{|l|}{ 4. Salary } \\
\hline \multicolumn{11}{|l|}{ 5. Tenure } \\
\hline \multicolumn{11}{|l|}{ 6. Hours Worked } \\
\hline \multicolumn{11}{|l|}{$\begin{array}{l}\text { 7. Actual } \\
\text { Episodic Memory }\end{array}$} \\
\hline \multicolumn{11}{|l|}{$\begin{array}{l}\text { 8. Imagined } \\
\text { Episodic Memory }\end{array}$} \\
\hline $\begin{array}{l}\text { 9. Imagined } \\
\text { Future Event }\end{array}$ & - & & & & & & & & & \\
\hline 10. Work Stress & $-.189 * *$ & - & & & & & & & & \\
\hline $\begin{array}{l}\text { 11. Positive } \\
\text { Affect }\end{array}$ & $.233^{* *}$ & $-.457 * *$ & - & & & & & & & \\
\hline $\begin{array}{l}\text { 12. Negative } \\
\text { Affect }\end{array}$ & $.169^{*}$ & $.300^{* *}$ & -.078 & - & & & & & & \\
\hline $\begin{array}{l}\text { 13. Job-Affective } \\
\text { Wellbeing }\end{array}$ & $.138^{*}$ & $-.698^{* *}$ & $.604 * *$ & $-.397 * *$ & - & & & & & \\
\hline $\begin{array}{l}\text { 14. Emotional } \\
\text { Intelligence }\end{array}$ & $.153^{*}$ & $-.435^{* *}$ & $.382 * *$ & $-.192^{* *}$ & $.314 * *$ & - & & & & \\
\hline $\begin{array}{l}\text { 15. Core Self- } \\
\text { Evaluations }\end{array}$ & .116 & $-.450^{* *}$ & $.469^{* *}$ & $-.378^{* *}$ & $.434 * *$ & $.541 * *$ & - & & & \\
\hline $\begin{array}{l}\text { 16. Social } \\
\text { Anxiety }\end{array}$ & -.044 & $.294 * *$ & $-.258 * *$ & $.325^{* *}$ & $-.354 * *$ & $-.372 * *$ & $-.488^{* *}$ & - & & \\
\hline 17. Depression & -.052 & $.296^{* *}$ & $-.391 * *$ & $.346^{* *}$ & $-.413 * *$ & $-.241 * *$ & $-.528 * *$ & $.353 * *$ & - & \\
\hline $\begin{array}{l}\text { 18. Job } \\
\text { Satisfaction }\end{array}$ & .038 & $-.726^{* *}$ & $.415^{* *}$ & $-.338 * *$ & $.703 * *$ & $.360^{* *}$ & $.454 * *$ & $-.304 * *$ & $-.304^{* *}$ & - \\
\hline $\begin{array}{l}\text { 19. Job } \\
\text { Motivation }\end{array}$ & .004 & $-.393^{* *}$ & $.246^{* *}$ & $-.276^{* *}$ & $.435^{* *}$ & $.344 * *$ & $.342 * *$ & $-.363^{* *}$ & $-.144^{* *}$ & $.486^{* *}$ \\
\hline
\end{tabular}


Table 5: Correlations - Memory Phenomenology \& Individual Variables

\begin{tabular}{|c|c|c|c|c|c|c|c|c|c|}
\hline Variables & $M$ & $S D$ & 1 & 2 & 3 & 4 & 5 & 6 & 7 \\
\hline 1. Vividness & 3.27 & 0.84 & - & & & & & & \\
\hline 2. Emotions & 4.79 & 1.24 & $.422 * *$ & - & & & & & \\
\hline 3. Intensity & 2.68 & 0.92 & $.413^{* *}$ & $.238^{* *}$ & - & & & & \\
\hline 4. Importance & 3.02 & 0.96 & $.452 * *$ & $.442 * *$ & $.415^{* *}$ & - & & & \\
\hline 5. Frequency & 2.08 & 0.89 & $.259 * *$ & $.194 * *$ & $.358 * *$ & $.544 * *$ & - & & \\
\hline 6. Ease & 3.19 & 1.26 & $-.304 * *$ & -.123 & -.047 & $-.156^{*}$ & -.039 & - & \\
\hline 7. Work Stress & 2.36 & 0.61 & $-.191 * *$ & $-.379 * *$ & -.072 & $-.172 *$ & .037 & $.185^{* *}$ & - \\
\hline 8. Positive Affect & 3.35 & 0.96 & $.298 * *$ & $.310^{* *}$ & $.212 * *$ & $.202 * *$ & $.211 * *$ & $-.156^{* *}$ & $-.457 * *$ \\
\hline 9. Negative Affect & 2.16 & 0.85 & -.019 & -.024 & .083 & .106 & $.358 * *$ & .090 & $.300 * *$ \\
\hline $\begin{array}{l}\text { 10. Job-Affective } \\
\text { Wellbeing }\end{array}$ & 3.34 & 0.73 & $.216^{* *}$ & $.364 * *$ & $.137 *$ & $.220 * *$ & .045 & $-.196 * *$ & $-.698 * *$ \\
\hline $\begin{array}{l}\text { 11. Emotional } \\
\text { Intelligence }\end{array}$ & 3.85 & 0.50 & $.239 * *$ & $.280 * *$ & .094 & .130 & -.017 & $-.291 * *$ & $-.435 * *$ \\
\hline $\begin{array}{l}\text { 12. Core Self- } \\
\text { Evaluations }\end{array}$ & 3.52 & 0.61 & $.247 * *$ & $.231 * *$ & .085 & .094 & -.056 & -.111 & $-.450 * *$ \\
\hline 13. Social Anxiety & 2.45 & 0.86 & $-.213^{* *}$ & $-.171 *$ & .040 & -.062 & $.141^{*}$ & $.139 *$ & $.294 * *$ \\
\hline 14. Depression & 29.20 & 7.91 & -.109 & $-.193 * *$ & -.049 & -.057 & .025 & -.033 & $.296 * *$ \\
\hline 15. Job Satisfaction & 3.86 & 0.59 & $.159^{*}$ & $.229^{* *}$ & .052 & $.196 * *$ & -.066 & $-.175^{* *}$ & $-.726^{* *}$ \\
\hline 16. Job Motivation & 4.63 & 1.04 & $.140^{*}$ & $.158^{*}$ & .019 & .059 & -.045 & $-.157 * *$ & $-.393 * *$ \\
\hline
\end{tabular}


Table 5, Continued

\begin{tabular}{|c|c|c|c|c|c|c|c|c|}
\hline Variables & 8 & 9 & 10 & 11 & 12 & 13 & 14 & 15 \\
\hline \multicolumn{9}{|l|}{ 1. Vividness } \\
\hline \multicolumn{9}{|l|}{ 2. Emotions } \\
\hline \multicolumn{9}{|l|}{ 3. Importance } \\
\hline \multicolumn{9}{|l|}{ 4. Intensity } \\
\hline \multicolumn{9}{|l|}{ 5. Frequency } \\
\hline \multicolumn{9}{|l|}{ 6. Ease } \\
\hline \multicolumn{9}{|l|}{ 7. Work Stress } \\
\hline 8. Positive Affect & - & & & & & & & \\
\hline 9. Negative Affect & -.078 & - & & & & & & \\
\hline $\begin{array}{l}\text { 10. Job-Affective } \\
\text { Wellbeing }\end{array}$ & $.604^{* *}$ & $-.397 * *$ & - & & & & & \\
\hline $\begin{array}{l}\text { 11. Emotional } \\
\text { Intelligence }\end{array}$ & $.382^{* *}$ & $-.192 * *$ & $-.314 * *$ & - & & & & \\
\hline $\begin{array}{l}\text { 12. Core Self- } \\
\text { Evaluations }\end{array}$ & $.469^{* *}$ & $-.378^{* *}$ & $.434^{* *}$ & $.541^{* *}$ & - & & & \\
\hline 13. Social Anxiety & $-.258 * *$ & $.325^{* *}$ & $-.354 * *$ & $-.372 * *$ & $-.488^{* *}$ & - & & \\
\hline 14. Depression & $-.391 * *$ & $.346^{* *}$ & $-.413 * *$ & $-.241 * *$ & $-.528^{* *}$ & $.353 * *$ & - & \\
\hline 15. Job Satisfaction & $.415^{* *}$ & $-.338 * *$ & $.703 * *$ & $.360^{* *}$ & $.454 * *$ & $-.304 * *$ & $-.304 * *$ & - \\
\hline 16. Job Motivation & $.246^{* *}$ & $-.276^{* *}$ & $.435^{* *}$ & $.344^{* *}$ & $.342 * *$ & $-.363^{* *}$ & $-.144 * *$ & $.486^{* *}$ \\
\hline
\end{tabular}


Table 6: Mediation of Negative Affect on the Stress-Memory Relationship

\begin{tabular}{|c|c|c|c|c|}
\hline & \multicolumn{2}{|c|}{$\begin{array}{c}\text { Involuntary Memory } \\
\text { Recall }\end{array}$} & \multicolumn{2}{|c|}{$\begin{array}{l}\text { Recurrent Involuntary } \\
\text { Memory Recall }\end{array}$} \\
\hline & $\begin{array}{c}\text { Step } 1 \\
\beta\end{array}$ & $\begin{array}{c}\text { Step } 2 \\
\beta\end{array}$ & $\begin{array}{c}\text { Step } 1 \\
\beta\end{array}$ & $\begin{array}{c}\text { Step 2 } \\
\beta\end{array}$ \\
\hline Work Stress & $.37 * *$ & .12 & $.47 * *$ & $.26 * *$ \\
\hline Negative Affect & -- & $.47^{* *}$ & -- & $.81^{* *}$ \\
\hline $\mathrm{R}^{2}$ & $26 * *$ & .52 & $.34 * *$ & .51 \\
\hline$\Delta \mathrm{R}^{2}$ & $.07 * *$ & .27 & $.11^{* *}$ & .26 \\
\hline
\end{tabular}


Table 7: Mediation of Positive Affect on the Stress-Memory Relationship

\begin{tabular}{|c|c|c|c|c|c|c|}
\hline & \multicolumn{2}{|c|}{$\begin{array}{l}\text { Actual Past } \\
\text { Memories }\end{array}$} & \multicolumn{2}{|c|}{$\begin{array}{l}\text { Imagined Past } \\
\text { Memories }\end{array}$} & \multicolumn{2}{|c|}{$\begin{array}{c}\text { Imaginary Future } \\
\text { Memories }\end{array}$} \\
\hline & $\begin{array}{c}\text { Step } 1 \\
\beta\end{array}$ & $\begin{array}{c}\text { Step } 2 \\
\beta\end{array}$ & $\begin{array}{c}\text { Step } 1 \\
\beta\end{array}$ & $\begin{array}{c}\text { Step } 2 \\
\beta\end{array}$ & $\begin{array}{c}\text { Step } 1 \\
\beta\end{array}$ & $\begin{array}{c}\text { Step } 2 \\
\beta\end{array}$ \\
\hline Work Stress & $-.08 * *$ & .05 & $-.17 * *$ & -.04 & $-.17 * *$ & -.06 \\
\hline Positive Affect & -- & $.17 * *$ & -- & $.16^{* *}$ & -- & $.15^{* *}$ \\
\hline $\mathrm{R}^{2}$ & $.08 * *$ & .25 & $.03 * *$ & .08 & $.02 * *$ & .06 \\
\hline$\Delta \mathrm{R}^{2}$ & $.01 * *$ & .06 & $.02 * *$ & .07 & $.01 * *$ & .05 \\
\hline
\end{tabular}


Table 8: Mediation of JAWS on the Stress-Memory Relationship

\begin{tabular}{|c|c|c|c|c|}
\hline & \multicolumn{2}{|c|}{ Actual Past Memories } & \multicolumn{2}{|c|}{ Imagined Past Memories } \\
\hline & $\begin{array}{c}\text { Step } 1 \\
\beta\end{array}$ & $\begin{array}{c}\text { Step } 2 \\
\beta\end{array}$ & $\begin{array}{c}\text { Step } 1 \\
\beta\end{array}$ & $\begin{array}{c}\text { Step } 2 \\
\beta\end{array}$ \\
\hline Work Stress & $-.08 * *$ & .09 & $-.17 * *$ & -.04 \\
\hline Positive Affect & -- & $.20 *$ & -- & $.16^{* *}$ \\
\hline $\mathrm{R}^{2}$ & $.01 * *$ & .034 & $.03 * *$ & .05 \\
\hline$\Delta \mathrm{R}^{2}$ & $.00 * *$ & .025 & $.03 * *$ & .04 \\
\hline
\end{tabular}


Table 9: Mediation of Emotional Intelligence on the Stress-Memory Relationship

\begin{tabular}{ccc} 
& \multicolumn{2}{c}{ Actual Past Memories } \\
\cline { 2 - 3 } & $\begin{array}{c}\text { Step 1 } \\
\beta\end{array}$ & $\begin{array}{c}\text { Step 2 } \\
\beta\end{array}$ \\
\cline { 2 - 3 } & & \\
Work Stress & $-.17^{* *}$ & -.11 \\
Emotional Intelligence & -- & $.16^{*}$ \\
\hline $\mathrm{R}^{2}$ & $.02^{* *}$ & .04 \\
\hline$\Delta \mathrm{R}^{2}$ & $.02^{* *}$ & .04 \\
\hline \multicolumn{2}{c}{${ }^{2}=p<.05, * *=p<.01$} &
\end{tabular}


Table 10: The Moderating Role of Memory on the Work Stress-Motivation Relationship

\begin{tabular}{|c|c|c|c|c|c|}
\hline Direct effects & Coefficient & $S E$ & $t$ & $P$ & Model $\mathrm{R}^{2}$ \\
\hline \multicolumn{6}{|c|}{ Voluntary Recall as DV } \\
\hline Constant & 3.19 & 1.13 & 2.80 & 0.005 & \\
\hline Motivation & 0.48 & 0.47 & 1.03 & 0.306 & \\
\hline Work Stress & 0.57 & 0.23 & 2.46 & 0.015 & \\
\hline $\begin{array}{l}\text { Voluntary Me } \\
\text { Stress }\end{array}$ & -0.22 & 0.10 & -2.24 & 0.026 & $.12 * * *$ \\
\hline \multicolumn{6}{|c|}{ Involuntary Recall as DV } \\
\hline Constant & 4.79 & 0.80 & 6.00 & 0.000 & \\
\hline Motivation & 0.08 & 0.35 & 0.23 & 0.820 & \\
\hline Work Stress & 0.42 & 0.32 & 1.32 & 0.189 & \\
\hline $\begin{array}{l}\text { Inoluntary M } \\
\text { Stress }\end{array}$ & -0.23 & 0.14 & -1.77 & 0.078 & $.12 * * *$ \\
\hline \multicolumn{6}{|c|}{$\begin{array}{l}\text { Recurrent Involuntary Recall as } \\
\text { DV }\end{array}$} \\
\hline Constant & 4.46 & 0.75 & 5.95 & 0.000 & \\
\hline Motivation & 0.17 & 0.32 & 0.53 & 0.599 & \\
\hline Work Stress & 0.62 & 0.33 & 1.88 & 0.061 & \\
\hline $\begin{array}{l}\text { Recurrent Ino } \\
\text { * Work Stress }\end{array}$ & 0.30 & 0.13 & -2.24 & 0.026 & $.12 * * *$ \\
\hline
\end{tabular}


Table 11: Means \& Frequencies, Averages Across Groups

\begin{tabular}{|c|c|c|c|c|}
\hline Measure & $\begin{array}{c}\text { Actual } \\
\text { past } \\
\text { events }\end{array}$ & $\begin{array}{c}\text { Imagined } \\
\text { past } \\
\text { events }\end{array}$ & $\begin{array}{c}\text { Imaginary } \\
\text { future } \\
\text { events }\end{array}$ & $\begin{array}{l}\text { Frequency } \\
\text { trend }\end{array}$ \\
\hline Valence & .20 & .39 & 1.90 & \\
\hline Intensity & 2.43 & 2.86 & 2.83 & \\
\hline Clients/customers & $28.0 \%$ & $10.6 \%$ & $6.2 \%$ & Decrease \\
\hline Coworkers & $14.4 \%$ & $6.3 \%$ & $4.6 \%$ & Decrease \\
\hline Boss/superior & $19.5 \%$ & $9.8 \%$ & $6.8 \%$ & Decrease \\
\hline Praise/promotion & $27.1 \%$ & $28.7 \%$ & $36.4 \%$ & Increase \\
\hline Write-up/firing & $9.0 \%$ & $15.3 \%$ & $14.7 \%$ & Increase/stable \\
\hline Fight, injury, yelling & $15.0 \%$ & $12.0 \%$ & $2.8 \%$ & Decrease \\
\hline $\begin{array}{l}\text { Non-work episodic } \\
\text { events }\end{array}$ & $8.0 \%$ & $5.7 \%$ & $1.7 \%$ & Decrease \\
\hline
\end{tabular}


Table 12: Means \& Frequencies, Actual Past Events

\begin{tabular}{|c|c|c|c|c|}
\hline Measure & $\begin{array}{c}\text { One } \\
\text { month in } \\
\text { the past }\end{array}$ & $\begin{array}{c}\text { One } \\
\text { year in } \\
\text { the past }\end{array}$ & $\begin{array}{l}5+\text { years in } \\
\text { the past }\end{array}$ & Average \\
\hline Valence & -.07 & .40 & .27 & .20 \\
\hline Intensity & 1.99 & 2.50 & 2.79 & 2.43 \\
\hline Clients/customers & $38.4 \%$ & $26.4 \%$ & $19.3 \%$ & $28.0 \%$ \\
\hline Coworkers & $21.8 \%$ & $9.6 \%$ & $11.7 \%$ & $14.4 \%$ \\
\hline Boss/superior & $28.4 \%$ & $18.3 \%$ & $11.7 \%$ & $19.5 \%$ \\
\hline Praise/promotion & $21.3 \%$ & $30.3 \%$ & $29.7 \%$ & $27.1 \%$ \\
\hline Write-up/firing & $6.6 \%$ & $7.2 \%$ & $13.1 \%$ & $9.0 \%$ \\
\hline $\begin{array}{l}\text { Fight, injury, } \\
\text { yelling }\end{array}$ & $17.1 \%$ & $13.5 \%$ & $14.5 \%$ & $15.0 \%$ \\
\hline $\begin{array}{l}\text { Non-work episodic } \\
\text { events }\end{array}$ & $12.0 \%$ & $7.0 \%$ & $4.9 \%$ & $8.0 \%$ \\
\hline
\end{tabular}

** Intensity was measured on a scale of 0 to 5 
Table 13: Means \& Frequencies, Imagined Past Events

\begin{tabular}{|c|c|c|c|c|}
\hline Measure & $\begin{array}{c}\text { One } \\
\text { month in } \\
\text { the past }\end{array}$ & $\begin{array}{c}\text { One } \\
\text { year in } \\
\text { the past }\end{array}$ & $\begin{array}{l}5+\text { years in } \\
\text { the past }\end{array}$ & Average \\
\hline Valence & .07 & .42 & .69 & .39 \\
\hline Intensity & 2.92 & 2.81 & 2.84 & 2.86 \\
\hline Clients/customers & $11.5 \%$ & $10.4 \%$ & $9.8 \%$ & $10.6 \%$ \\
\hline Coworkers & $6.7 \%$ & $8.9 \%$ & $3.3 \%$ & $6.3 \%$ \\
\hline Boss/superior & $14.4 \%$ & $8.4 \%$ & $6.5 \%$ & $9.8 \%$ \\
\hline Praise/promotion & $26.4 \%$ & $29.7 \%$ & $30.1 \%$ & $28.7 \%$ \\
\hline Write-up/firing & $15.9 \%$ & $14.4 \%$ & $15.7 \%$ & $15.3 \%$ \\
\hline Fight, injury, yelling & $16.3 \%$ & $12.4 \%$ & $7.2 \%$ & $12.0 \%$ \\
\hline $\begin{array}{l}\text { Non-work episodic } \\
\text { events }\end{array}$ & $8.0 \%$ & $5.0 \%$ & $4.0 \%$ & $5.7 \%$ \\
\hline
\end{tabular}

$* *$ Valence was measured on a scale of -5 to +5

**Intensity was measured on a scale of 0 to 5 
Table 14: Means \& Frequencies, Imaginary Future Events

\begin{tabular}{lcccc}
\hline \multicolumn{1}{c}{ Measure } & $\begin{array}{c}\text { One } \\
\text { month in } \\
\text { the future }\end{array}$ & $\begin{array}{c}\text { One year } \\
\text { in the } \\
\text { future }\end{array}$ & $\begin{array}{c}\text { 5+ years } \\
\text { in the } \\
\text { future }\end{array}$ & Average \\
\hline Valence & 1.71 & 1.81 & 2.19 & 1.90 \\
\hline Intensity & 2.72 & 2.68 & 3.10 & 2.83 \\
\hline Clients/customers & $13.6 \%$ & $2.4 \%$ & $2.5 \%$ & $6.2 \%$ \\
\hline Coworkers & $8.9 \%$ & $3.3 \%$ & $0.1 \%$ & $4.6 \%$ \\
\hline Boss/superior & $9.2 \%$ & $7.7 \%$ & $3.5 \%$ & $6.8 \%$ \\
\hline Praise/promotion & $34.5 \%$ & $40.2 \%$ & $34.5 \%$ & $36.4 \%$ \\
\hline Write-up/firing & $10.2 \%$ & $14.8 \%$ & $19.0 \%$ & $14.7 \%$ \\
\hline Fight, injury, yelling & $4.4 \%$ & $2.9 \%$ & $1.0 \%$ & $2.8 \%$ \\
\hline $\begin{array}{l}\text { Non-work episodic } \\
\text { events }\end{array}$ & $3.0 \%$ & $1.0 \%$ & $1.0 \%$ & $1.7 \%$ \\
\hline
\end{tabular}

$* *$ Valence was measured on a scale of -5 to +5

**Intensity was measured on a scale of 0 to 5 
Table 15: Correlations - Actual Past Events Qualitative Data

\begin{tabular}{lccccccc}
\hline Variables & 1 & 2 & 3 & 4 & 5 & 6 & 7 \\
\hline 1. Valence & - & & & & & \\
2. Intensity & $-.495^{* *}$ & - & & & & \\
3. Clients/customers & $-.290^{* *}$ & $.159^{*}$ & - & & & \\
4. Coworkers & -.065 & .136 & -.147 & - & & & \\
5. Boss/superior & $-.210^{*}$ & $.349^{* *}$ & -.043 & .083 & - & & \\
6. Praise/promotion & $.663^{* *}$ & $-.183^{*}$ & -.047 & -.054 & .029 & - & \\
7. Write-up/firing & $-.291^{* *}$ & $.161^{*}$ & $-.331^{* *}$ & $.176^{*}$ & .109 & -.071 & - \\
8. Fighting, yelling, & $-.550^{* *}$ & $.490^{* *}$ & $.342^{* *}$ & $.155^{*}$ & $.224^{* *}$ & $-.313^{* *}$ & -.007 \\
injury & & & & & & & \\
& & & & & & & \\
\hline
\end{tabular}

$M=$ mean; $S D=$ standard deviation; ${ }^{*} p<.05, * * p<.01$ 
Table 16: Correlations - Imagined Past Events Qualitative Data

\begin{tabular}{|c|c|c|c|c|c|c|c|}
\hline Variables & 1 & 2 & 3 & 4 & 5 & 6 & 7 \\
\hline 1. Valence & - & & & & & & \\
\hline 2. Intensity & $-.733 * *$ & - & & & & & \\
\hline 3. Clients/customers & $-.285 * *$ & $.202 *$ & - & & & & \\
\hline 4. Coworkers & -.090 & .067 & .092 & - & & & \\
\hline 5. Boss/superior & -.015 & .067 & -.113 & .039 & - & & \\
\hline 6. Praise/promotion & $.623 * *$ & $-.459 * *$ & $-.293 * *$ & -.042 & -.082 & - & \\
\hline 7. Write-up/firing & $-.410 * *$ & $.343 * *$ & -.090 & .000 & $.210^{*}$ & $-.323 * *$ & - \\
\hline 8. Fighting, yelling, injury & $-.509 * *$ & $.546 * *$ & $.346^{* *}$ & .069 & .124 & $-.354 * *$ & -.036 \\
\hline
\end{tabular}

$M=$ mean; $S D=$ standard deviation; $* p<.05, * * p<.01$ 
Table 17: Correlations - Imaginary Future Events Qualitative Data

\begin{tabular}{|c|c|c|c|c|c|c|c|}
\hline Variables & 1 & 2 & 3 & 4 & 5 & 6 & 7 \\
\hline 1. Valence & - & & & & & & \\
\hline 2. Intensity & $-.444 * *$ & - & & & & & \\
\hline 3. Clients/customers & $-.176^{*}$ & $.196 * *$ & - & & & & \\
\hline 4. Coworkers & $-.143 *$ & .076 & -.090 & - & & & \\
\hline 5. Boss/superior & -.120 & $.310 * *$ & -.026 & $.249 * *$ & - & & \\
\hline 6. Praise/promotion & $.548 * *$ & $-.144 *$ & $-.181 * *$ & $-.151 *$ & -.092 & - & \\
\hline 7. Write-up/firing & $-.489 * *$ & $.382 * *$ & -.015 & .111 & .113 & $-.147^{*}$ & - \\
\hline 8. Fighting, yelling, injury & $-.515 * *$ & $.342 * *$ & $.299 * *$ & -.009 & .088 & $-.217 * *$ & -.029 \\
\hline
\end{tabular}

$M=$ mean; $S D=$ standard deviation; $* p<.05, * * p<.01$ 


\section{FIGURES}

Figure 1: Proposed Model of Work Stress, Episodic Memory, and Interpersonal Differences

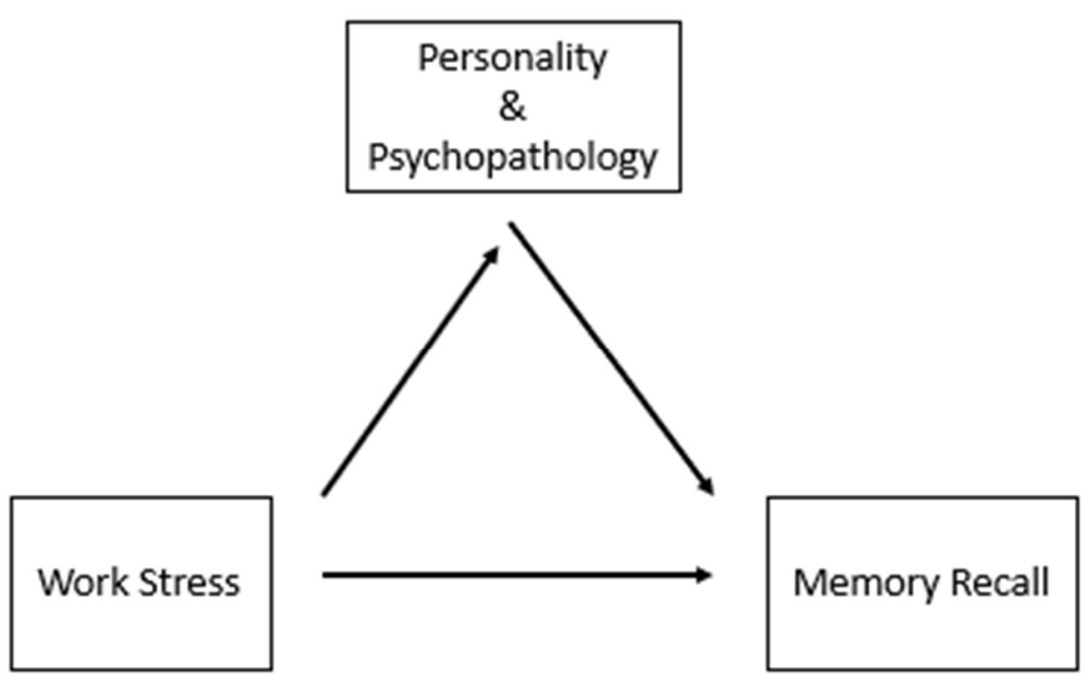


Figure 2: Proposed Model of Work Stress, Episodic Memory, and Job Outcomes

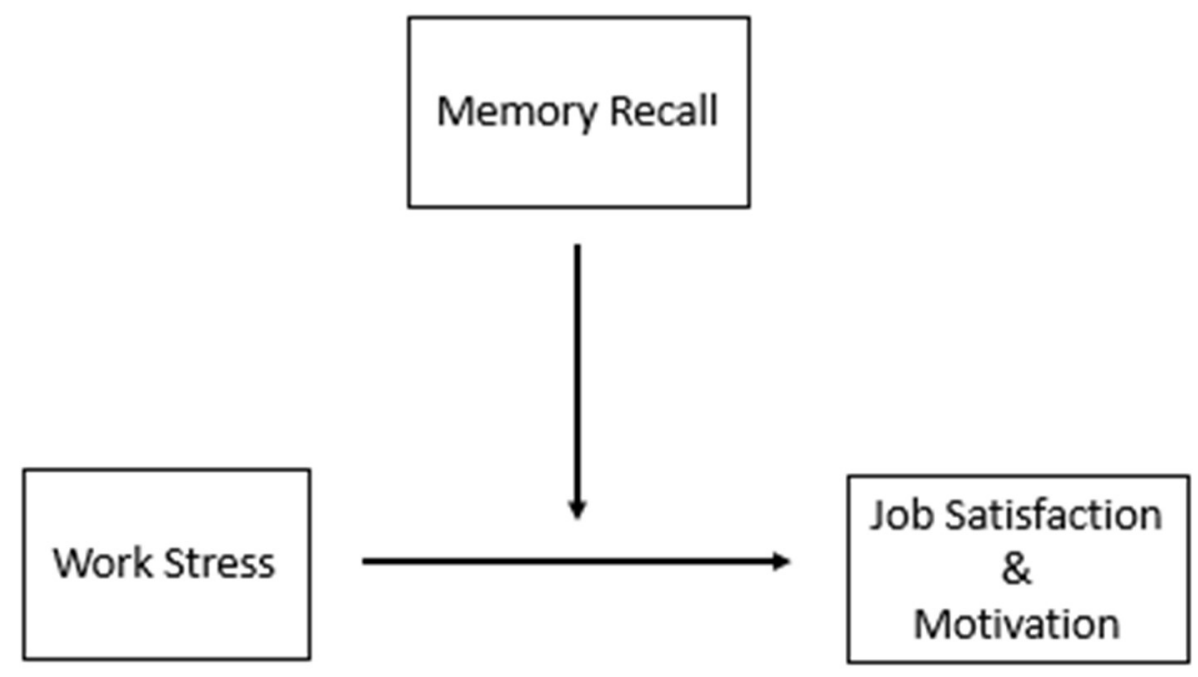


Figure 3: Integrated Model of Memory, Stress, Individual Differences, and Job

Outcomes

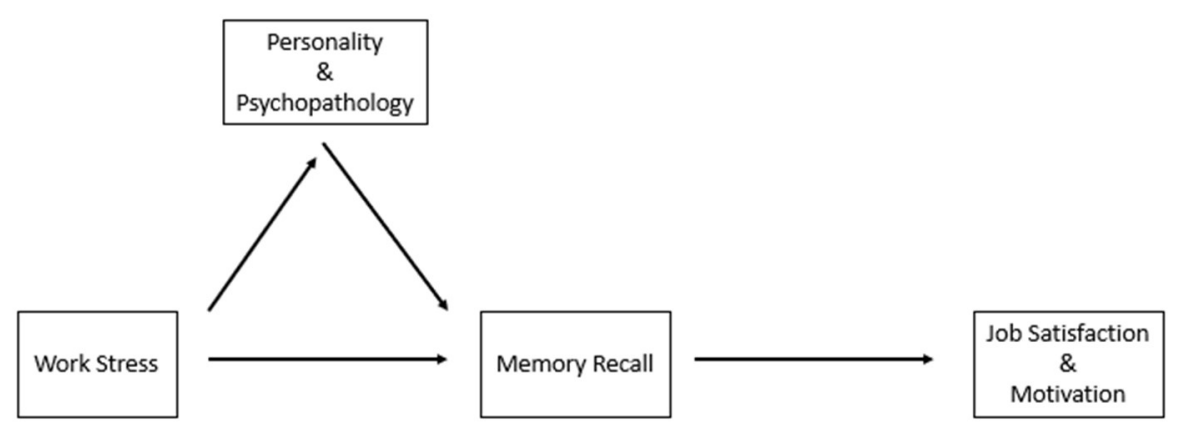


Figure 4: Voluntary Memory Recall as a Moderator of Work Stress \& Motivation at

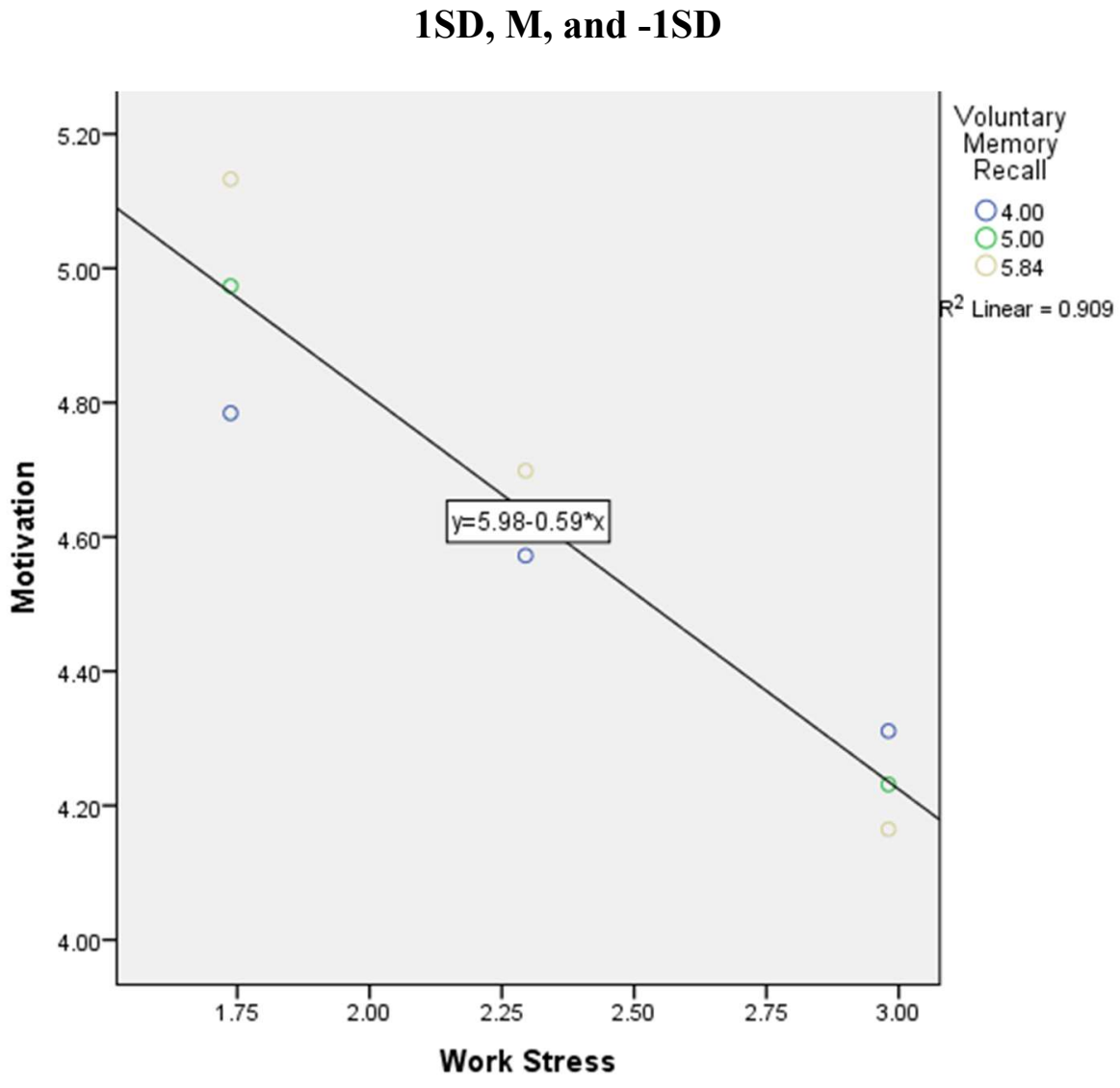


Figure 5: Involuntary Memory Recall as a Moderator of Work Stress \& Motivation at 1SD, $M$, and -1SD

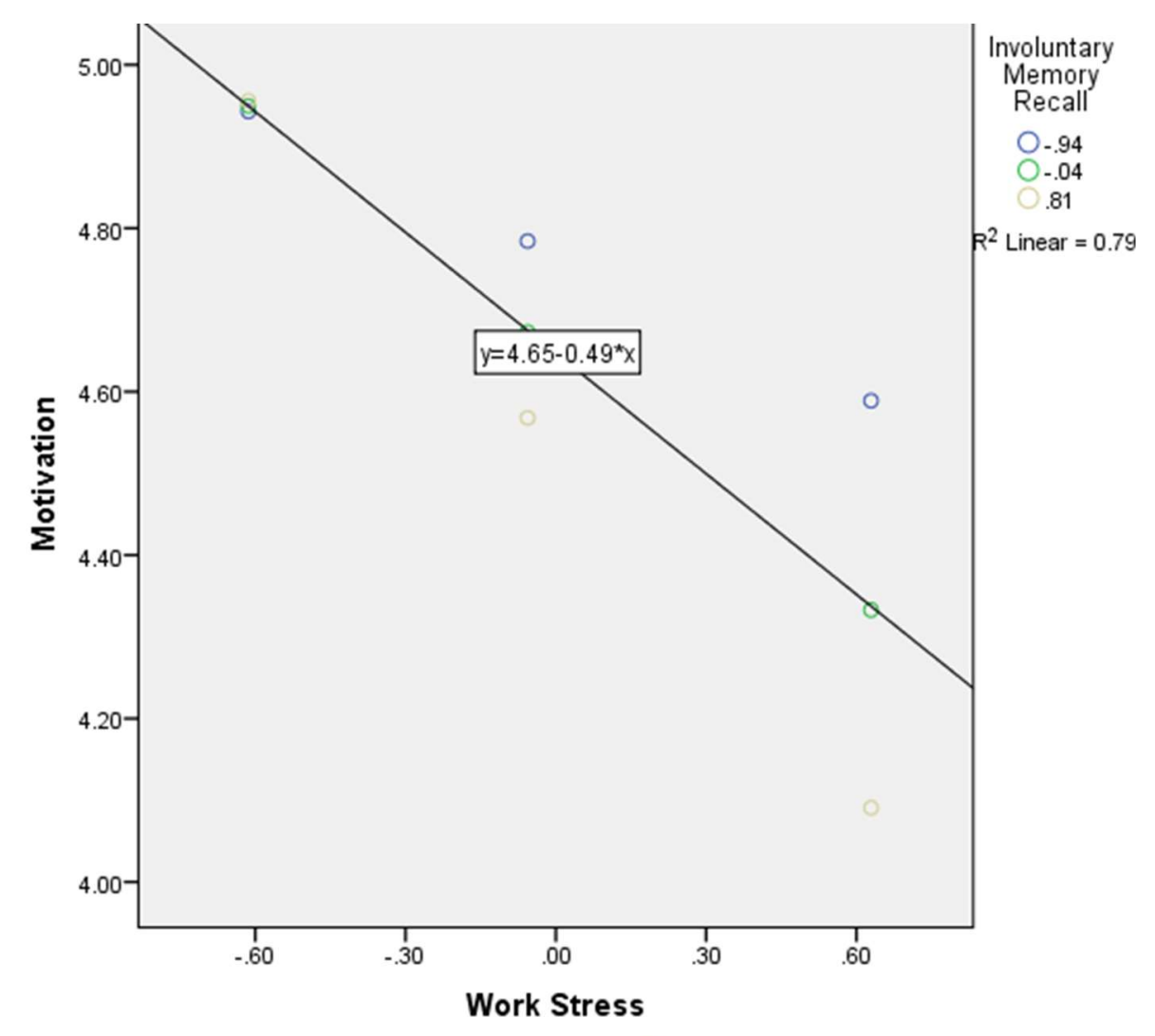


Figure 6: Recurrent Involuntary Memory Recall as a Moderator of Work Stress \&

Motivation at 1SD, $M$, and -1SD

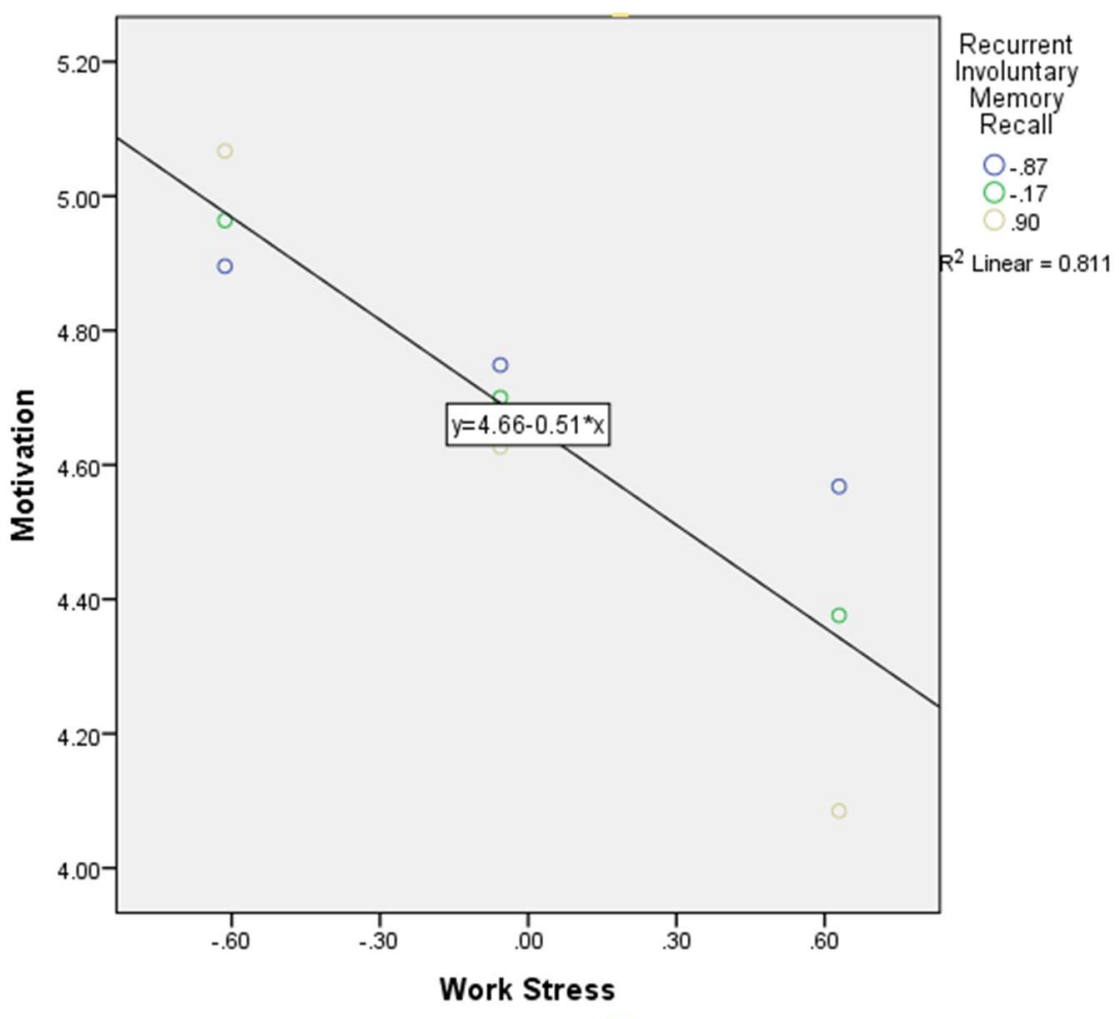


Figure 7: Frequencies of Exploratory Analyses Variables (Study 2)

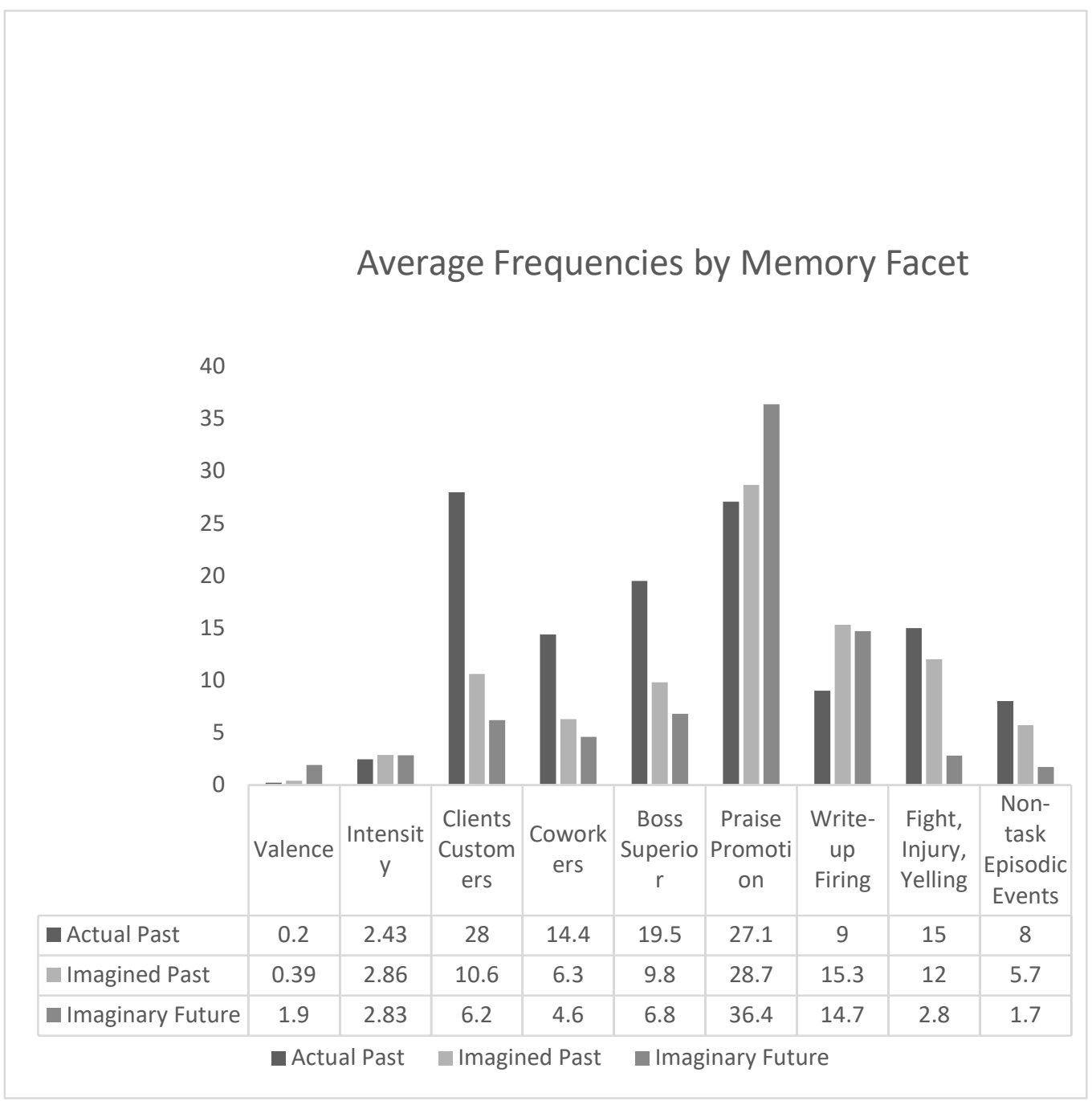




\section{APPENDICES}

\section{Appendix A: Experimental Consent Form (Study 1)}

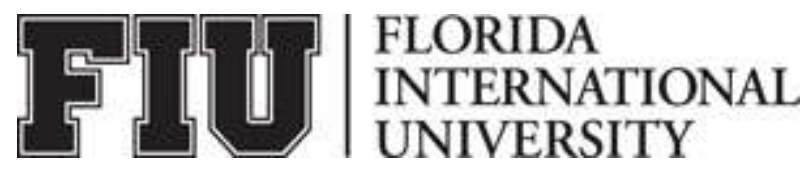

\section{ADULT ONLINE CONSENT TO PARTICIPATE IN A RESEARCH STUDY \\ Employee Differences in the Perception of Supervision}

\section{PURPOSE OF THE STUDY}

You are being asked to be in a research study. The purpose of this study is to look at individual differences amongst employees and whether or not these differences are linked to the way you remember events in your workplace.

\section{NUMBER OF STUDY PARTICIPANTS}

If you decide to be in this study, you will be one of 500 people in this research study.

\section{DURATION OF THE STUDY}

Your participation will require one hour.

\section{PROCEDURES}

If you agree to be in the study, we will ask you to do the following things:

1. Answer questions about individual difference traits

2. Answer questions related to memory

\section{RISKS AND/OR DISCOMFORTS}

There are no known risks of this study.

\section{BENEFITS}

There are no known benefits of this study.

\section{CONFIDENTIALITY}

The records of this study will be kept private and will be protected to the fullest extent provided by law. In any sort of report we might publish, we will not include any information that will make it possible to identify a subject. Research records will be stored securely and only the researcher team will have access to the records. Your records may also be reviewed for audit purposes by authorized University or other agents who will be bound by the same provisions of confidentiality. 


\section{RIGHT TO DECLINE OR WITHDRAW}

Your participation in this study is voluntary. You are free to participate in the study or withdraw your consent at any time during the study.

\section{RESEARCHER CONTACT INFORMATION}

If you have any questions about the purpose, procedures, or any other issues relating to this research study you may contact Jennifer Houston at FIU, (305) 479-0238,jhous003@fiu.edu.

\section{IRB CONTACT INFORMATION}

If you would like to talk with someone about your rights of being a subject in this research study or about ethical issues with this research study you may contact the FIU Office of Research Integrity by phone at (305) 348-2494 or by email at ori@fiu.edu.

\section{PARTICIPANT AGREEMENT}

I have read the information in this consent form and agree to participate in this study. I have had a chance to ask any questions I have about this study, and they have been answered for me. By clicking on the "consent to participate" button below I am providing my informed consent.

CONSENT TO PARTICIPATE 


\section{Appendix B: Experimental Consent Form (Study 2)}

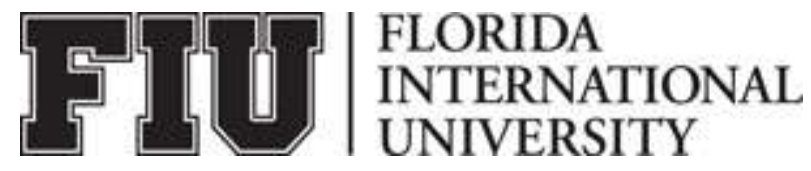

\section{ADULT ONLINE CONSENT TO PARTICIPATE IN A RESEARCH STUDY \\ Employee Differences in the Perception of Supervision}

\section{PURPOSE OF THE STUDY}

You are being asked to be in a research study. The purpose of this study is to look at individual

differences amongst employees and whether or not these differences are linked to the way you remember events in your workplace.

\section{NUMBER OF STUDY PARTICIPANTS}

If you decide to be in this study, you will be one of 100 people in this research study.

\section{DURATION OF THE STUDY}

Your participation will require two hours.

\section{PROCEDURES}

If you agree to be in the study, we will ask you to do the following things:

1. Answer questions about individual difference traits

2. Answer questions about memory

\section{RISKS AND/OR DISCOMFORTS}

There are no known risks of this study.

\section{BENEFITS}

The following benefits may be associated with your participation in this study: Sona Systems Psychology Research Participation credits.

\section{CONFIDENTIALITY}

The records of this study will be kept private and will be protected to the fullest extent provided by law. In any sort of report we might publish, we will not include any information that will make it possible to identify a subject. Research records will be stored securely and only the researcher team will have access to the records. Your records may also be reviewed for audit purposes by authorized University or other agents who will be bound by the same provisions of confidentiality.

\section{RIGHT TO DECLINE OR WITHDRAW}

Your participation in this study is voluntary. You are free to participate in the study or withdraw your consent at any time during the study. 


\section{RESEARCHER CONTACT INFORMATION}

If you have any questions about the purpose, procedures, or any other issues relating to this research study you may contact Jennifer Houston at FIU, (305) 479-0238, jhous003@fiu.edu.

\section{IRB CONTACT INFORMATION}

If you would like to talk with someone about your rights of being a subject in this research study or about ethical issues with this research study you may contact the FIU Office of Research Integrity by phone at (305) 348-2494 or by email at ori@fiu.edu.

\section{PARTICIPANT AGREEMENT}

I have read the information in this consent form and agree to participate in this study. I have had a chance to ask any questions I have about this study, and they have been answered for me. By clicking on the "consent to participate" button below I am providing my informed consent.

CONSENT TO PARTICIPATE 


\section{Appendix C: Autobiographical Memory Questionnaire}

The scale has been modified from its original version to include specific stressful memories of the workplace as opposed to generic episodic memory recall.

Prompt: For the following questions, imagine a stressful event that has happened in your workplace over the past six months.

The following measures will be assessed with a 7-point Likert scale with anchors of $1=$ strongly disagree and $7=$ strongly agree.

1. While remembering the event, I feel as though I am reliving the original event.

2. While remembering the event, I can see it in my mind.

3. While remembering the event, I can smell or taste it in my mind.

4. While remembering the event, I recall the physical surroundings.

5. The memory is vivid.

6. While remembering the event, I feel the particular bodily sensations I felt then.

7. While remembering the event, I feel the particular emotions I felt then.

8. The emotions I have when I recall the episode are intense.

9. When I recall the event, it comes to me in words.

10. When I recall the event, I worry about it happening again.

11. Since it happened, I have deliberately chosen to think back to the event in my mind.

12. Since it happened, this memory has popped into my mind by itself - that is, without me trying to recall it.

The following measure will be assessed with a 7-point Likert scale with anchors of $1=$ extremely negative and $7=$ extremely positive.

13. The emotions I have when I recall the episode are:

The following measure will be assessed with a 7-point Likert scale with anchors of $1=$ my own eyes and $7=$ an observer's eyes.

14. When I recall the event, I primarily see what happened from a perspective as seen through:

The following measure will be assessed with a 7-point Likert scale with anchors of $1=$ $100 \%$ fantasy and $7=100 \%$ reality.

15. I believe that the event really took place the way I remember it, and that I did not imagine or invent anything that took place. 


\section{Appendix D: Involuntary Autobiographical Memory Inventory (IAMI; adapted)}

The scale has been modified from its original version to include specific stressful memories of the workplace as opposed to generic episodic memory recall.

Prompt: The following questions address how frequently past memories and imagined future events come to your mind by themselves (without trying) during a typical workday. Past memories refer to things that have already happened to you, and imagined future events refer to events that you picture happening in your future. Please use the response option that best fits the frequency of your experiences.

The following measure will be assessed with a 5-point Likert scale with anchors of $1=$ never and $5=$ once an hour or more.

1. When I am relaxing or doing routine work, stressful imaginary future events come to my mind by myself - without me consciously trying to evoke them.

2. Memories of stressful work events pop into my mind by themselves - without me consciously trying to remember them.

3. Some locations or places at work bring stressful imaginary future events to mind without me consciously trying to evoke them.

4. After something surprising has happened, I spontaneously remember it; without trying, it just comes to me.

5. Stressful imaginary future events pop into my mind by themselves, without me consciously trying to evoke them.

6. Some emotions, moods or thoughts bring stressful imaginary future events to mind - without me consciously trying to evoke them.

7. When I am bored, stressful imaginary future events come to my mind by themselves - without me consciously trying to evoke them.

8. After I have experienced a stressful event, I spontaneously remember it without consciously trying. It just comes to me.

9. Some emotions, moods, or thoughts bring memories of past stressful events to mind - without me consciously trying to remember them.

10. When I am physically active, for example walking, bicycling, or running, stressful imaginary future events come to my mind by themselves - without me consciously trying to evoke them.

11. Listening to some music or songs brings memories of past stressful events to mind - without me consciously trying to evoke them.

12. After seeing something stressful happen, I spontaneously imagine related events in the future, without consciously trying. It just comes to me.

13. When I am relaxing or doing routine work, memories of past stressful events come to my mind by themselves - without me consciously trying to remember them. 
14. When I am bored, memories of stressful past events come to my mind by themselves - without me consciously trying to remember them.

15. Some sensory experiences, such as certain odors or tastes, bring stressful imaginary future events to mind without me consciously trying to evoke them.

16. After I have experienced something stressful, I spontaneously imagine related events in the future, without consciously trying. It just comes to me.

17. When I am physically example, for example walking, bicycling, or running, memories of past stressful events come to my mind by themselves - without me consciously trying to evoke them.

18. Listening to some music or songs bring stressful imaginary future events to mind - without me consciously trying to evoke them.

19. Some locations or places bring stressful memories of past events to mind without me consciously trying to remember them.

20. Some sensory experiences, such as some odors or tastes, bring memories of stressful past events to mind - without me consciously trying to remember them. 


\section{Appendix E: Recurrent Involuntary Autobiographical Memory Inventory (adapted from IAMI)}

The scale has been modified from its original version to include specific stressful memories of the workplace as opposed to generic episodic memory recall. It has also been adapted to measure recurrent involuntary memories as opposed to singular involuntary memories.

Prompt: The following questions address how whether or not the same past memories and imagined future events come to your mind by themselves (without trying) during a typical workday, in a recurrent way.

The following measure will be assessed with a 5-point Likert scale with anchors of $1=$ never and $5=$ once an hour or more.

1. When I am relaxing or doing routine work, the same memories repeatedly come to my mind by themselves.

2. I experience recurrent memories of stressful work events, and they come to my mind by themselves.

3. There are locations at work that trigger the same imagined future thoughts on more than one occasion without me consciously trying to evoke them.

4. After something surprising has happened, I relive the event frequently without trying.

5. The same stressful imaginary future events pop into my mind by themselves, without me consciously trying to evoke them.

6. Some emotions, moods or thoughts bring recurrent stressful imaginary future events to mind - without me consciously trying to evoke them.

7. When I am bored, the same stressful imaginary future events repeatedly come to my mind by themselves - without me consciously trying to evoke them.

8. After I have experienced a stressful event, I spontaneously remember it more than once without consciously trying. It just comes to me.

9. Some emotions, moods, or thoughts bring repeated memories of past stressful events to mind - without me consciously trying to remember them.

10. When I am physically active, I tend to think about the same stressful imaginary future events without trying to evoke them.

11. Listening to some music or songs causes me to involuntarily relive the same memories of past stressful events.

12. After seeing something stressful happen, I spontaneously imagine the same related events happening in the future; without consciously trying. It just comes to me. 
13. When I am relaxing or doing routine work, recurrent memories of past stressful events come to my mind by themselves - without me consciously trying to remember them.

14. When I am bored, recurrent memories of stressful past events come to my mind by themselves - without me consciously trying to remember them.

15. Some sensory experiences, such as certain odors or tastes, bring recurrent stressful imaginary future events to mind without me consciously trying to evoke them.

16. After I have experienced something stressful, I spontaneously imagine related events in the future, without consciously trying. I have the same events come to mind more than once.

17. When I am physically active, for example walking, bicycling, or running, memories of the same past stressful events come to my mind by themselves without me consciously trying to evoke them.

18. Listening to some music or songs brings the same stressful imaginary future events to mind - without me consciously trying to evoke them.

19. Some locations or places bring repeated stressful memories of past events to mind - without me consciously trying to remember them.

20. Some sensory experiences, such as some odors or tastes, bring recurrent memories of stressful past events to mind - without me consciously trying to remember them. 


\section{Appendix F: Work-Related Stress Questionnaire}

Prompt: Please answer the following questions in regard to your feelings about your work environment. It is important that your responses reflect your work in the last six months.

The following measure will be assessed with a 5-point Likert scale with anchors of $1=$ never and $5=$ always.

1. I am clear what is expected of me at work. *

2. I can decide when to take a break. *

3. Different groups at work demand things from me that are hard to combine.

4. I know how to go about getting my job done. *

5. I am subject to personal harassment in the form of unkind words or behavior.

6. I have unachievable deadlines.

7. If work gets difficult, my colleagues will help me. *

8. I am given supportive feedback on the work I do.*

9. I have to work very intensively.

10. I have a say in my own work speed. *

11. I am clear what my duties and responsibilities are. *

12. I have to neglect some tasks because I have too much to do.

13. I am clear about the goals and objectives for my department. *

14. There is friction or anger between my colleagues.

15. I have a choice in deciding how I do my work. *

16. I am unable to take sufficient breaks.

17. I understand how my work fits into the overall aim of the organization. *

18. I am pressured to work long hours.

19. I have a choice in deciding what I do at work. *

20. I have to work very fast.

21. I am subject to bullying at work.

22. I am aware of others being subject to bullying at work.

23. If I were aware of bullying I would feel able to challenge it. *

24. If I reported bullying, I would be confident that it would be stopped. *

25. I have unrealistic time pressures.

26. I can rely on my line manager to help me out with a work problem. *

The following measure will be assessed with a 5-point Likert scale with anchors of $1=$ strongly disagree and $5=$ strongly agree.

27. I get help and support I need from coworkers. *

28. I have some say over the way I work. *

29. I have sufficient opportunities to question managers about change at work. *

30 . I receive the respect at work I deserve from my colleagues. *

31. Staff are always consulted about change at work. * 
32. I can talk to my line manager about something that has upset or annoyed me about work. *

33. My work time can be flexible. *

34. My working location can be flexible (subject to business constraints). *

35. My colleagues are willing to listen to my work-related problems. *

36. When changes are made at work, I am clear how they will work out in practice. *

37. I am supported through emotionally demanding work. *

38. Relationships at work are strained.

39. My line manager encourages me at work. *

*Items denoted with an asterisk are reverse coded. 


\section{Appendix G: Positive and Negative Affect Schedule (PANAS)}

Prompt: Indicate the extent you have felt this way over the past week:

The following measure will be assessed with a 5-point Likert scale with anchors of $1=$ very slightly or not at all and $5=$ extremely.

1. Interested

2. Distressed

3. Excited

4. Upset

5. Strong

6. Guilty

7. Scared

8. Hostile

9. Enthusiastic

10. Proud

11. Irritable

12. Alert

13. Ashamed

14. Inspired

15. Nervous

16. Determined

17. Attentive

18. Jittery

19. Active

20. Afraid

*Items $1,3,5,9,10,12,14,16,17, \& 19$ are scored to determine positive affect.

*Items $2,4,6,7,8,11,13,15,18, \& 20$ are scored to determine negative affect. 


\section{Appendix H: Job-related Affective Well-being Scale (JAWS)}

Prompt: Below are a number of statements that describe different emotions that a job can make a person feel. Please indicate the amount to which any part of your job (e.g., the work, coworkers, supervisor, clients, pay) has made you feel that emotion in the past 30 days.

\begin{tabular}{|c|c|c|c|c|c|}
\hline $\begin{array}{l}\text { Please check one response for each item that best } \\
\text { indicates how often you've experienced each } \\
\text { emotion at work over the past } 30 \text { days. }\end{array}$ & $\begin{array}{l}\dot{\bar{d}} \\
\bar{d} \\
\bar{z}\end{array}$ & $\begin{array}{l}\frac{\lambda}{0} \\
\stackrel{0}{\vec{c}} \\
\stackrel{4}{4}\end{array}$ & 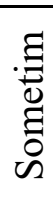 & $\stackrel{\mathscr{\sigma}}{\sigma}$ & 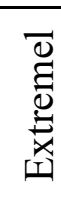 \\
\hline 1. My job made me feel angry.* & & & & & \\
\hline 2. My job made me feel anxious.* & & & & & \\
\hline 3. My job made me feel at ease. & & & & & \\
\hline 4. My job made me feel bored. * & & & & & \\
\hline 5. My job made me feel calm. & & & & & \\
\hline 6. My job made me feel content. & & & & & \\
\hline 7. My job made me feel depressed. * & & & & & \\
\hline 8. My job made me feel discouraged. * & & & & & \\
\hline 9. My job made me feel disgusted. * & & & & & \\
\hline 10. My job made me feel ecstatic. & & & & & \\
\hline 11. My job made me feel energetic. & & & & & \\
\hline 12. My job made me feel enthusiastic. & & & & & \\
\hline 13. My job made me feel excited. & & & & & \\
\hline 14. My job made me feel fatigued. * & & & & & \\
\hline 15. My job made me feel frightened. * & & & & & \\
\hline 16. My job made me feel furious. ${ }^{*}$ & & & & & \\
\hline 17. My job made me feel gloomy. * & & & & & \\
\hline 18. My job made me feel inspired. & & & & & \\
\hline 19. My job made me feel relaxed. & & & & & \\
\hline 20. My job made me feel satisfied. & & & & & \\
\hline
\end{tabular}

*Items denoted with an asterisk are reverse coded. 


\section{Appendix I: Emotional Intelligence}

\section{Prompt: Indicate the extent to which each statement represents you.}

The following measure will be assessed with a 5-point Likert scale with anchors of $1=$ strongly disagree and 5 = strongly agree.

1. I know when to speak about my personal problems to others.

2. When I am faced with obstacles, I remember times I faced similar obstacles and overcame them.

3. I expect that I will do well on most things I try.

4. Other people find it easy to confide in me.

5. I find it hard to understand the nonverbal messages of other people. *

6. Some of the major events of my life have led me to re-evaluate what is important and not important.

7. When my mood changes, I see new possibilities.

8. Emotions are some of the things that make my life worth living.

9. I am aware of my emotions as I experience them.

10. I expect good things to happen.

11. I like to share my emotions with others.

12. When I experience a positive emotion, I know how to make it last.

13. I arrange events others enjoy.

14. I seek out activities that make me happy.

15. I am aware of the nonverbal messages I send to others.

16. I present myself in a way that makes a good impression on others.

17. When I am in a positive mood, solving problems is easy for me.

18. By looking at their facial expressions, I recognize the emotions people are experiencing.

19. I know why my emotions change.

20. When I am in a positive mood, I am able to come up with new ideas.

21. I have control over my emotions.

22. I easily recognize my emotions as I experience them.

23. I motivate myself by imagining a good outcome to tasks I take on.

24. I compliment others when they have done something well.

25. I am aware of the nonverbal messages other people send.

26. When another person tells me about an important event in his or her life, I almost feel as though I have experienced this event myself.

27. When I feel a change in emotions, I tend to come up with new ideas.

28. When I am faced with a challenge, I give up because I believe I will fail. *

29. I know what other people are feeling just by looking at them.

30. I help other people feel better when they are down.

31. I use good moods to help myself keep trying in the face of obstacles.

32. I can tell how people are feeling by listening to the tone of their voice.

33. It is difficult for me to understand why people feel the way they do. *

*Items with an asterisk are reverse coded. 


\section{Appendix J: Core Self-Evaluations Scale}

Prompt: Below are several statements about you which you may agree or disagree with. Using the response scale below, indicate your agreement or disagreement with each item.

The following measure will be assessed with a 5-point Likert scale with anchors of $1=$ strongly disagree and $5=$ strongly agree.

The core self-evaluations scale (CSES)

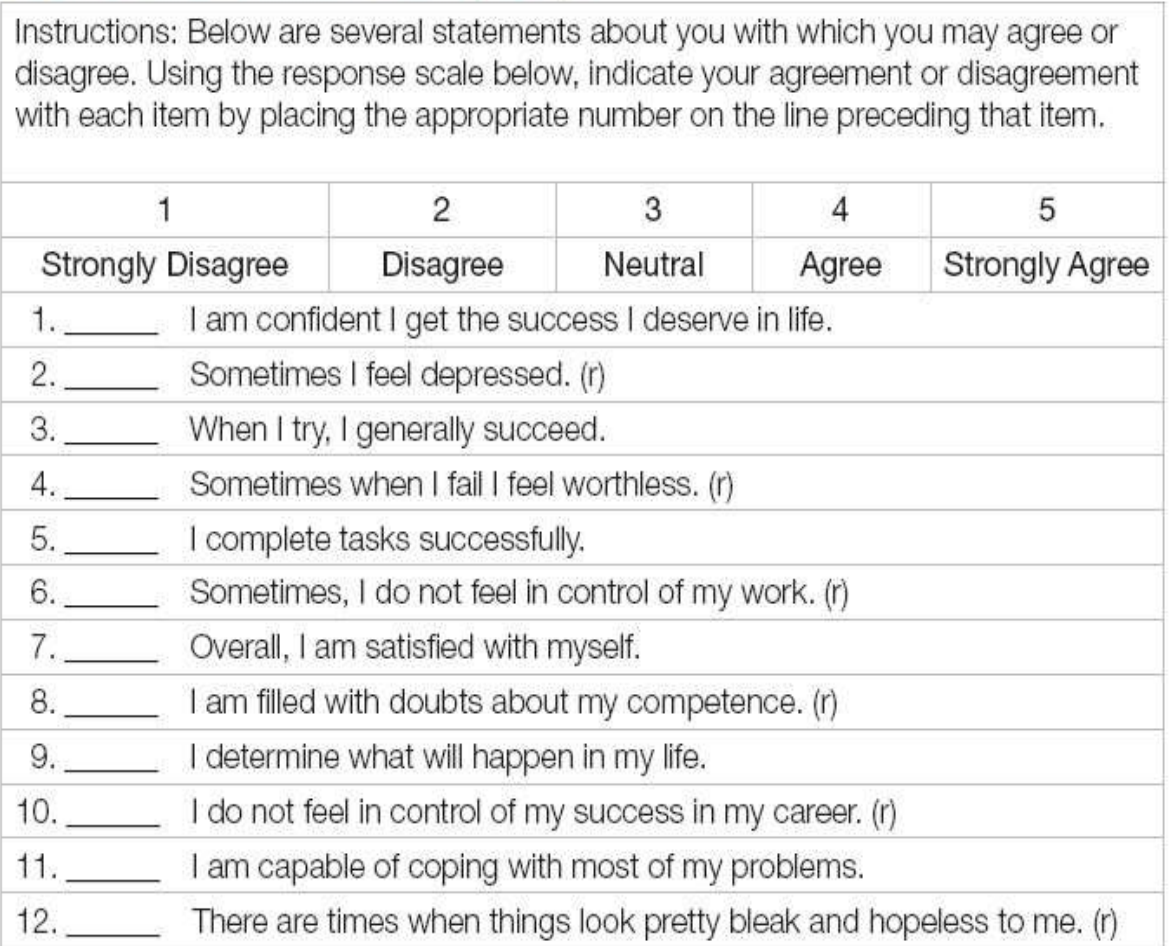

Note: $r=$ reverse-scored, i.e., a "5" becomes a "1." Add up your total points and divide by 12 to compute your average score per item. The mean score is around 3.8 to 3.9 .

Source: Judge, T., Bono, J., \& Thorensen, C. (2003). The core self-evaluations scale: Development of a measure. Personnel Psychology, 56, 303-331. 


\section{Appendix K: The Social Interaction Anxiety Scale}

Instructions: For each item, please indicate the degree to which you feel the statement is characteristic or true for you. $1=$ Not at all characteristic or true of me, $2=$ Slightly characteristic or true of me, $3=$ Moderately characteristic or true of me, $4=$ Very characteristic or true of me, $5=$ Extremely characteristic or true of me.

1. I get nervous if I have to speak with someone in authority (teacher, boss, etc.).

2. I have difficulty making eye contact with others.

3. I become tense if I have to talk about myself or my feelings.

4. I find it difficult to mix comfortably with the people I work with.

5. I find it easy to make friends my own age. *

6. I tense up if I meet an acquaintance in the street.

7. When mixing socially, I am uncomfortable.

8. I feel tense if I am alone with just one other person.

9. I am at ease meeting people at parties, etc. *

10. I have difficulty talking with other people.

11. I find it easy to think of things to talk about. *

12. I worry about expressing myself in case I appear awkward.

13. I find it difficult to disagree with another's point of view.

14. I have difficulty talking to attractive persons of the opposite sex.

15. I find myself worrying that I won't know what to say in social situations.

16. I am nervous mixing with people I don't know well.

17. I feel I'll say something embarrassing when talking.

18. When mixing in a group, I find myself worrying I will be ignored.

19. I am tense mixing in a group.

20. I am unsure whether to greet someone I know only slightly.

*Items with an asterisk are reverse coded. 


\section{Appendix L: Beck's Depression Inventory (BD-II)}

1.

0

1

2.

3.

4.

5.

6.
I do not feel sad.

I feel sad

I am sad all the time and I can't snap out of it.

I am so sad and unhappy that I can't stand it.

I am not particularly discouraged about the future.

I feel discouraged about the future.

I feel I have nothing to look forward to.

I feel the future is hopeless and that things cannot improve.

I do not feel like a failure.

I feel I have failed more than the average person.

As I look back on my life, all I can see is a lot of failures.

I feel I am a complete failure as a person.

I get as much satisfaction out of things as I used to.

I don't enjoy things the way I used to.

I don't get real satisfaction out of anything anymore.

I am dissatisfied or bored with everything.

I don't feel particularly guilty

I feel guilty a good part of the time.

I feel quite guilty most of the time.

I feel guilty all of the time.

I don't feel I am being punished.

I feel I may be punished. 
7.

I don't feel disappointed in myself.

I am disgusted with myself.

I hate myself.

8.

I don't feel I am any worse than anybody else.

I am critical of myself for my weaknesses or mistakes.

I blame myself all the time for my faults.

I blame myself for everything bad that happens.

9.

I don't have any thoughts of killing myself.

I have thoughts of killing myself, but I would not carry them out.

I would like to kill myself.

I would kill myself if I had the chance.

10.

I don't cry any more than usual.

I cry more now than I used to.

I cry all the time now.

I used to be able to cry, but now I can't cry even though I want to.

11.

I am no more irritated by things than I ever was.

I am slightly more irritated now than usual.

I am quite annoyed or irritated a good deal of the time.

I feel irritated all the time.

12.

I have not lost interest in other people. 
I have lost most of my interest in other people.

13.

I make decisions about as well as I ever could.

I have greater difficulty in making decisions more than I used to.

I can't make decisions at all anymore.

14.

0

1

2

15.

16.

17.

18.
I don't feel that I look any worse than I used to.

I am worried that I am looking old or unattractive.

I feel there are permanent changes in my appearance that make me look unattractive

I believe that I look ugly.

I can work about as well as before.

It takes an extra effort to get started at doing something.

I have to push myself very hard to do anything.

I can't do any work at all.

I can sleep as well as usual.

I don't sleep as well as I used to.

I wake up 1-2 hours earlier than usual and find it hard to get back to sleep.

I wake up several hours earlier than I used to and cannot get back to sleep.

I don't get more tired than usual.

I get tired more easily than I used to.

I get tired from doing almost anything.

I am too tired to do anything.

My appetite is no worse than usual. 
1

2

3

19.

20.

21.

My appetite is not as good as it used to be.

My appetite is much worse now.

I have no appetite at all anymore.

I haven't lost much weight, if any, lately.

I have lost more than five pounds.

I have lost more than ten pounds.

I have lost more than fifteen pounds.

I am no more worried about my health than usual.

I am worried about physical problems like aches, pains, upset stomach, or constipation.

I am very worried about physical problems and it's hard to think of much else.

I am so worried about my physical problems that I cannot think of anything else.

I have not noticed any recent change in my interest in sex.

I am less interested in sex than I used to be.

I have almost no interest in sex.

I have lost interest in sex completely.

\section{INTERPRETING THE BECK DEPRESSION INVENTORY}

Now that you have completed the questionnaire, add up the score for each of the twenty-one questions by counting the number to the right of each question you marked. The highest possible total for the whole test would be sixty-three. This would mean you circled number three on all twenty-one questions. Since the lowest possible score for each question is zero, the lowest possible score for the test would be zero. This would mean you circles zero on each question.

You can evaluate your depression according to the table below.

$\begin{array}{ll}\text { Total Score } & \text { Levels of Depression } \\ 1-10 & \text { These ups and downs are considered normal } \\ 11-16 & \text { Mild mood disturbance } \\ 17-20 & \text { Borderline clinical depression } \\ 21-30 & \text { Moderate depression }\end{array}$


$31-40$

Severe depression

over 40

Extreme depression 


\section{Appendix M: The Job Satisfaction Survey}

\begin{tabular}{|c|c|c|c|}
\hline $\begin{array}{l}\text { Item } \\
\text { No. }\end{array}$ & Subscaler & $\begin{array}{l}\text { Wording } \\
\text { direction }\end{array}$ & Item \\
\hline 1 & 1 & + & $\begin{array}{l}\text { I feel I am being paid a fair amount } \\
\text { for the work I do. }\end{array}$ \\
\hline 2 & 2 & - & $\begin{array}{l}\text { There is really too little chance for } \\
\text { promotion on my job. }\end{array}$ \\
\hline 3 & 3 & + & $\begin{array}{l}\text { My supervisor is quite competent in } \\
\text { doing his/her job. }\end{array}$ \\
\hline 4 & 4 & - & $\begin{array}{l}\text { I am not satisfied with the benefits I } \\
\text { receive. }\end{array}$ \\
\hline 5 & 5 & + & $\begin{array}{l}\text { When I do a good job, I receive the } \\
\text { recognition for it that I should } \\
\text { receive. }\end{array}$ \\
\hline 6 & 6 & - & $\begin{array}{l}\text { Many of our rules and procedures } \\
\text { make doing a good job difficult. }\end{array}$ \\
\hline 7 & 7 & + & I like the people I work with. \\
\hline 8 & 8 & - & $\begin{array}{l}\text { I sometimes feel my job is } \\
\text { meaningless. }\end{array}$ \\
\hline 9 & 9 & + & $\begin{array}{l}\text { Communications seem good within } \\
\text { this organization. }\end{array}$ \\
\hline 10 & 1 & - & Raises are too few and far between. \\
\hline 11 & 2 & + & $\begin{array}{l}\text { Those who do well on the job stand } \\
\text { a fair chance of being promoted. }\end{array}$ \\
\hline 12 & 3 & - & My supervisor is unfair to me. \\
\hline 13 & 4 & + & $\begin{array}{l}\text { The benefits we receive are as good } \\
\text { as most other organizations offer. }\end{array}$ \\
\hline 14 & 5 & - & $\begin{array}{l}\text { I do not feel that the work I do is } \\
\text { appreciated. }\end{array}$ \\
\hline 15 & 6 & + & $\begin{array}{l}\text { My efforts to do a good job are sel- } \\
\text { dom blocked by red tape. }\end{array}$ \\
\hline 16 & 7 & - & $\begin{array}{l}\text { I find I have to work harder at my } \\
\text { job than I should because of the in- } \\
\text { competence of people I work with. }\end{array}$ \\
\hline 17 & 8 & + & I like doing the things I do at work. \\
\hline 18 & 9 & - & $\begin{array}{l}\text { The goals of this organization are } \\
\text { not clear to me. }\end{array}$ \\
\hline
\end{tabular}




\begin{tabular}{|c|c|c|c|}
\hline 19 & 1 & - & $\begin{array}{l}\text { I feel unappreciated by the organiza- } \\
\text { tion when I think about what they } \\
\text { pay me. }\end{array}$ \\
\hline 20 & 2 & + & $\begin{array}{l}\text { People get ahead as fast here as they } \\
\text { do in other places. }\end{array}$ \\
\hline 21 & 3 & - & $\begin{array}{l}\text { My supervisor shows too little in- } \\
\text { terest in the feelings of subordinates. }\end{array}$ \\
\hline 22 & 4 & + & $\begin{array}{l}\text { The benefit package we have is } \\
\text { equitable. }\end{array}$ \\
\hline 23 & 5 & - & $\begin{array}{l}\text { There are few rewards for those who } \\
\text { work here. }\end{array}$ \\
\hline 24 & 6 & - & I have too much to do at work. \\
\hline 25 & 7 & + & I enjoy my co-workers. \\
\hline 26 & 9 & - & $\begin{array}{l}\text { I often feel that I do not know what } \\
\text { is going on with the organization. }\end{array}$ \\
\hline 27 & 8 & + & $\begin{array}{l}\text { I feel a sense of pride in doing my } \\
\text { job. }\end{array}$ \\
\hline 28 & 1 & + & $\begin{array}{l}\text { I feel satisfied with my chances for } \\
\text { salary increases. }\end{array}$ \\
\hline 29 & 4 & - & $\begin{array}{l}\text { There are benefits we do not have } \\
\text { which we should have. }\end{array}$ \\
\hline 30 & 3 & + & I like my supervisor. \\
\hline 31 & 6 & - & I have too much paperwork. \\
\hline 32 & 5 & - & $\begin{array}{l}\text { I don't feel my efforts are rewarded } \\
\text { the way they should be. }\end{array}$ \\
\hline 33 & 2 & + & $\begin{array}{l}\text { I am satisfied with my chances for } \\
\text { promotion. }\end{array}$ \\
\hline 34 & 7 & - & $\begin{array}{l}\text { There is too much bickering and } \\
\text { fighting at work. }\end{array}$ \\
\hline 35 & 8 & + & My job is enjoyable. \\
\hline 36 & 9 & - & $\begin{array}{l}\text { Work assignments are often not fully } \\
\text { explained. }\end{array}$ \\
\hline
\end{tabular}

-Subscale numbers refer to order in Tables II-IV. Response choices are scored as 1 = disagree very much, 2 = disagree moderately, 3 = disagree slightly, $4=$ agree slightly, $5=$ agree moderately, 6 = agree very much. All items with wording directions marked - should be reverse scored. 


\section{Appendix N: Work Extrinsic and Intrinsic Motivation Scale (WEIMS)}

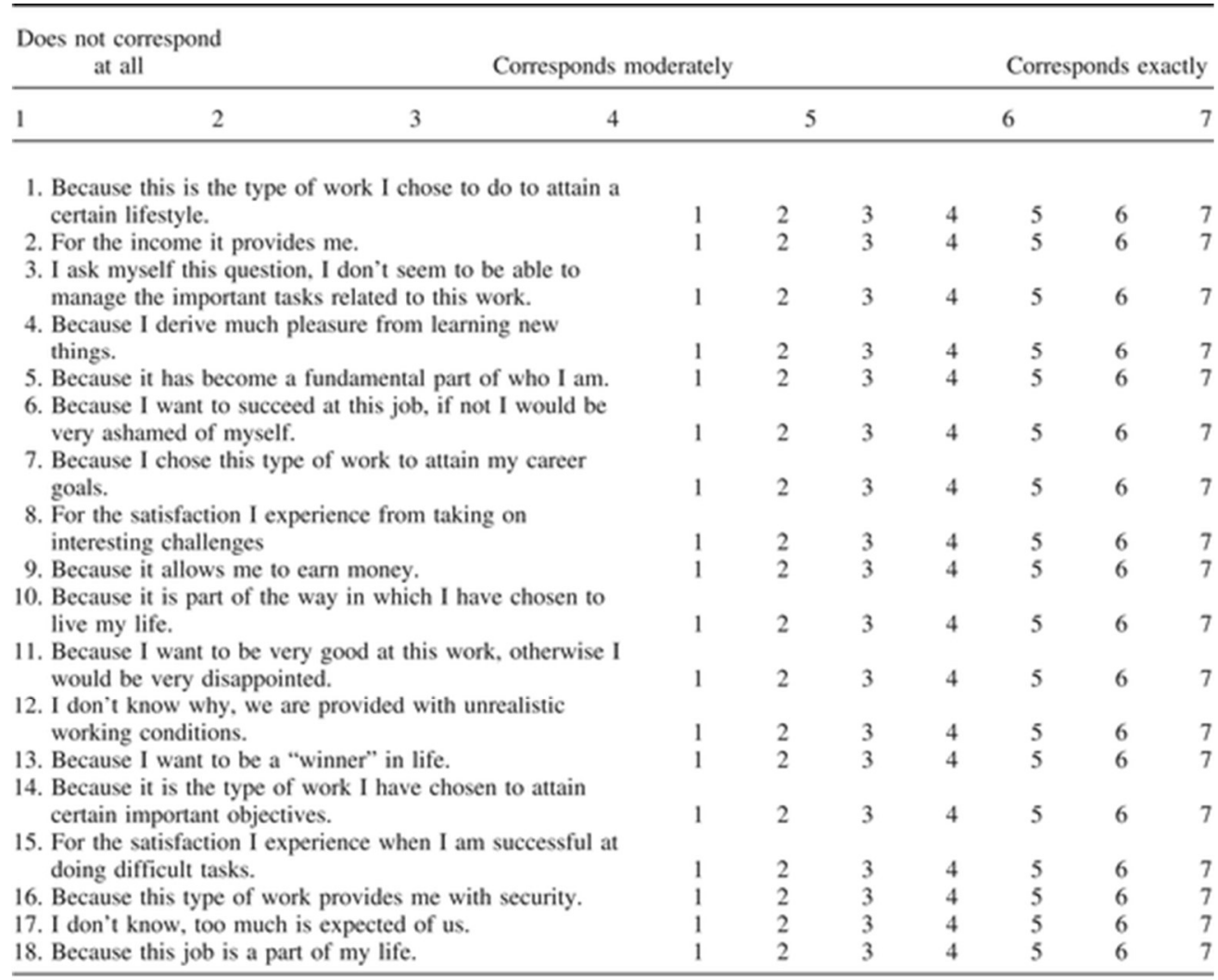

Note. Intrinsic motivation $=4,8,15$; integrated regulation $=5,10,18$; identified regulation $=1,7,14$; introjected regulation $=6,11,13$; external regulation $=2,9,16$; amotivation $=3,12,17$. 


\section{Appendix O: Episodic Future Memory Scale}

Prompt: This is a study about memories and imagined events. On the following pages you will be asked to remember important memories from your workplace. You will also be asked to imagine important events that might happen in future work experiences or might have happened in your past jobs but did not actually occur. Please read the instructions on each page carefully and write down specific memories/imagined events. This means that memories/imagined events you write should belong to a specific time and a specific place and their duration should not exceed a full day -24 hours. Please write a few sentences for each memory/imagined event. After you finish writing each memory/imagined event, please provide a brief title and answer a number of questions about it. All of your answers will remain confidential.

Block One: Actual past event

1. Please write a brief summary of your memory of an important event that has happened to you in the workplace within the past month.

2. Please write a brief summary of your memory of an important event that happened to you in the workplace one year ago.

3. Please write a brief summary of your memory of an important event that happened to you in the workplace five or more years ago.

Block Two: Imagined past event

4. Imagine an important event that could have happened in your workplace over the past month, but that has not actually happened. Briefly describe this imagined past event.

5. Imagine an important event that could have happened in your workplace over the past year, but that has not actually happened. Briefly describe this imagined past event.

6. Imagine an important event that could have happened in your workplace over the past five or more years, but that has not actually happened. Briefly describe this imagined past event.

Block Three: Imagined future event

7. Imagine an important event that may happen in your workplace over the next month. Briefly describe this imagined future event.

8. Imagine an important event that may happen in your workplace over the next year. Briefly describe this imagined future event.

9. Imagine an important event that may happen in your workplace over the next five or more years. Briefly describe this imagined future event. 


\section{Appendix P: Phenomenology Questions (Episodic Future Events)}

Prompt: How vivid were the following memories:

The following measure will be assessed with a 5-point Likert scale with anchors of $1=$ not at all vivid and $5=$ extremely vivid.

1. Your memory of an actual important past event in the workplace

2. Your memory of an imagined important past event in the workplace

3. Your memory of an important imagined future event in the workplace

4. Your memories generated from one month ago/into the future

5. Your memories generated from one year ago/into the future

6. Your memories generated from five or more years ago/into the future

Prompt: What were the emotions like that you had upon recalling the following memories:

The following measure will be assessed with a 7-point Likert scale with anchors of $1=$ very negative and $7=$ very positive.

1. Your memory of an actual important past event in the workplace

2. Your memory of an imagined important past event in the workplace

3. Your memory of an important imagined future event in the workplace

4. Your memories generated from one month ago/into the future

5. Your memories generated from one year ago/into the future

6. Your memories generated from five or more years ago/into the future

Prompt: How intense were the emotions that you felt when recalling the following memories:

The following measure will be assessed with a 5-point Likert scale with anchors of $1=$ not at all intense and $5=$ extremely intense.

1. Your memory of an actual important past event in the workplace

2. Your memory of an imagined important past event in the workplace

3. Your memory of an important imagined future event in the workplace

4. Your memories generated from one month ago/into the future

5. Your memories generated from one year ago/into the future

6. Your memories generated from five or more years ago/into the future 
Prompt: How important are the following memories to your life:

The following measure will be assessed with a 5-point Likert scale with anchors of $1=$ not at all important and $5=$ extremely important .

1. Your memory of an actual important past event in the workplace

2. Your memory of an imagined important past event in the workplace

3. Your memory of an important imagined future event in the workplace

4. Your memories generated from one month ago/into the future

5. Your memories generated from one year ago/into the future

6. Your memories generated from five or more years ago/into the future

Prompt: For the following memories, have you willfully thought back to the event in your mind, thinking about or talking about the event that occurred?

The following measure will be assessed with a 5-point Likert scale with anchors of $1=$ never and $5=$ daily.

1. Your memory of an actual important past event in the workplace

2. Your memory of an imagined important past event in the workplace

3. Your memory of an important imagined future event in the workplace

4. Your memories generated from one month ago/into the future

5. Your memories generated from one year ago/into the future

6. Your memories generated from five or more years ago/into the future

Prompt: How easy was it to remember the following memories:

The following measure will be assessed with a 7-point Likert scale with anchors of $1=$ extremely easy and $7=$ extremely difficult.

1. Your memory of an actual important past event in the workplace

2. Your memory of an imagined important past event in the workplace

3. Your memory of an important imagined future event in the workplace

4. Your memories generated from one month ago/into the future

5. Your memories generated from one year ago/into the future

6. Your memories generated from five or more years ago/into the future 


\title{
JENNIFER L. HOUSTON
}

\author{
Born: Homestead, Florida
}

2004-2009

BA in Psychology, Summa Cum Laude

Minor in Religious Studies \& Fine Art

Phi Beta Kappa, Honors Society

Phi Kappa Phi, Honors Society

Golden Key, Honors Society

Psi Chi, Psychology Honors Society

Theta Alpha Kappa, Religious Studies Honors Society

CASE Outstanding Achievement in Psychology Award

Ronald E. McNair Fellow, $5^{\text {th }}$ Cohort

Florida International University in Miami, FL

$2009-2010$

MS in Management, Hough Graduate School of

Business Scholarship Recipient

University of Florida in Gainesville, FL

Ronald E. McNair Graduate Fellowship Recipient

Omicron Delta Kappa, Leadership Honors Society

Florida International University in Miami, FL

Graduate Teaching Assistant, Department of Psychology

Florida International University in Miami, FL

2014-Present

Adjunct Professor, Department of Psychology Florida International University in Miami, FL

2014-Present

Ancillary Preparer of Textbook and Online Resources SAGE Publications in Thousand Oaks, CA

2016-Present

Adjunct Professor, School of Business

Miami Dade College in Kendall, FL

2016

Defended Doctoral Thesis and Passed Comprehensive

Exams in Industrial/Organizational Psychology

Florida International University in Miami, FL

2017-Present

Doctoral Candidate in Industrial/Organizational

Psychology

Florida International University in Miami, FL 